\title{
The Impact of Idiosyncratic Risk on Mutual Fund Fees
}

\author{
Lorenzo Casavecchia and Hardy Hulley*
}

August 30, 2013

\footnotetext{
${ }^{*}$ Casavecchia and Hulley are with the Finance Discipline Group at the University of Technology, Sydney. The current article is an amalgam of two previous works. The first, entitled "The Effect of Idiosyncratic Risk-Taking on Mutual Fund Performance and Fees," was presented at the 2010 Finance and Corporate Governance Conference in Melbourne, and at the 2010 Annual Meeting of the Financial Management Association in New York, where it was a finalist for the best paper award. It was also presented at seminars at the Queensland University of Technology, the University of Western Australia, and the University of Technology, Sydney. The second paper, entitled "The Impact of Idiosyncratic Risk on Mutual Fund Fees and Performance," focused on a mathematical analysis of the model in Section I. It was presented at the Fourth International Conference on Mathematical Finance held in the Kruger Park in 2011, and at the 2011 Quantitative Methods in Finance Conference in Sydney. The authors thank the participants at those conferences and seminars for several helpful comments. In particular, they appreciate the suggestions and encouragement offered by Tony Berrada, Phil Brown, David Feldman, Mario Fiorini, Doug Foster, David Gallagher, Massimo Guidolin, Tony Hall, Marcin Kacperczyk, Ron Kaniel, John Knight, Nahid Rahman, Massimo Scotti, Toru Suzuki, Terry Walter and John Wooders. Casavecchia gratefully acknowledges the financial assistance received from the University of Technology, Sydney, in the form of a Faculty of Business Research Grant (\#2010393) and an Early Career Researcher Grant (\#2007002456). He also thanks the Finance Discipline Group at the University of Technology, Sydney for additional financial support.
} 
The Impact of Idiosyncratic Risk on Mutual Fund Fees

August 30, 2013 


\begin{abstract}
In the context of a theoretical model for the interaction between an active fund manager and a risk-averse investor, we show that mutual fund fees should exhibit a positive concave dependence on their idiosyncratic volatilities. The crucial ingredients are the infeasibility of short-selling the fund, and the fact that its idiosyncratic volatility generates uncertainty about its performance. Our empirical investigations provide strong support for this result. In fact, idiosyncratic volatility appears to be the most important determinant of mutual fund fees. Moreover, we demonstrate that when it is included as an explanatory variable in cross-sectional regressions, the widely-reported negative dependence of fees on performance dissipates. Significantly, our resolution for this puzzle does not require assumptions of investor unsophistication or fund manager opportunism. In fact, we provide positive evidence for a certain amount of investor sophistication, by demonstrating their apparent unwillingness to pay active fees for passive performance, as predicted by our model.
\end{abstract}

Keywords: Mutual fund fees; idiosyncratic risk; uncertainty; short-selling

JEL Codes: C72; D58; D83; G11; G12; G23 
Fraction-of-fund fees are the predominant feature of advisory compensation contracts in the mutual fund industry. In this study, we provide new intriguing evidence on the determinants of advisory fees. Our argument can be summarized by illustrating a striking feature of the empirical sensitivity of mutual fund advisory fees to performance. Figure 1 exhibits the existence of a U-shaped dependence of fees on either before- or after-fees risk-adjusted performance. This nonlinear fee-performance sensitivity implies that both the best-performing funds and the worstperforming funds appear responsible for the highest advisory fees. It is curious that although this U-shaped dependence of fees on performance is implicit in the mutual fund literature (see e.g. Gruber (1996), Carhart (1997), Kosowski, Timmermann, Wermers, and White (2006), GilBazo and Ruiz-Verdú (2009)), it has gone unremarked until now. We provide a parsimonious explanation for this nonlinearity and show that it reveals an overlooked determinant of advisory fees, namely fund idiosyncratic volatility.

\section{** INSERT FIGURE 1 HERE **}

Since funds with either good or bad estimated performance are characterized by higher standard errors of these estimates, and since these standard errors are naturally proportional to their associated idiosyncratic volatilities, it follows that nonlinear fee-performance sensitivities could exist only if mediated by a significant positive dependence of advisory fees on fund idiosyncratic volatilities. The evidence of Figure 1 illustrates this point clearly using percentiles of idiosyncratic volatility: Advisory fees are a positive function of idiosyncratic risk. Our main contribution is to provide an economic explanation for this relationship and also casts new light on the role of mutual fund performance and investors sophistication for mutual fund fee-setting policies.

Why do mutual funds with higher idiosyncratic volatility set above-average advisory fees? To address this question, we develop a theoretical model of the interaction between a risk-averse investor and a risk-neutral mutual fund manager. The objective of the investor is to maximize the expected utility of his terminal wealth, by allocating his initial wealth optimally across a risk-free money-market account, the market portfolio, and the mutual fund. The fund manager, on the other hand, generates an income by charging the investor a fee, expressed as a percentage of the end-of-period assets under management. His objective is to maximize his income. Our model is based on two fundamental assumptions which are consistent with the characteristics of the mutual fund industry: (i) the existence of idiosyncratic noise in performance impairs investors ability to differentiate skill from luck in the cross section of mutual fund returns; and (ii) the impossibility to short-sell mutual fund shares. The first assumption is supported by several studies documenting the existence of significant idiosyncratic volatility in mutual fund 
performance. Kosowski, Timmermann, Wermers, and White (2006) emphasize the importance of controlling for idiosyncratic volatility in fund performance when evaluating fund managers skills. Khorana (1996) shows that the noise in performance could impair the decision of the management company to replace fund managers. Berk and Green (2004) argue that higher idiosyncratic noise in observed returns would increase investor uncertainty about fund managers ability. More recently, Huang, Wei, and Yan (2012) show that high volatility in mutual fund performance dampens the response to past performance of rational investors.

Our second assumption short selling constraint is widely accepted in the literature, and reflects the fact that the management company is the counter-party for all purchases and redemptions of shares in the fund, which are settled at net-asset-value. Consistent with the argument by Miller (1977), our model predicts that the existence of strict short selling constraints reduces the supply of funds with high idiosyncratic volatility in the market, consequently preventing short sales from moderating the tendency of riskier funds characterized by high idiosyncratic volatility to charge higher advisory fees.

The papers contribution is in four areas. First, our study shows that the optimal advisory fee derived explicitly from our model is both monotonically increasing and generally concave in the idiosyncratic volatility of the fund, and monotonically increasing in fund gross performance. Since higher idiosyncratic volatility makes investors more likely to overestimate fund performance substantially, the increasing (in idiosyncratic volatility) uncertainty about funds performance causes investors optimal allocation to exhibit a positive convex dependence on their estimates of fund performance. In this context, the optimal fee charged by the fund becomes a contingent claim on the investors estimate of its performance. In a simulation framework, we show that our model reproduces very closely the empirical relationships observed in the data. These simulated sensitivities are compared to the empirical sensitivities in Figure 1.

Using a sample of US open-end active equity mutual funds over the period from 1993 to 2007, we verify that fund advisory fees do indeed exhibit a strongly positive and concave crosssectional dependence on idiosyncratic risk, as predicted by our model. Specifically, a-one standard deviation increase in idiosyncratic volatility corresponds to a 25 basis point increase in both operating expenses and management fees. ${ }^{1}$ We observe that this relationship survives even after controlling for a host of fund and family characteristics, investment objectives, share classes, and investors sensitivities that are known to affect fees from previous literature. Our

\footnotetext{
${ }^{1}$ Recurring mutual fund operating expenses have a number of components, the largest of which are advisory or management fees, followed by $12 \mathrm{~b}-1$ fees (i.e. marketing and distribution costs). In addition, there are sometimes also once-off charges, called loads. Strictly speaking, the fee considered in our model should be interpreted as a management fee. However, when testing the predictions of our model against empirical data, we report separately the results for management fees and total operating expenses, in the service of transparency.
} 
findings indicate that idiosyncratic volatility impairs significantly investors ability to assess fund managers performance consequently inducing a strong cross-sectional relationship between this volatility and advisory fees.

In their study, Barber, Odean, and Zheng (2005) hypothesized that the steady drain on fund performance constituted by operating expenses could be masked by the considerable volatility in mutual fund returns. They argue that investors could be less likely to avoid funds with high operating expenses if these funds are also those characterized by high performance volatility. Similarly, Deli (2002) shows that funds characterized by greater return volatility are associated with higher marginal compensation rates and concludes that this evidence could be somehow a reflection of cross-sectional differences in the difficulty of performance monitoring due to greater volatility. Our model and empirical analysis establish a framework to explain the dispersion in advisory compensation as captured by fund idiosyncratic volatility, and suggest a provocative connection between fund fees and contingent claims.

Our second contribution is to show that our documented positive sensitivity of advisory payoffs to idiosyncratic volatility sheds new light on a number of anomalies that have been previously identified in the mutual fund literature. Explicitly, several papers including Gruber (1996), Malkiel (1995), Carhart (1997), Sirri and Tufano (1998), Harless and Peterson (1998), Wermers (2000), Wermers (2003), Christoffersen and Musto (2002), Hortacsu and Syverson (2004), Kuhnen (2005), Gil-Bazo and Ruiz-Verdú (2009) have provided evidence of a puzzling negative relationship between advisory fees and mutual fund (gross or net) performance. This evidence has awkward economic implications, since it is incompatible with even the most charitable interpretation of investor rationality as it suggests that investors are willing to pay aboveaverage advisory fees to their underperforming managers. Christoffersen and Musto (2002) and Gil-Bazo and Ruiz-Verdú (2009) explain this anomaly by appealing to the existence of an exogenously convex flow-performance relationship according to which performance-insensitive (or sleeping) investors do not promptly flee poor performing funds. They argue that the scarce elasticity of investor demand incentivizes underperforming fund managers to extract rents by charging higher advisory fees. As such, investors performance unsophistication, combined with fund managers rent-seeking behavior, has been interpreted as an important determinant of fund fee-setting policies.

On the contrary, our study shows that previous estimates of the fee-performance sensitivity are significant negatively biased as they do not account for the cross-sectional variation in fund idiosyncratic volatility. We provide clear evidence that the problematic negative fee-performance sensitivity is animated by an omitted variable bias. This result is first established in the context 
of a simulated environment, before being demonstrated empirically. Our findings are reminiscent of the empirical evidence documented in the literature on executive compensation whence pay-performance sensitivity is a decreasing function of the level of (idiosyncratic) volatility in performance (Aggarwal and Samwick (1999), Garen (1994), and Jin (2002). We illustrate that in the case of mutual fund advisory fees the omission bias is originated by the failure to control for the relationship between fees and idiosyncratic volatility, which is also higher among funds inhabiting the tails of the estimated performance distribution. We show that when the fee-performance sensitivity is estimated by including as a regressor idiosyncratic volatility, and its interaction with performance, the negative fee-performance sensitivity disappears, leaving a positive albeit not always significant relationship.

Third, our model also predicts that investors allocation to a mutual fund is totally independent of its systematic risk exposure and suggests that investors are unwilling to pay active management fees for passive performance, which can be obtained at a significant lower cost via the market portfolio. Our empirical findings confirm the model prediction and indicate that the optimal fee charged by fund managers is invariant with respect to the systematic risk of their managed portfolio. This evidence also suggests that mutual fund investors are risk-averse, and hence sensitive to performance.

Our fourth contribution is to examine whether the dispersion of advisory fees is a function of investor sensitivity. We conclude that fund managers do not charge higher fees to exploit the density of performance-insensitive investors in the worse-prospect funds. In particular, we illustrate that the previous argument proposed in the literature that fund managers would opportunistically charge higher fees to their disadvantaged investors does not consider the possibility that investors may be more sophisticated than previously thought. Consistent with Huang, Wei, and Yan (2012), our theoretical and empirical findings show that as idiosyncratic noise in performance increases, investors learn less from performance about fund manager skill, and a given return triggers less response in flows. After controlling for the dampening effect on investors flows of idiosyncratic volatility, which our model predicts to be also positively related to advisory fees, we show that the fees are not higher among investors with lower performance sensitivity. Using several proxies for investors' flow-performance sensitivity, we provide robust evidence which is inconsistent with the arguments based on investors' self-selection and fund managers' opportunism.

Overall, our paper is related to the growing body of literature on the determinants of fund advisory fees. Previous studies have suggested that cross-sectional differences in advisory compensation rates could depend on several factors such as: marginal product of fund advisors 
(Golec (1992), Tufano and Sevick (1997), Jeffrey L. Coles and Woodbury (2000), and Deli (2002)), economies of scale of the fund or the family (Chen, Hong, Huang, and Kubik (2004), Warner and Wu (2001), and, Elton, Gruber, and Blake (2012)), differences in fund investment styles and active shares (Deli (2002), Kuhnen (2005), and Cremers and Petajisto (2009)), differences in funds internal (Tufano and Sevick (1997)) and external (Capon, Fitzsimons, and Prince (1996), Christoffersen and Musto (2002), and Gil-Bazo and Ruiz-Verdú (2009)) control environments. We add to this body of research by emphasizing the remarkable role of investors uncertainty and institutional short-sale constraints for the cross-sectional dispersion of mutual fund advisory compensation. Our paper also contributes to the extensive literature on the compensation of decision makers by providing a model of the determinants of advisory compensation and new empirical evidence on the effect of idiosyncratic volatility on pay-performance sensitivities.

The remainder of the article is structured as follows. Section I introduces the model, and presents the theoretical results that emanate from it. Section II reports on the Monte Carlo experiment described earlier. Section III formulates the empirically testable hypotheses and describes the data and the methodology employed in the empirical part of the article. Section IV presents the findings of the empirical analysis. Finally, Section V offers some conclusions, and Appendix A proves the theoretical results presented in Section I.

\section{A Model for Mutual Fund Fees}

This section investigates a model for the interaction between a risk-neutral mutual fund manager and a risk-averse investor. The investor is uncertain about the performance of the fund, and is unable to sell its shares short. We examine how the fee-setting policy of the fund manager responds to the investor's constraints.

\section{A. The Model Framework}

We consider a single-period economy comprising a risk-free money-market account, the market portfolio, and an active mutual fund. The risk-free return is taken to be zero, while the market portfolio is assumed to pay a normally distributed return $r_{\mathrm{M}} \sim \mathcal{N}\left(\mu_{\mathrm{M}}, \sigma_{\mathrm{M}}^{2}\right)$. The before-fee return offered by the the mutual fund is specified by

$$
r_{\mathrm{P}}=\alpha+\beta r_{\mathrm{M}}+\varepsilon
$$

where $\varepsilon \sim \mathcal{N}\left(0, \sigma_{\varepsilon}^{2}\right)$ 
Our analysis focuses on the interaction between the fund manager and a risk-averse investor, whom we regard as a representative stand-in for a large number of identical investors. The investor attempts to maximise his expected utility from terminal wealth, by optimally allocating his initial wealth across the three available assets. However, the fund's idiosyncratic volatility induces uncertainty about its performance, while his portfolio choice is constrained by the fact that the fund cannot be sold short. In addition, we assume that the investor is only boundedly rational, in the sense that he makes an optimal portfolio decision, based on his belief about the fund's performance, without exploiting the performance information inherent in the fee itself.

The fund manager's objective is to maximise his expected income, by choosing an optimal advisory fee, which is communicated to the investor in advance. ${ }^{2}$ Since the return earned by the investor from his contribution to the fund is adversely affected by the fee, it is clear that a very large fee would discourage him, and would therefore be suboptimal for the fund manager, whose income in that case would correspond to a very large portion of a relatively small value of assets under management. Conversely, a very small fee would conceivably entice the investor to contribute a relatively large portion of his wealth to the fund, but it would also be suboptimal for the fund manager, since his income would then correspond to a very small portion of a relatively large value of assets under management.

\section{B. The Investor's Problem}

We assume that the investor estimates the before-fee performance of the mutual fund by sampling from a normal distribution:

Assumption 1. The investor believes that the fund's before-fee alpha is $\widehat{\alpha} \sim \mathcal{N}\left(\alpha, \sigma_{\varepsilon}^{2}\right)$.

The intuition underlying this assumption is that the investor's uncertainty about the fund's performance is proportional to its idiosyncratic volatility. This idea finds support in the empirical asset pricing literature, where ?, among others, use idiosyncratic volatility as a proxy for the dispersion of investor opinions about the performance of common stock.

Assumption 1 can also be justified on econometric grounds, since the standard error of the OLS estimate for the constant term in a linear model is proportional to the standard deviation of the residual. In detail, if the investor uses OLS regression to estimate the value of $\alpha$, then the value of $\kappa>0$ is determined by the size of the sample used for that purpose. Since a smaller

\footnotetext{
${ }^{2}$ Mutual fund fees consist of advisory fees, $12 \mathrm{~b}-1$ fees, and various other administrative costs. Of these, advisory fees are the most significant, followed by $12 \mathrm{~b}-1$ fees, which are marketing and distribution costs. The remaining components are comparatively unimportant. Since our model is specifically concerned with advisory fees, we implicitly assume that marketing and distribution costs, as well as all other expenses, are zero.
} 
value for $\kappa$ implies that the investor is generally better at judging the fund's true performance, we interpret it as an investor expertise parameter.

After completing the estimation procedure above, the investor believes that the before-fee return of the mutual fund takes the following form:

$$
\widehat{r}_{\mathrm{P}}=\widehat{\alpha}+\beta r_{\mathrm{M}}+\varepsilon .
$$

He then allocates a fraction $\xi$ of his initial wealth $w$ to the mutual fund, and a fraction $\eta$ to the market portfolio. The remaining fraction $1-\xi-\eta$ is deposited in the money-market account. We assume that there are no costs associated with the market portfolio or the money-market account, but an investment in the mutual fund incurs a proportional advisory fee $\zeta$, levied on the end-of-period assets of the fund. ${ }^{3,4}$ Finally, we allow the investor to short-sell the market portfolio and the money-market account, but not the mutual fund. This reflects the fact that the management company is the counter-party for all purchases and redemptions of shares in the fund, which are settled at net-asset-value. Short-selling is infeasible without a secondary market:

Assumption 2. The fraction invested in the mutual fund satistifes $\xi \geq 0$.

We use a CARA utility function $\mathcal{U}(x):=1-\mathrm{e}^{-\gamma x}$, with risk-aversion parameter $\gamma>0$, to model the investor's preferences. His objective is to identify the portfolio strategy $\left(\xi_{*}, \eta_{*}\right)$ that maximises his expected utility from terminal wealth, conditional on his estimate for the fund's performance:

$$
\left(\xi_{*}, \eta_{*}\right)=\underset{(\xi, \eta) \in \mathbb{R}_{+} \times \mathbb{R}}{\arg \max } \mathrm{E}(\mathcal{U}(W(\xi, \eta)) \mid \widehat{\alpha})
$$

where

$$
\begin{aligned}
W(\xi, \eta) & :=w\left(1+\xi\left((1-\zeta) \widehat{r}_{\mathrm{P}}-\zeta\right)+\eta r_{\mathrm{M}}\right) \\
& =w\left(1+\xi((1-\zeta) \widehat{\alpha}-\zeta)+(\eta+\xi(1-\zeta) \beta) r_{\mathrm{M}}+\xi(1-\zeta) \varepsilon\right)
\end{aligned}
$$

is his assessment of his terminal wealth, for a given portfolio strategy $(\xi, \eta)$. Note that the

\footnotetext{
${ }^{3}$ It has become easy for investors to obtain cheap passive exposure to the equity market via an array instruments, such as equity index futures, passive mutual funds, and a variety of exchange-traded funds. By comparison, the fees charged by active mutual funds are very substantial. For example, the median annual expense ratio for active equity mutual funds was 144 basis points in 2009, while equity index mutual funds offered annual expense ratios as low as 7 basis points in the same year.

${ }^{4}$ Our assumption that the management fee levied by the fund is a fraction of the value of its end-of-period assets under management provides the best match with industry practice. Mutual fund fees are modelled in the same way by Lynch and Musto (2003), and Hugonnier and Kaniel (2010), for example.
} 
investor believes that the after-fee return of the fund takes the form

$$
(1-\zeta)\left(1+\widehat{r}_{\mathrm{P}}\right)-1=(1-\zeta) \widehat{r}_{\mathrm{P}}-\zeta=(1-\zeta) \widehat{\alpha}-\zeta+(1-\zeta) \beta r_{\mathrm{M}}+(1-\zeta) \varepsilon
$$

His estimate for the fund's after-fee alpha is thus $(1-\zeta) \widehat{\alpha}-\zeta$, while its after-fee beta is $(1-\zeta) \beta$, and the idiosyncratic component of its after-fee return is $(1-\zeta) \varepsilon$. So, according to (3), the investor's assessment of his terminal wealth depends on his estimate for the fund's after-fee alpha, as well as its after-fee beta, and its after-fee idiosyncratic return.

It is well-documented that mutual fund investors are sensitive to historical performance, but that they are indifferent to operating expenses. For example, in an experimental study of the information investors use to select funds, ? found that his subjects payed a great deal of attention to past after-fee returns, and that they attached significantly more importance to loads than to expense ratios. Similarly, Barber, Odean, and Zheng (2005) reported no relationship between investment flows and operating expenses for equity mutual funds, while they observed a significant negative relationship between flows and front-end loads. In a more recent experimental study of investor choice, ? reported that their subjects failed to minimise operating expenses when choosing index funds, but that they attached substantial importance to historical after-fee returns. The evidence above suggests that investors are implicitly sensitive to operating expenses, insofar as they affect after-fee returns, but that they do not treat operating expenses as informative about before-fee performance:

Assumption 3. The investor makes no inferences about the value of $\alpha$ from the fee $\zeta$.

Since we assume that the fund manager has perfect information about the before-fee performance of the fund, a fully rational investor would attempt to extract that information from the advisory fee. Hence, Assumption 3 implies that the investor in our model is merely boundedly rational. The following theorem solves his problem:

Theorem 4. The optimal portfolio strategy $\left(\xi_{*}, \eta_{*}\right)$ for the investor is given by

$$
\xi_{*}=\frac{1}{\gamma w} \frac{((1-\zeta) \widehat{\alpha}-\zeta)^{+}}{(1-\zeta)^{2} \sigma_{\varepsilon}^{2}} \quad \text { and } \quad \eta_{*}=\frac{1}{\gamma w} \frac{\mu_{M}}{\sigma_{M}^{2}}-\xi_{*}(1-\zeta) \beta
$$

where $x^{+} \equiv \max \{x, 0\}$ denotes the positive part of $x$.

Theorem 4 reveals that the investor separates his alpha and beta allocations, in the sense that the portion of his wealth allocated to the mutual fund depends explicitly on his assessment of its after-fee alpha, but is invariant with respect to its after-fee beta. Instead, we see that he relies exclusively on the market portfolio for his beta requirements. In fact, he uses the market 
portfolio to hedge the after-fee beta arising from his exposure to the mutual fund, so that his decision to invest in it depends only on the tradeoff between its after-fee alpha and its after-fee idiosyncratic risk. ${ }^{5}$

The economic intuition underlying the investor's separation of his alpha and beta allocations is quite straightforward: since investing in the market portfolio incurs no costs, he has no reason to compensate the fund manager for the component of the return of the mutual fund that can be attributed to its exposure to the market portfolio. Instead, he obtains his desired level of exposure to the market portfolio for free, by investing in it directly, so that his only concern when considering the mutual fund is the after-fee alpha he expects it to produce, relative to its level of idiosyncratic risk. In particular, the investor will pay the active management fee only if he perceives the mutual fund to be a sufficiently attractive source of active performance.

Mutual fund investors are assumed to be risk-neutral in the theoretical models of Gil-Bazo and Ruiz-Verdú (2008), and Cheng, Massa, and Zhang (2013). Although such an assumption improves tractability, it also produces qualitatively different investor behaviour from (4). To wit, consider a risk-neutral investor in our setup, who faces the additional constraints that he cannot borrow at the risk-free interest rate or short-sell the market portfolio. ${ }^{6}$ His optimal strategy is to invest his entire wealth in the asset with the highest expected net return, based on his belief about the performance of the mutual fund. In particular, he does not discriminate between the alpha and the beta of the fund.

\section{The Fund Manager's Problem}

As stated earlier, we assume that the fund manager seeks to maximise his expected income from fees. Recall that the investor's contribution to the mutual fund is $\xi_{*} w$, where $\xi_{*}$ is determined by (4), for a given advisory fee $\zeta$. The fund manager therefore seeks to identify the optimal fee $\zeta_{*}$ that solves the following maximization problem:

$$
\zeta_{*}=\underset{\zeta \in \mathbb{R}}{\arg \max } F\left(\alpha, \sigma_{\varepsilon}, \zeta\right), \quad \text { where } \quad F\left(\alpha, \sigma_{\varepsilon}, \zeta\right):=\mathrm{E}\left(\xi_{*} w\left(1+r_{\mathrm{P}}\right) \zeta\right)
$$

\footnotetext{
${ }^{5}$ Lynch and Musto (2003) make a similar point, observing that since the investor separates his exposure to the market from his allocation to the mutual fund, the latter must be invariant with respect to the beta of the mutual fund. In a similar vein, Huang, Wei, and Yan (2007) reason that the investor uses the market portfolio to hedge the systematic risk of the mutual fund. Those articles appeal to such arguments to justify a simpler modeling framework, without a market portfolio, in which the return of the mutual fund is purely idiosyncratic. Since the current article seeks specifically to elucidate the impact of idiosyncratic risk on mutual fund fees, it is important that we are able to distinguish explicitly between the effects of systematic and unsystematic risk in our model. Abstracting away from systematic risk is therefore not appropriate here.

${ }^{6}$ These constraints are necessary for a risk-neutral investor to have a well-defined optimal portfolio. Without them, he would attempt to fund an unlimited long position with an unlimited short position, unless the expected returns of all three assets are equal.
} 
We obtain the following expression for the fund manager's objective function from (4):

$$
\begin{array}{r}
F\left(\alpha, \sigma_{\varepsilon}, \zeta\right)=\frac{1+\alpha+\beta \mu_{\mathrm{M}}}{\gamma \sigma_{\varepsilon}^{2}} \frac{\zeta}{(1-\zeta)^{2}} \mathrm{E}\left(((1-\zeta) \widehat{\alpha}-\zeta)^{+}\right) \\
=\frac{1+\alpha+\beta \mu_{\mathrm{M}}}{\gamma \sigma_{\varepsilon}^{2}} \frac{\zeta}{(1-\zeta)^{2}}\left(((1-\zeta) \alpha-\zeta) \Phi\left(\frac{(1-\zeta) \alpha-\zeta}{(1-\zeta) \kappa \sigma_{\varepsilon}}\right)\right. \\
\left.+(1-\zeta) \kappa \sigma_{\varepsilon} \varphi\left(\frac{(1-\zeta) \alpha-\zeta}{(1-\zeta) \kappa \sigma_{\varepsilon}}\right)\right)
\end{array}
$$

where $\Phi(\cdot)$ denotes the standard normal CDF, and $\varphi(\cdot)$ denotes the associated PDF. The second equality above follows from the fact that $(1-\zeta) \widehat{\alpha}-\zeta \sim \mathcal{N}\left((1-\zeta) \alpha-\zeta,(1-\zeta)^{2} \kappa^{2} \sigma_{\varepsilon}^{2}\right)$, together with the expression for the mean of a truncated normal random variable (see e.g. Johnson, Kotz, and Balakrishnan 1994).

Since $r_{\mathrm{P}}$ is normally distributed in our setup, it follows that $\mathrm{P}\left(r_{\mathrm{P}}<-1\right)>0$. In other words, an investment in the mutual fund could become an end-of-period liability. To reduce the likelihood of such an outcome, we make the following benign assumption:

Assumption 5. The fund's before-fee return satisfies $\mathrm{E}\left(r_{P}\right)>-1 \Rightarrow 1+\alpha+\beta \mu_{\mathrm{M}}>0$.

To be economically meaningful, the fee imposed by the fund manager should be a fraction of its end-of-period assets under management that is both positive and less than one. Assumption 5 ensures that these constraints are endogenous to the formulation of the fund manager's problem (5):

Lemma 6. The optimal fee $\zeta_{*}$ satisfies $0<\zeta_{*}<1$.

The first-order condition for the optimal fee charged by the fund manager is obtained by differentiating his objective function (6), to get

$$
\frac{\partial F}{\partial \zeta}\left(\alpha, \sigma_{\varepsilon}, \zeta\right)=\frac{1+\alpha+\beta \mu_{\mathrm{M}}}{\gamma \sigma_{\varepsilon}^{2}} \frac{1}{(1-\zeta)^{3}} G\left(\alpha, \sigma_{\varepsilon}, \zeta\right)
$$

where

$$
G\left(\alpha, \sigma_{\varepsilon}, \zeta\right):=((1-\zeta) \alpha-2 \zeta) \Phi\left(\frac{(1-\zeta) \alpha-\zeta}{(1-\zeta) \kappa \sigma_{\varepsilon}}\right)+(1-\zeta) \kappa \sigma_{\varepsilon} \varphi\left(\frac{(1-\zeta) \alpha-\zeta}{(1-\zeta) \kappa \sigma_{\varepsilon}}\right)
$$

The optimal fee $\zeta_{*}$ is thus characterized as the solution for the equation $G\left(\alpha, \sigma_{\varepsilon}, \zeta_{*}\right)=0$. Since $\beta$ does not appear in (7), it follows that the optimal fee charged by the manager of the mutual fund is independent of its level of systematic risk:

Corollary 7. The optimal fee $\zeta_{*}$ is invariant with respect to $\beta$. 
Corollary 7 is a direct consequence of the separation of alpha and beta in (4), which, in turn, follows from the risk-aversion of the investor in our model. Testing the cross-sectional dependence of the advisory fees on systematic risk could therefore provide empirical evidence on the risk-aversion of mutual fund investors.

\section{The Relationship Between the Optimal Fee and Idiosyncratic Volatility}

To establish the dependence of the optimal advisory fee on the idiosyncratic volatility of the mutual fund in our model, we first refine the bounds in Lemma 6:

Lemma 8. The optimal fee $\zeta_{*}$ admits the following bounds:

$$
\frac{\alpha^{+}}{2+\alpha^{+}}<\zeta_{*}<\frac{\alpha \wedge \frac{\alpha}{2}+\kappa \sigma_{\varepsilon} \frac{\varphi\left(\frac{\alpha \wedge \frac{\alpha}{2}}{\kappa \sigma_{\varepsilon}}\right)}{\Phi\left(\frac{\alpha \wedge \frac{\alpha}{2}}{\kappa \sigma \varepsilon}\right)}}{1+\alpha \wedge \frac{\alpha}{2}+\kappa \sigma_{\varepsilon} \frac{\varphi\left(\frac{\alpha \wedge \frac{\alpha}{2}}{\kappa \sigma_{\varepsilon}}\right)}{\Phi\left(\frac{\alpha \wedge \frac{\alpha}{2}}{\kappa \sigma \varepsilon}\right)}},
$$

where $x \wedge y \equiv \min \{x, y\}$ denotes the minimum of $x$ and $y$. In particular, $\left.\zeta_{*}\right|_{\sigma_{\varepsilon}=0+}=\frac{\alpha^{+}}{2+\alpha^{+}}$.

Observe that Lemma 8 is consistent with Lemma 6. In particular, the lower bound in (8) is clearly non-negative, while the upper bound is less than one, by virtue of Lemma A.2. ${ }^{7}$ Next, an analysis of the equation $G\left(\alpha, \sigma_{\varepsilon}, \zeta_{*}\right)=0$ reveals the sensitivity of the optimal fee to the idiosyncratic volatility of the mutual fund:

Theorem 9. The optimal fee $\zeta_{*}$ satisfies

$$
\frac{\partial \zeta_{*}}{\partial \sigma_{\varepsilon}}=\frac{\left(1-\zeta_{*}\right)\left(2 \zeta_{*}-\left(1-\zeta_{*}\right) \alpha\right)\left(\left(1-\zeta_{*}\right) \zeta_{*} \alpha-\zeta_{*}^{2}+\left(1-\zeta_{*}\right)^{2} \kappa^{2} \sigma_{\varepsilon}^{2}\right)}{\sigma_{\varepsilon}\left(\left(1-\zeta_{*}\right) \zeta_{*} \alpha-2 \zeta_{*}^{2}+2\left(1-\zeta_{*}\right)^{2} \kappa^{2} \sigma_{\varepsilon}^{2}\right)}
$$

In particular, $\frac{\partial \zeta_{*}}{\partial \sigma_{\varepsilon}}>0$.

Theorem 9 leads to the remarkable conclusion that funds with higher idiosyncratic volatilities charge higher fees. To gain an economic insight into this result, note that a higher idiosyncratic volatility on the part of the mutual fund makes the investor more likely to overestimate or underestimate its performance substantially. Observe also that the fraction of wealth the investor

\footnotetext{
${ }^{7}$ Simply note that the first inequality in (A.9) implies that

$$
\alpha \wedge \frac{\alpha}{2}+\kappa \sigma_{\varepsilon} \frac{\varphi\left(\frac{\alpha \wedge \frac{\alpha}{2}}{\kappa \sigma_{\varepsilon}}\right)}{\Phi\left(\frac{\alpha \wedge \frac{\alpha}{2}}{\kappa \sigma_{\varepsilon}}\right)}>0
$$
}

and the desired conclusion follows. 
allocates to the fund exhibits a positive convex dependence on his estimate for the value of its before-fee alpha, as is evident from (4). The convexity results in a higher equilibrium fee as the investor's uncertainty about the fund's performance increases, due to an increase in its idiosyncratic volatility. This observation is reminiscent of the well-known phenomenon in option pricing, where the price of a contract with a convex payoff is monotonically increasing with respect to the volatility of the underlying asset. Indeed, it is fruitful to view the optimal fee in our setting as a contingent claim on the investor's estimate of the fund's before-fee alpha, with the idiosyncratic volatility of the fund playing the role of asset price volatility in traditional option pricing.

It is also instructive to interpret Theorem 9 in the light of Miller (1977), who argued that the combination of restrictions on short-selling and divergences of opinion among investors inflate the prices of risky securities. Moreover, since the opinions of investors are more divergent in the face of greater uncertainty about future returns, Miller (1977) predicted a positive relationship between security prices and uncertainty, in the presence of short-sale constraints. Our model is amenable to this analysis, by dint of the fact that the mutual fund cannot be sold short. In particular, a higher level of idiosyncratic risk increases the investor's uncertainty about the before-fee alpha of the fund, making him more likely to overestimate or underestimate its value substantially. In the former case he will be willing to pay a higher fee to invest in the fund, while his inability to short-sell the fund prevents him from exerting downward pressure on the fee in the latter case. The overall effect is that a higher fee can be sustained in equilibrium.

Theorem 4.1 in Hugonnier and Kaniel (2010) offers some parallels to Theorem 9, although the economic mechanism is quite different. In their model, a higher fee results in a smaller allocation to the fund by the investor. This provokes greater risk-taking by the fund manager, in order to increase the likelihood of a substantial return, as compensation for the adverse impact of a smaller investment on the fund's assets.

By interpreting Theorem 9 to mean that the optimal fee charged by the fund manager is monotonically increasing in the investor's uncertainty about his performance, we obtain a similar result Corollary 1 in Cheng, Massa, and Zhang (2013). In the context of a simple model, in which two types of investors observe different facets of managerial skills, they show that a fund manager will charge a fee equal to his before-fee performance if the investors agree about his skill, while the fee will exceed his before-fee performance if they disagree. The search costs associated with the investment strategies of mutual fund managers are the catalyst for such disagreements.

Fama and French (2010) recently argued that active investment returns should be subject 
to a conservation principle, referred to as "equilibrium accounting," according to which the aggregate before-fee alpha achieved by active investors should be zero. They arrived at this conclusion by arguing that the before-fee alphas of individual passive portfolios (including the market portfolio) should each be zero, since passive investment strategies should not yield abnormal expected returns relative to passive benchmarks. Active investors must therefore be consigned to a zero-sum game, with some winners and some losers, but where the before-fee alpha is zero in aggregate.

The reasoning above suggests that we should pay special attention to the situation when the before-fee alpha of the mutual fund in our model is zero. In that case, Theorem 9 indicates that the optimal fee $\zeta_{*}$ satisfies

$$
\frac{\partial \zeta_{*}}{\partial \sigma_{\varepsilon}}=\frac{\left(1-\zeta_{*}\right) \zeta_{*}}{\sigma_{\varepsilon}}
$$

In particular, it is concave with respect to the idiosyncratic volatility of the fund:

Proposition 10. Suppose $\alpha=0$. Then the optimal fee $\zeta_{*}$ satisfies $\frac{\partial^{2} \zeta_{*}}{\partial \sigma_{\varepsilon}^{2}}<0$.

When $\alpha$ is non-zero, numerical experiments (see e.g. Figure 3) reveal that $\zeta_{*}$ is initially convex with respect to $\sigma_{\varepsilon}$, but concave thereafter. Concavity does, however, appear to be the dominant overall feature of the shape of the relationship.

Another useful feature of (10) is its separability. This allows us to compute the optimal fee explicitly, by direct integration:

Proposition 11. Suppose $\alpha=0$. Then the optimal fee $\zeta_{*}$ is given by

$$
\zeta_{*}=\frac{k \sigma_{\varepsilon}}{1+k \sigma_{\varepsilon}},
$$

where the constant $k>0$ is determined by the equation

$$
\frac{k}{\kappa} \Phi\left(\frac{k}{\kappa}\right)+\frac{1}{2} \varphi\left(\frac{k}{\kappa}\right)=\frac{k}{\kappa}
$$

In particular, $k \approx 0.6120 \kappa$.

Figure 2 uses the parameter values $\alpha=0$ and $\kappa=0.5$ to plot $\zeta_{*}$ as a function of $\sigma_{\varepsilon}$. This value of $\kappa$ was inferred from the empirical data described in Section III, by computing the average ratio of the standard errors of the estimated before-fee alphas of the funds in our sample to their gross idiosyncratic volatilities (see Assumption 1). Figure 2 (a) illustrates the relationship between the optimal fee $\zeta_{*}$ and the bounds obtained by Lemma 8, while Figure 2 (b) compares the optimal fee $\zeta_{*}$ with observed fees. The correspondence between the theoretical fee-idiosyncratic 
risk relationship arising from our model, and the observed relationship, is impressive. Note that the concavity of the relationship appears to be a more pronounced feature of the data than it is for the model.

\section{** INSERT FIGURE 2 HERE **}

\section{E. The Relationship Between the Optimal Fee and Performance}

The next theorem reveals that the optimal fee is monotonically increasing with respect to the before-fee alpha of the mutual fund. We also observe that the fund manager passes at least some part of any increase in performance on to the investor, rather than adjusting the fee to consume it entirely:

Theorem 12. The optimal fee $\zeta_{*}$ satisfies

$$
\frac{\partial \zeta_{*}}{\partial \alpha}=\left(1-\zeta_{*}\right)^{2} \frac{\left(\left(1-\zeta_{*}\right) \alpha-2 \zeta_{*}\right) \zeta_{*}+\left(1-\zeta_{*}\right)^{2} \kappa^{2} \sigma_{\varepsilon}^{2}}{\left(\left(1-\zeta_{*}\right) \alpha-2 \zeta_{*}\right) \zeta_{*}+2\left(1-\zeta_{*}\right)^{2} \kappa^{2} \sigma_{\varepsilon}^{2}}
$$

In particular, $0<\frac{\partial \zeta_{*}}{\partial \alpha}<\left(1-\zeta_{*}\right)^{2}<1$.

Theorem 12 emphasizes the differences between our model and other theoretical models for mutual fund fees. For example, in the model developed by Gil-Bazo and Ruiz-Verdú (2008), poorer-performing funds charge higher fees than their better-performing counterparts, due to the presence of unsophisticated investors. Similarly, the information costs borne by the fund manager in the Cheng, Massa, and Zhang (2013) model can cause a decrease in the before-fee alpha of the fund to coincide with an increase in its fee.

Note that the inequality $\frac{\partial \zeta_{*}}{\partial \alpha}<\left(1-\zeta_{*}\right)$ suggests that the optimal fee becomes less sensitive to the performance of the mutual fund as its idiosyncratic volatility increases, since the fee is monotonically increasing with respect to idiosyncratic volatility (see Figure 3 for visual confirmation). As we shall see in Section I.G, a similar observation applies to the flow-performance sensitivity as idiosyncratic volatility increases.

\section{F. The Relationship Between the Optimal Fee and Investor Expertise}

Mathematically, the investor expertise parameter $\kappa$ and the before-fee idiosyncratic volatility $\sigma_{\varepsilon}$ of the mutual fund exert exactly the same influence on the optimal advisory fee. To appreciate this, simply observe that those two parameters always appear in tandem in (7), as the product $\kappa \sigma_{\varepsilon}$. Consequently, the results concerning the dependence of the optimal fee on the idiosyncratic volatility of the fund also pertain to the relationship between the fee and the expertise of the 
investor. Hence, Theorem 9 indicates that a more sophisticated investor will pay a lower fee (all else being equal), while it follows from the limiting case in Lemma 8 that an omniscient investor will pay $\left.\zeta_{*}\right|_{\kappa=0+}=\frac{\alpha^{+}}{2+\alpha^{+}}$. Since such an investor experiences no uncertainty about the fund's performance, the optimal fee is invariant with respect to its idiosyncratic volatility.

Figure 3 plots $\zeta_{*}$ as a function of $\alpha$ and $\sigma_{\varepsilon}$, for $\kappa=0,0.5,1,1.5$. As expected, lower levels of investor expertise correspond with higher fees, for the same values of the remaining parameters. The monotonically increasing relationship between the optimal fee and the idiosyncratic volatility of the mutual fund, as well as the monotonically increasing dependence of the optimal fee on the fund's before-fee alpha, are also clearly evident. In addition, we note that Figure 3 provides a striking illustration of our interpretation of the optimal fee as an option on the investor's estimate of the fund's performance.

\section{** INSERT FIGURE 3 HERE **}

The bold curves in Figure 3 indicate where $\zeta_{*}=\alpha$. Along those curves the optimal fee equals the before-fee alpha of the mutual fund, implying that its after-fee performance is zero. To their left (i.e. for lower values of $\alpha$ and higher values of $\sigma_{\varepsilon}$ ), the after-fee performance of the fund is negative, while to their right (i.e. for higher values of $\alpha$ and lower values of $\sigma_{\varepsilon}$ ), it is positive. With this in mind, Figure 3 reveals that investors with more expertise obtain positive after-fee alphas at lower levels of before-fee alpha and higher levels of idiosyncratic volatility than less expert investors.

Observe that the after-fee alpha of the mutual fund can be positive or negative in the equilibrium solution for our model. By contrast, competition between investors in Berk and Green's (2004) model causes after-fee alphas to be zero, in equilibrium. Similarly, after-fee alphas cannot be positive in Cheng, Massa, and Zhang's (2013) model.

\section{G. The Relationship Between the Investor's Allocation and Idiosyncratic Volatility}

Given an advisory fee is $\zeta$, (4) allows us to determine the investor's expected dollar allocation to the mutual fund:

$$
\begin{aligned}
\omega & :=\mathrm{E}\left(\xi_{*} w\right)=\frac{1}{\gamma(1-\zeta)^{2} \sigma_{\varepsilon}^{2}} \mathrm{E}\left(((1-\zeta) \widehat{\alpha}-\zeta)^{+}\right) \\
& =\frac{1}{\gamma(1-\zeta)^{2} \sigma_{\varepsilon}^{2}}\left(((1-\zeta) \alpha-\zeta) \Phi\left(\frac{(1-\zeta) \alpha-\zeta}{(1-\zeta) \kappa \sigma_{\varepsilon}}\right)+(1-\zeta) \kappa \sigma_{\varepsilon} \varphi\left(\frac{(1-\zeta) \alpha-\zeta}{(1-\zeta) \kappa \sigma_{\varepsilon}}\right)\right) \\
& =\frac{1}{\gamma(1-\zeta)^{2} \sigma_{\varepsilon}^{2}}\left(G\left(\alpha, \sigma_{\varepsilon}, \zeta\right)+\zeta \Phi\left(\frac{(1-\zeta) \alpha-\zeta}{(1-\zeta) \kappa \sigma_{\varepsilon}}\right)\right) .
\end{aligned}
$$


In equilibrium, when the fund manager charges the optimal fee $\zeta_{*}$, this simplifies to

$$
\omega_{*}=\left.\omega\right|_{\zeta=\zeta_{*}}=\frac{\zeta_{*}}{\gamma\left(1-\zeta_{*}\right)^{2} \sigma_{\varepsilon}^{2}} \Phi\left(\frac{\left(1-\zeta_{*}\right) \alpha-\zeta_{*}}{\left(1-\zeta_{*}\right) \kappa \sigma_{\varepsilon}}\right)
$$

by virtue of the identity $G\left(\alpha, \sigma_{\varepsilon}, \zeta_{*}\right)=0$.

It is natural to interpret $\omega_{*}$ as the equilibrium expected investment flow into the fund. Unsurprisingly, a better gross performance yields a larger expected flow:

Theorem 13. The expected flow $\omega_{*}$ satisfies

$$
\frac{\partial \omega_{*}}{\partial \alpha}=\frac{\zeta_{*}}{\gamma\left(1-\zeta_{*}\right) \sigma_{\varepsilon}^{2}} \frac{\frac{1+\zeta_{*}}{\zeta_{*}}\left(1-\zeta_{*}\right)^{2} \kappa^{2} \sigma_{\varepsilon}^{2}+\left(\left(1-\zeta_{*}\right) \alpha-2 \zeta_{*}\right)}{2\left(1-\zeta_{*}\right)^{2} \kappa^{2} \sigma_{\varepsilon}^{2}+\left(\left(1-\zeta_{*}\right) \alpha-2 \zeta_{*}\right)} \Phi\left(\frac{\left(1-\zeta_{*}\right) \alpha-\zeta_{*}}{\left(1-\zeta_{*}\right) \kappa \sigma_{\varepsilon}}\right) .
$$

In particular, $\frac{\partial \omega_{*}}{\partial \alpha}>\left(1-\zeta_{*}\right) \omega_{*}>0$.

Figure 4 plots the equilibrium expected flow $\omega_{*}$, and the equilibrium expected flow-performance sensitivity $\frac{\partial \omega_{*}}{\partial \alpha}$, as functions of the before-fee alpha $\alpha$ and the gross idiosyncratic volatility $\sigma_{\varepsilon}$ of the fund. We observe that our model captures the convexity of the flow-performance relationship identified empirically by Ippolito (1992), and Sirri and Tufano (1998). ${ }^{8}$ This relationship is generally regarded as an exogenous feature of the interaction between mutual funds and their investors, and is typically interpreted as evidence that investors contribute enthusiastically to funds that have performed well, but hesitate to withdraw their investments from funds that have performed poorly. By contrast, a convex flow-performance relationship is endogenous to our model, and requires no assumption that investors respond asymmetrically to good and bad performance.

\section{** INSERT FIGURE 4 HERE **}

Several studies have investigated whether the convexity of the flow-performance relationship acts as an inducement for fund managers to manipulate investment flows by adjusting the risk levels of their portfolios in response to prior performance. For example, Brown, Harlow, and Starks (1996), and ? presented evidence in support of the so-called "tournament hypothesis," according to which interim loser funds increase their risk levels relative to interim winners, towards the end of the year, in response to the shape of the flow-performance relationship.

\footnotetext{
${ }^{8}$ There are two important differences between the the flow-performance relationship in our model and its empirical specification. First, flows are expressed as fractions of assets under management in empirical studies, whereas $\omega_{*}$ measures the expected dollar inflow of investment in the fund. Second, empirical studies of the flowperformance relationship equate performance with prior return, whereas the performance of the mutual fund in our model its true before-fee alpha. Nevertheless, the theoretical insights offered by our model are applicable to the empirical flow-performance relationship.
} 
However, their results were subsequently disputed on methodological grounds by ?, and ?. In another prominent empirical study, Chevalier and Ellison (1997) estimated the shape of the flowperformance relationship, and used it to infer the risk-taking incentives of fund managers. They found that small funds, in particular, tend to change their risk levels relative to a benchmark, in line with these incentives. Finally, the results of ? indicate a tendency for mutual funds to increase their tracking error volatilities as their relative performance declines.

Although the level of risk of the mutual fund is exogenous in our model, Figure 4(a) offers some insight into the fund manager's risk-taking incentives. First, since the investor's allocation to the fund is independent of its systematic risk, it follows that any strategic risk-taking by the fund manager will be limited to its idiosyncratic risk. Our model is thus more consistent with the results of Chevalier and Ellison (1997), and ? than it is with the results of Brown, Harlow, and Starks (1996), and ?.

\section{A Simulated Mutual Fund Market}

In this section we conduct a Monte Carlo experiment to investigate how the stylized features of the optimal fee charged by the mutual fund manager in our model express themselves in empirical data. In practice, we observe noisy estimates for the expected risk-adjusted returns of mutual funds, and the source of that noise is idiosyncratic risk, which also drives fees in our model. This raises the possibility of an interaction between the fees charged by mutual funds and the estimation errors associated with their alphas, with potentially unwelcome consequences for cross-sectional regressions.

\section{A. The Simulation Framework}

We begin by generating a cross-section of 10,000 mutual funds, whose true (but unobservable) gross alphas are i.i.d. realizations of a normal random variable $\alpha_{i} \sim \mathcal{N}\left(0, \sigma_{\alpha}^{2}\right)$. Their gross idiosyncratic volatilities are modelled as i.i.d. realizations of an independent log-normal random variable $\sigma_{\varepsilon_{i}} \sim \ln \mathcal{N}(-4.2263,0.5532)$. The independence of these distributions implies that managerial skills are unrelated to idiosyncratic risk.

The assumption that the gross alphas have a mean of zero is consistent with the equilibrium accounting hypothesis of Fama and French (2010), while the standard deviation $\sigma_{\alpha}>0$ of the gross alpha distribution measures the cross-sectional dispersion of risk-adjusted performance. The parameters for the distribution of gross idiosyncratic volatilities were obtained by maximum likelihood estimation, using the empirical data described in Section III.B (see Figure 5). The resulting distribution has a mean of $1.70 \%$ and a standard deviation of $1.02 \%$, matching the 
statistics reported in Section III.A.3.

** INSERT FIGURE 5 HERE **

Next, we solve the equation $G\left(\alpha_{i}, \sigma_{\varepsilon_{i}}, \zeta_{i}\right)=0$ numerically, for each fund in the sample, to determine its fee $\zeta_{i}$. We then generate a time-series of 30 annual gross returns for each fund, according to the model $r_{i, t}=\alpha_{i}+\varepsilon_{i, t}$, by sampling its i.i.d. residuals $\varepsilon_{i, t} \sim \mathcal{N}\left(0, \sigma_{\varepsilon_{i}}^{2}\right)$. The corresponding net returns are thus $r_{i, t}-\zeta_{i}$. The final step is to compute the estimates $\hat{\alpha}_{i}$ and $\hat{\sigma}_{\varepsilon_{i}}$ for the gross alphas and the gross idiosyncratic volatilities of the funds in the sample from their time-series data. The estimates for the net alphas of are thus $\hat{\alpha}_{i}-\zeta_{i}$.

\section{B. An Informal Analaysis of the Fee-Performance Relationship}

In this subsection we consider the situation when $\sigma_{\alpha}=0$, in which case all fund managers are (equally) unskilled. This scenario is computationally convenient, since fees are easily determined by evaluating (11). It is also important, since it allows us to identify the impact of heterogeneous idiosyncratic risk-taking on the observed fee-performance relationship, without having to disentangle the effects of performance heterogeneity.

The solid curves in Figure 1 illustrate the results of a typical simulation, using the investor expertise parameter $\kappa=0.5$. We are immediately struck by the dramatic U-shape in Figure 1(a). It can be attributed to the influence of idiosyncratic risk in two distinct ways. First, since the standard errors of estimated alphas are proportional to idiosyncratic volatilities, the funds with the highest idiosyncratic volatilities tend to exhibit the most extreme estimated gross alphas. In other words, the tails of the estimated gross alpha distribution tend to be populated by the funds with the highest levels of idiosyncratic risk, as illustrated by Figure 1(d). Second, since the fees are generated by our model, they naturally exhibit a positive dependence on idiosyncratic volatilities, as seen in Figure 1(c). By combining these two observations, we see that the funds with the highest fees tend to exhibit the most extreme estimated gross alphas.

Since the true gross alphas are all zero in the scenario under consideration, it follows that the interaction between idiosyncratic volatilities and estimated gross alphas, depicted in Figure 1(d), is merely statistical noise generated by the impact of idiosyncratic volatilities on estimation errors. ${ }^{9}$ This noise is amplified by the dependence of fees on idiosyncratic risk, to produce the U-shaped dependence of fees on estimated gross alphas in Figure 1(a). That relationship is obviously spurious, as well.

\footnotetext{
${ }^{9}$ In fact, interactions between idiosyncratic volatilities and estimated gross alphas are spurious in all simulations, since gross alphas and idiosyncratic volatilities are sampled from independent distributions.
} 
By contrast, the observable skewness in Figure 1(b) is indicative of an authentic dependence of fees on true net alphas, which is again attributable to the fact that fees are monotonically increasing in idiosyncratic risk. In detail, since all funds have true gross alphas of zero in the scenario under consideration, their true net alphas are simply the negative values of their fees, whence funds with higher levels of idiosyncratic risk have higher fees and lower true net alphas. This also explains the skewness of the relationship between idiosyncratic volatilities and estimated net alphas in Figure 1(e).

The dotted curves in Figure 1 present an analogous picture to the solid curves, for the empirical data described in Section III.B. Once again, the extent to which our model replicates the stylized features of real mutual fund data is remarkable. In fact, even the numerical values in the two sets of figures are comparable. The most noticeable difference is that the empirical relationship between fees and estimated net alphas in Figure 1(e) is quite symmetric, whereas the corresponding relationship for the simulated data is significantly skewed. To explain this difference, recall that higher idiosyncratic volatilities induce larger standard errors in estimated net alphas, while simultaneously increasing fees. The former effect is responsible for the Ushape of the relationship between estimated gross idiosyncratic volatilities and estimated net alphas, while the latter effect expresses itself as a negative trend in that relationship. Since estimated gross idiosyncratic volatilities range between $0 \%$ and $10 \%$, for both the empirical data and the simulated data, the impact of idiosyncratic risk on the estimation errors of net alphas is similar in both cases. However, empirical management fees lie between $0.6 \%$ and $1.5 \%$, while (11) produces fees between $0 \%$ and $3 \%$, for the range of idiosyncratic volatilities above (see Figure 2(a)). In other words, the larger variability of fees in the simulated data induces a stronger negative trend in the relationship between estimated gross idiosyncratic volatilities and estimated net alphas than is witnessed for the empirical data.

The U-shaped dependence of estimated gross idiosyncratic volatilities on estimated gross alphas, illustrated by the solid curve in Figure 1(d), persists if we increase the value of $\sigma_{\alpha}$, although it flattens out and becomes less regular. When $\sigma_{\alpha} \approx 1.5 \%$, it ceases to be distinguishable. At that point, the cross-sectional variation in true alphas dominates the cross-sectional variation in idiosyncratic volatilities (recall that gross idiosyncratic volatilities are drawn from a distribution with a standard deviation of $1.02 \%$ ). The distribution of the estimated alphas of the funds in a sample then begins to reflect the distribution of their true alphas, rather than by the distribution of their idiosyncratic volatilities. Since fees in our model are positively related to true gross alphas, this results in a monotonically increasing dependence of fees on estimated (gross and net) alphas, rather than the relationships depicted by the solid curves in 
Figures 1(a)-(b).

The previous discussion suggests that the ratio of the standard deviation of true gross alphas to the standard deviation of gross idiosyncratic volatilities may be interpreted as a type of crosssectional signal-to-noise ratio. A larger value decreases the importance of the cross-sectional interaction between idiosyncratic volatilities and the standard errors of estimated alphas. It also decreases the cross-sectional variation in fees relative to the variation in true alphas. As a result, the U-shaped dependence of idiosyncratic volatilities on estimated alphas dissipates, and the relationship between fees and estimated alphas begins to reflect the true fee-performance relationship. The solid curves in Figure 1 represent the worst-case scenario, when the signalto-noise ratio is zero.

The analysis above sheds new light on some empirical results in the mutual fund literature. For example, the U-shaped dependence of fees on estimated net performance, illustrated by Figure 1(b), is discernible in the tables presented by Gruber (1996), and Carhart (1997). More recently, ? developed a theoretical model in which a U-shaped relationship between the relative risk adopted by fund managers and their prior performance results from the interplay of compensation structure incentives and career concerns. Naturally, they interpreted the empirical evidence for this relationship as confirmation of their model. However, our account of the Ushape in Figure 1(e) offers a more parsimonious explanation. In particular, we suggest that the U-shaped relationship between relative risk and prior performance identified by ? is simply a manifestation of the noisy interaction between idiosyncratic volatilities and the standard errors of estimated alphas.

\section{A Formal Analysis of the Fee-Performance Relationship}

To understand how our theoretical model expresses itself in cross-sectional regressions of fees against (gross and net) performance, we use data from the Monte Carlo simulations described earlier to estimate the following models:

$$
\zeta_{i}=a_{1}+b_{1} \hat{\alpha}_{i}+c_{1} \hat{\sigma}_{\varepsilon_{i}}+d_{1} \sqrt{\hat{\sigma}_{\varepsilon_{i}}}+e_{1} \hat{\alpha}_{i} \hat{\sigma}_{\varepsilon_{i}}+v_{1, i}
$$

and

$$
\zeta_{i}=a_{2}+b_{2}\left(\hat{\alpha}_{i}-\zeta_{i}\right)+c_{2} \hat{\sigma}_{\varepsilon_{i}}+d_{2} \sqrt{\hat{\sigma}_{\varepsilon_{i}}}+e_{2}\left(\hat{\alpha}_{i}-\zeta_{i}\right) \hat{\sigma}_{\varepsilon_{i}}+v_{2, i}
$$

Table I presents the results of fitting (13) to the data generated by three simulations, with $\sigma_{\alpha}=0, \sigma_{\alpha}=0.0025$, and $\sigma_{\alpha}=0.005$. We immediately observe that the positive concave dependence of fees on idiosyncratic volatilities is an unambiguous and statistically significant 
feature of the simulated data. Of course, this reflects the properties our model, which was used to generate the data. We also observe a dramatic increase in the $R^{2}$ statistic when estimated gross idiosyncratic volatility is added as an independent variable, indicating that idiosyncratic risk is far more important for describing fees in the simulated data than performance. This is not surprising, since the variability of performance is very small relative to the variability of idiosyncratic risk, in all three simulations.

\section{** INSERT TABLE I HERE **}

According to Panel A, the dependence of fees on estimated gross alphas is never significantly negative, even without controlling for the effect of idiosyncratic risk. Moreover, it becomes progressively stronger as the dispersion of performance increases, and is significantly positive when $\sigma_{\alpha}=0.0025$ or $\sigma_{\alpha}=0.005$. In other words, the positive relationship between fees and gross performance, which is inherent in our model, becomes more visible as the heterogeneity of managerial skills increases. Including the dependence of fees on estimated gross idiosyncratic volatilities, as well as their interactions with estimated gross alphas, further strengthens the relationship between fees and estimated gross alphas.

By contrast, Panel B reveals that the dependence of fees on estimated net alphas is always significantly negative when the effect of idiosyncratic risk is not taken into account. However, the inclusion of estimated gross idiosyncratic volatilities, and their interactions with estimated net alphas, changes things dramatically, and even produces significant positive relationships when $\sigma_{\alpha}=0.0025$ and $\sigma_{\alpha}=0.005$.

\section{** INSERT TABLE II HERE **}

The significant negative correlations between estimated net alphas and estimated gross idiosyncratic volatilities reported in Table II identify the negative dependence of fees on estimated net alphas in Panel B of Table I as the manifestation of an omitted variable bias. It arises from the fact that true net alphas - being true gross alphas less fees - are negatively correlated with idiosyncratic volatilities, due to the positive dependence of fees on idiosyncratic risk in our model. Consequently, regressing fees against estimated net alphas, without controlling for the impact of idiosyncratic risk, creates the false impression of a significant negative relationship between those variables, when that relationship is non-negative (and sometimes significantly positive) in a properly specified regression.

By contrast, the negligible correlations between estimated gross alphas and estimated gross idiosyncratic volatilities reported in Table II indicate that the relationship between fees and 
estimated gross alphas is not affected by an omitted variable problem. This is supported by the fact that the dependence of fees on estimated gross alphas does not change appreciably with the addition of idiosyncratic volatility as an independent variable, as seen in Panel A of Table I. Of course, the inclusion of idiosyncratic risk, and its interaction with gross performance, improves the quality the regressions there considerably, but not because of an omitted variable bias.

\section{Hypotheses, Data and Empirical Methodology}

In this section we formulate a number of hypotheses arising from the analysis of the theoretical model in Section I, and from the Monte Carlo experiment in Section II, and we briefly describe the data used to test those predictions in Section IV. In addition, we specify the regression models employed in Section IV, and we present the summary statistics for our data.

\section{A. Empirically Testable Hypotheses}

According to Theorem ?? and Proposition ??, the optimal fee charged by the mutual fund manager in our model is monotonically increasing and concave in the gross idiosyncratic volatility of the fund. These features are captured by Columns (i) and (ii) in all the panels of Table I, for simulated data, while Figure ?? suggests that the concavity of fees with respect to idiosyncratic risk is stronger in the empirical data than in our model:

Hypothesis 1. Fees exhibit a positive concave dependence on idiosyncratic volatility.

Theorem ?? demonstrates that the investor's allocation to the mutual fund is independent of its level of systematic risk, implying that the optimal fee charged by the fund manager is invariant with respect to the fund's exposure to the market portfolio. The same conclusion follows from the absence of the beta of the mutual fund in (7):

Hypothesis 2. Fees are independent of market risk.

According to Column (i) of Panels B.1-B.3 in Table I, the fees charged by mutual funds appear to exhibit a negative dependence on their net alphas, in cross-sectional regressions that exclude idiosyncratic volatility as an explanatory variable. However, the inclusion of estimated gross idiosyncratic volatilities in those regressions eliminates this negative relationship. The strong dependence of fees on idiosyncratic risk, together with the significantly negative correlations in Table II, diagnose an omitted variable bias in the original regressions:

Hypothesis 3. Fees exhibit a spurious negative dependence on net alphas, due to the omission of idiosyncratic volatility as an explanatory variable. 
Proposition ?? demonstrates that the optimal fee charged by the fund manager in our model is a monotonically increasing function of the gross performance of the fund. This is evident in the first columns of Panels A.1-A.3 in Table I, where we see that fees are positively related to estimated gross alphas, even before we control for the effect of idiosyncratic risk:

Hypothesis 4. Fees exhibit a non-negative dependence on gross alphas, even without controlling for the effect of idiosyncratic risk.

Note that since our model is concerned specifically with managerial fees, the hypotheses above should be interpreted in that light. Nevertheless, for the sake of completeness, we report results for both managerial fees and expense ratios in Section IV.

\section{B. Data}

Our data was obtained from the Center for Research in Security Prices (CRSP) SurvivorBias-Free U.S. Mutual Fund Database, for the period from January 1990 to December 2007. Since the subjects of our study are actively-managed diversified U.S. equity mutual funds, we began by excluding all fixed-income funds, money-market funds, international funds, and specialized sector funds from our initial sample. It was then reduced further, through the exclusion of all index funds and institutional funds. To obtain our sample of diversified domestic equity mutual funds, we use the information on fund policy codes and that provided by different classifications of funds by investment objective. In the Internet Appendix, we provide a more detailed account of the steps followed to construct our final sample, as well as the descriptive statistics of the main variables.

The availability of multiple share classes, with different fee schedules, offers investors a range of alternatives for investing in a given fund. Since mutual funds compete in each share class, classifying funds by their share classes is an essential ingredient for analyzing the feeperformance relationship. Moreover, in order to capture the effect of the structure of the mutual fund industry, we first grouped the funds into families using the management company codes provided by CRSP, after which we manually checked the dataset to expand the number of missing codes for each unique management company name. ${ }^{10}$

In order for a fund to have been included in our sample, it must have reported on its total net assets under management and on its returns. We also considered only those funds with at least one year's worth of reported returns. In line with established practice, the monthly growth

\footnotetext{
${ }^{10}$ This procedure increased the number of unique company codes by $15.77 \%$, when compared with those available in CRSP, and increased fund coverage by $13.16 \%$.
} 
rates in net flows for the funds in our sample were calculated as follows:

$$
\frac{T N A_{i, t}-T N A_{i, t-1}\left(1+R_{i, t}\right)-M_{i, t}}{T N A_{i, t-1}},
$$

where $T N A_{i, t}$ denotes the total net assets of fund $i$ in month $t, R_{i, t}$ denotes the after-fee return reported by that fund in the same month, and $M_{i, t}$ represents the aggregate total net assets of all dead funds that were merged into it during the month in question. ${ }^{11}$

Mutual fund fees are reported as annual operating expenses, even though they are accrued on a daily basis, in practice. By convention, the annual operating expenses of any given fund during any particular year are expressed as a percentage of the average of its total assets under management during that year. The major components of annual mutual fund operating expenses are management fees and 12b-1 fees, which are marketing and distribution costs. Since management fees are not available in CRSP before 1999, we estimate management fees as total operating expenses net of $12 \mathrm{~b}-1$ fees. For robustness, we repeat our analysis using the actual management fees provided by CRSP over the period 1999 to 2007.

\section{Empirical Methodology}

We use a number of models to estimate the (before-fee and after-fee) expected risk-adjusted returns of the funds in our sample. These include the CAPM, the three-factor model of Fama and French (1993), and the four-factor model of Carhart (1997). We find that these models yield qualitatively similar results, whence our tables focus on the results of the Carhart (1997) model, as the chosen representative. ${ }^{12}$ However, we occasionally report results for some of the other models in the paper to demonstrate robustness.

The month $t$ return on fund $i$, in excess of the monthly T-Bill rate, is modeled as follows by Carhart (1997):

$$
r_{i, t}=\alpha_{i}+\beta_{i} R M R F_{t}+\gamma_{i} S M B_{t}+\zeta_{i} H M L_{t}+\eta_{i} P R 1 Y R_{t}+\varepsilon_{i, t},
$$

where $R M R F_{t}$ is the month $t$ excess return on a value-weighted market proxy, and $S M B_{t}, H M L_{t}$, and $P R 1 Y R_{t}$ are the month $t$ returns on value-weighted zero-investment factor-mimicking portfolios for size, book-to-market equity, and one-year momentum, respectively. Following Carhart (1997), we employ overlapping three-year estimation periods. If fewer than three years of previous data are available for a specific fund in a given estimation month, then we require it to have

\footnotetext{
${ }^{11}$ The average (median) growth rate in net flows is about $16 \%(4.8 \%)$, and the first (ninety-ninth) percentile is $-57 \%(232 \%)$.

${ }^{12}$ The results obtained for the other models are reported in our Supplementary Appendix.
} 
at least 30 months of available observations, for it to be included in the estimation. To cater for the possibility that the sensitivity of fees to past performance is contingent on performance levels, we introduce the dummy variables DMPERF and DHPERF, which indicate whether or not a given fund belongs to the middle tercile or the top tercile, respectively, of the performance distribution.

The variable $I D V O L$, defined as the standard deviation of 36 monthly residuals with respect to the Carhart (1997) model, is the chosen proxy for idiosyncratic volatility. To examine the relationships between fees, performance, and idiosyncratic risk, for mutual funds, we pool the time-series and cross-sectional data and use Fama and MacBeth (1973) estimations. Since the timing of fee changes is crucial for our analysys, we use the actual date ranges for the fee data of each fund, rather than assuming that fees are set regularly on certain dates. We also use a fixed-effect approach, with year-dummies, to ensure that estimated coefficients capture the cross-sectional relationships between the variables, without possible distortions induced by the correlations between the residuals of different funds. All regressions include untabulated dummy variables for investment objectives and fund share classes in the regressions. To control for the small-fund effect, we include the dummy variable $S M L F N D$, which indicates whether or not the assets of a given fund exceed $\$ 5$ million (see Fama and French (2010)). The standard errors of coefficient estimates are determined by the Newey and West (1987) methodology, to account for the effects of heteroskedasticity and autocorrelation in the sample data. Moreover, since the OLS regression assumption of independent residuals is often violated in panel data (particularly in mutual fund panels), we report standard errors for estimated coefficients that are clustered by fund, by time, and by fund-and-time (see Petersen (2009)).

\section{An Empirical Investigation of Mutual Fund Fees}

This section is devoted to an empirical analysis of mutual fund fees, with an emphasis on the predictions in Section III.A. Our focus reflects the fact that the model in Section I is explicitly concerned with management fees. Nevertheless, for completeness, we test our predictions against both management fees and expense ratios.

\section{A. The Determinants of Management Fees}

We examine the nature of the relationship between management fees and idiosyncratic volatility, while controlling for other fund characteristics that are known to affect fees. This is done by constructing several contingency tables based on quintile portfolios formed on IDVOL and each of the following fund characteristics: the logarithm of fund TNA (FNDSIZE); the 
logarithm of fund family TNA (FAMSIZE); portfolio turnover (TRNOVR); and the logarithm of fund age (FNDAGE). The result is a cross-tabulation of 25 quintile portfolios. For each, we calculate the average management fee charged by its constituent funds in the following year.

Panels A and B in Table III condition the quintile portfolios of idiosyncratic volatility on FNDSIZE and FAMSIZE. As funds grow, we observe that economies of scale and scope are realized, due to the decreasing costs of transactions processing and investor service provision, as fractions of assets under management. This cost reduction is economically and statistically relevant, and varies between 30 and 60 basis points, depending on the level of IDVOL. However, after controlling for fund TNA and family TNA, IDVOL continues to explain the cross-sectional variation in management fees. This suggests that the idiosyncratic volatility of mutual funds captures more than the decreasing marginal compensation rates in the sizes of funds and families.

\section{** INSERT TABLE III HERE **}

In Panel $\mathrm{C}$ we average the management fees across portfolios separated by both IDVOL and portfolio turnover (TRNOVR). Chalmers, Edelen, and Kadlec (1999) found that portfolio turnover constitutes the largest portion of total trading costs of mutual funds. If fund managers are overconfident about their ability to outperform the market, they could trade too much (Barber and Odean (2001)). This increases not only the extent of portfolio rebalancing, but also trading costs. If these costs translate into cross-sectionally higher management fees, we might witness a positive and significant relationship between fees and TRNOVR, even after controlling for IDVOL. The evidence in Panel C suggests that funds with higher levels of turnover seem to demand higher levels of compensation, within each quintile portfolio of idiosyncratic volatility. Similarly, for each quintile portfolio of fund portfolio turnover, the differences in management fees between high and low idiosyncratic volatility portfolios are significantly stable at around 40 basis points.

Finally, in Panel D we control for the relationship between fund age and management fees. The literature is unclear about this relationship. One could argue that young funds incur high incubation costs. On the other hand, if such funds also belong to large families, their startup cost could be subsidized by the family to boost their performance, with the intention of attracting new investments quickly (Barber, Odean, and Zheng (2005), and ?). The findings in Panel D are consistent with those of Tufano and Sevick (1997), and suggest that fund age does not seem to be a determining factor for management fees, since fees do not vary much across the quintile portfolios of fund age, after unsystematic risk has been taken into account.

In summary, for the majority of mutual funds, idiosyncratic volatility appears to explain most of the cross-sectional variation in advisory compensation. In addition, among the other 
fund characteristics, fund size and family size exhibit significant negative relationships with management fees. By contrast, portfolio turnover is positively related to management fees.

\section{B. A Multivariate Regression Analysis of Mutual Fund Fees}

We now test our empirical predictions about the relationship between fees and idiosyncratic volatility in a multivariate framework. The dependent variable is fees, expressed as a percentage, and measured either as management fees $(M G M T)$ or total operating expenses (OPEX). The representative measure of idiosyncratic volatility (IDVOL) is the standard deviation of residuals from the Carhart (1997) model, estimated over the previous 36 months. Our regression specifications include several lagged control variables that have been shown to affect mutual fund fees. These include the logarithm of fund TNA (FNDSIZE); the logarithm of one plus the total family TNA (FAMSIZE); the total number of funds in a family (NFNDFAM); the logarithm of fund age since inception (FNDAGE); the volatility of returns over the past 12 months $(V O L)$; the minimum of the aggregated purchases and sales of securities in the underlying portfolio (TRNOVR); the intercept for the Carhart (1997) model (NPERF); and the net inflows (FLOWS). In addition, we isolate the effect on fees of the different cost structures associated with small funds, by using the dummy variable $S M L F N D$, which indicates whether or not the assets of a fund are less than $\$ 5$ million (see Evans (2010), and Fama and French (2010)). Finally, we control for fund share classes and investment objective codes, since these variables are known to be associated with pricing and product differentiation at the family level.

The results of our analysis are reported in Table IV. The dependent variable is MGMT in Columns (i)-(viii), and OPEX in Columns (ix)-(xvi). To account for different average levels of advisory compensation in each sample year, we pool all variables and run year-fixed effect regressions, with standard errors clustered by fund. For robustness, we employ the Fama and MacBeth (1973) approach to repeat the analysis in Columns (v)-(viii) and (xiii)-(xvi), with Newey and West (1987) standard errors. The strongly significant positive dependence of MGMT on IDVOL in Table IV is consistent with Hypothesis 1. Moreover, the positive loadings of fees on idiosyncratic volatility are not explained by time-series variations in the dependent variable, since they remain highly significant even after controlling for time-fixed effects.

We find that a one standard deviation increase in idiosyncratic volatility corresponds with a 25.2 basis point increase in management fees. Since the average fund TNA of the funds in our sample is about $\$ 860$ million, this translates to about $\$ 2.2$ million for a fund of average size. We note that the economic impact of IDVOL remains virtually unchanged across different model specifications, when we consider operating expenses (OPEX) in Columns (ix)-(xvi). 


\section{** INSERT TABLE IV HERE **}

Turning to the impact of fund and family characteristics on management fees, the evidence presented in Table IV indicates that management fees decrease significantly with fund size (FNDSIZE), with the estimated coefficients ranging between -0.6 and -0.76 . The negative relationship between fees and FAMSIZE or NFNDFAM suggests that economies of scope operate at the family level, with larger families spreading the costs of investment research, managerial expertise, and portfolio rebalancing across their member funds. In addition, by offering larger sets of funds and investment styles, larger families could amortize the marketing and selling efforts of their (un)affiliated brokers across many products (Tufano and Sevick (1997)).

Since high levels of idiosyncratic risk may proxy for greater portfolio rebalancing, all regression models include the variable TRNOVR. Deli (2002) offers preliminary evidence on the link between advisory compensation and the characteristics of the underlying portfolios, by showing that the marginal compensation rates of equity or foreign mutual funds exceed those of debt or domestic mutual funds by about 20 basis points. He argues that these differences are indicative of more intensive trading by equity funds and foreign funds. The positive loadings of fees on TRNOVR in Table IV confirm that high portfolio rebalancing signals frequent trading, which in turn demands a greater managerial effort. It is therefore unsurprising that funds that trade intensively are more costly to manage.

We note the negative relationship between fees and performance in Table IV, whose existence is a long-standing puzzle (see e.g. Gruber (1996), Carhart (1997), Wermers (2000), Barber, Odean, and Zheng (2005), Kosowski, Timmermann, Wermers, and White (2006)). Gil-Bazo and Ruiz-Verdú (2009) argue that it is a consequence of intense competition for investor flows in the mutual fund industry, which sees competent managers attract sophisticated performancesensitive investors. This leaves unsophisticated investors at the mercy of under-performing fund managers, who increase their fees to exploit the performance-insensitivity of their clientele (see e.g. Christoffersen and Musto (2002)). We will return to this issue later, when we provide intriguing new evidence on the fee-performance relationship.

We note that the positive relationship between fees and idiosyncratic volatility survives, even after accounting for several fund and family characteristics. This suggests that IDVOL is indeed an important determinant of mutual fund fees. Overall, the evidence reported in Table IV lends strong support to Hypothesis 1, although the concavity of the relationship between fees and idiosyncratic risk remains to be demonstrated. 


\section{The Concavity of the Relationship Between Fees and Idiosyncratic Risk}

Having established the positive dependence of fees on idiosyncratic volatility, we now address the second part of Hypothesis 1, which concerns the concavity of that relationship. The dependent variable is once again fees, expressed as a percentage. To test the shape of the relationship between fees and idiosyncratic volatility, we introduce the following two variables: the square-root of fund idiosyncratic volatility $(\sqrt{I D V O L})$; and fund idiosyncratic volatility squared $\left(I D V O L^{2}\right)$. If the dependence of management fees on IDVOL is indeed concave, then a positive coefficient should attach to $\sqrt{I D V O L}$, and a negative coefficient should attach to $I D V O L^{2}$. Table IV reveals that this is indeed the case. In particular, we observe significant and positive and negative coefficients of fees on $\sqrt{I D V O L}$ and $I D V O L^{2}$, respectively, after controlling for other fund and family characteristics. This is precisely what we expect from the Monte Carlo experiment in Section II. In fact, when we compare Tables I and IV, we see that the concavity of the fee-idiosyncratic volatility relationship appears to be more pronounced in the empirical data than in the model (the coefficients on $\sqrt{I D V O L}$ in Table IV are larger and generally more significant than the corresponding coefficients in Table I). This is unsurprising, given the visual evidence in Figure ??.

The implicit assumption thus far is that advisory contracts are structured as single-rate contracts, whose payoffs are linear in fund assets. Another possible explanation for a concave relationship between fees and idiosyncratic volatility, which departs from the explanation provided by our model, is that high idiosyncratic volatility funds could be more likely to be associated with decreasing marginal compensation rates in fund TNA (i.e. advisory rates decrease marginally with increasing asset-based breakpoints). We can exclude this explanation, however, for two reasons. First, Deli (2002) points out that only a small fraction (less than one third) of advisory contracts exhibit breakpoints in fee schedules. Second, additional statistics reported in our Supplementary Appendix indicate that idiosyncratic volatility is inversely related to fund TNA. In other words, funds with fewer assets under management are characterized by higher levels of idiosyncratic risk. Small funds (and funds that belong to small families) are more likely to be granted single-rate contracts, to motivate their advisors to assume more risk (Deli (2002)). Consequently, the effect of decreasing marginal compensation rates on our results is most likely causing us to underestimate the positive (negative) loading of fees on $\sqrt{I D V O L}$ $\left(I D V O L^{2}\right)$, rather than the other way around. We confirm this in an unreported test, where we demonstrate that the concavity of fees with respect to IDVOL becomes even stronger when funds with breakpoint-based advisory contracts are excluded from the sample. 


\section{The Dependence of Fees on Market Risk}

In his presidential address to the American Finance Association, French (2008) quantified the total cost of active investing (defined as the average difference between the actual standardized cost of investing and the passive cost) to be $0.67 \%$ of the total market capitalisation each year, for the period from 1980 to 2006. Likewise, Deli (2002) estimated the average advisory compensation rate of active equity mutual funds to be almost $0.4 \%$ higher than the rates charged by similar passive equity mutual funds. These results indicate that passive investments are substantially less costly than active investments.

According to Hypothesis 2, the management fees of active mutual funds should not be dependent on systematic market risk. This may be interpreted to mean that investors should be unwilling to pay high active management fees for passive performance. To illustrate the scale of the difference between active and passive management fees, the Vanguard 500 Admiral Fund provides passive exposure to the S\&P 500 index for around 96 basis points less than the average expense ratio of active mutual funds with similar portfolio holdings.

To test Hypothesis 2, we first use the Carhart (1997) model to estimate the level systematic risk (BETA) for mutual funds. We then determine the extent to which BETA explains management fees, after controlling for fund and family characteristics. The results for these tests are also reported in Table IV, where we see that the loadings of fees on BETA are both statistically insignificant and economically irrelevant, for all regressions.

Our findings offer an explanation for the evidence provided by Golec (1992) on the lack of any significant relationship between single-fee contracts and systematic risk in mutual fund portfolios. ${ }^{13}$ They also provide several interesting insights into the determinants of advisory fee contracts. First, they support our primary prediction (Hypothesis 2) that advisory compensation rates do not price the systematic component of mutual fund returns, since investors can easily and cheaply adjust their exposures to market risk. Second, they provide some evidence of rationality on the part of mutual fund investors, by suggesting that investors separate their alpha and beta decisions, on the basis of cost.

It is worth noting that Hypothesis 2 follows from the fact that the investor in our model is risk-averse. A risk-neutral investor would not separate his alpha and beta allocations, whence the fee charged by the fund manager to a risk-neutral investor would depend on the beta of the fund. So the results presented in this section could also be interpreted as a rejection of the hypothesis that investors are risk-neutral.

\footnotetext{
${ }^{13}$ Interestingly, Golec (1992) demonstrates that for advisory contracts with no incentive fees, the base fee parameter is strongly positively related to idiosyncratic volatility, but unrelated to systematic risk (see Golec (1992), Panel II, p. 92).
} 


\section{E. The Relationship Between Fees and After-Fee Performance}

According to Hypothesis 3, the widely reported negative dependence of fees on after-fee performance is the consequence of an omitted variable bias. It results from the fact that fees and net performance (being gross performance less fees) are both dependent on idiosyncratic volatility. This section retraces the steps in the Monte Carlo experiment in Section II, by conducting a battery of tests to quantify the impact of idiosyncratic volatility on the feeperformance relationship.

We pool all variables and estimate cross-sectional time-series regressions with fund- and time-fixed effects. For robustness, we repeat this analysis using random effects, and the twostep Fama and MacBeth (1973) estimation procedure. To capture the non-linear relationship between fees and performance indicated in Table IV and Section II, we interact fund performance (NPERF $)$ with the following two dummy variables: DMPERF, which indicates whether fund performance is in the second performance tercile; and DHPERF, which indicates whether fund performance is in the top performance tercile. The primary independent variable of interest is the interaction between fund performance and idiosyncratic volatility $(N P E R F \times I D V O L)$.

The results of this analysis are presented in Table V. Consistent with the positive coefficient of fees on NPERF ${ }^{2}$ in Table IV, the loading of MGMT on NPERF in Column (i) is negative and significant (-0.465), suggesting that poorly performing funds charge higher management fees. This relationship intensifies significantly in Columns (ii)-(iv), when we separate performance in terciles using the dummy variables DMPERF and DHPERF. Following the evidence in Section II, we expect that the addition of IDVOL to the regression should reduce the underestimation of the fee-performance sensitivity significantly. Our findings show that the interaction variable $N P E R F \times I D V O L$ not only enters negatively in all regression specifications, but that it renders insignificant the negative coefficient of fees on NPERF. Specifically, the negative loading (-0.465) of MGMT on NPERF in Column (i) is completely transferred to the interaction term NPERF $\times$ IDVOL (-0.140) in Column (v), leaving a non-negative sensitivity of fees to after-fee risk-adjusted returns. The same conclusions apply when fund total operating expenses OPEX is the dependent variable.

\section{** INSERT TABLE V HERE **}

Overall, the findings in this section indicate that the omission of the interaction variable $N P E R F \times I D V O L$ incorrectly forces its negative and significant coefficient into the error term of the regression, giving the false impression that the managers of funds that perform poorly charge higher fees. Our findings cast doubt on the strategic fee-setting explanation provided 
by Gil-Bazo and Ruiz-Verdú (2009) for the negative relationship between advisory fees and after-fee performance.

\section{F. Advisory Fees and the Flow-Performance Relationship}

To determine whether the fee-setting policies of management companies are a perverse function of the performance-chasing behavior of investors, we estimate several proxies for the elasticity of investor demand. Following Gil-Bazo and Ruiz-Verdú (2009), the first proxy, $S_{1}$, is the first derivative of expected net flows with respect to mutual fund performance $\left(\partial \mathrm{E}\left(F L O W S_{i, t} \mid I_{i, t-1}\right) / \partial N P E R F_{i, t-1}\right)$, given the lagged information set $I_{i, t-1}$ (consisting of FNDSIZE, FAMSIZE, FNDAGE, NFNDFAM, NPERF ${ }^{2}$, NPERF $\times$ FNDAGE, TRNOVR, and $V O L)$. The second proxy, $S_{2}$, controls for the possibility that investor sensitivity is affected by back-end loads. Chordia (1996) shows that mutual funds charge higher back-end loads to dissuade investors from redeeming their shares. With a lower probability of redemptions, mutual funds are able to invest more aggressively in risky assets. As such, $S_{2}$ is computed by adding the additional variable $B K L O A D S$ and its interaction with fund performance $N P E R F \times B K L O A D S$ to the existing lagged information set $I_{i, t-1}$, previously used in the definition of $S_{1}$. Since we are not interested in separating the income accruing to the fund from that which accrues to its brokers, BKLOADS includes both redemption fees and contingent deferred sales charges.

Our findings are reported in Table VI. The dependent variable (expressed in percentage terms) is the fund management fee (MGMT) in Columns (i)-(viii), and the fund total operating expenses (OPEX) in Columns (ix)-(xvi). As indicated in Table VI, the loadings of fees on the investor sensitivity proxies $S_{1}$ and $S_{2}$ are negative and significant, irrespective of the fee that is used as the dependent variable. This negative relationship has been interpreted as direct evidence that fund managers exploit the performance insensitivity of unsophisticated investors to maximize their income from asset-based fees. However, that argument does not consider the possibility that mutual fund investors may be more sophisticated than previously thought, and may attempt to learn about managerial abilities in a context where idiosyncratic volatility could dampen their response to past performance (see Berk and Green (2004)).

In a recent study, Huang, Wei, and Yan (2012) provide theoretical and empirical evidence on the existence of sophisticated investors who are capable of rational learning. They show that the flow-performance sensitivity decreases significantly in the presence of high noise in performance, but only when investors are rational. ${ }^{14}$ An important issue at this stage is whether the negative loading of fees on $S_{1}$ and $S_{2}$ results from the rent-seeking behavior of under-performing fund

\footnotetext{
${ }^{14}$ In Supplement Table VI in our Internet Appendix we confirm the existence of a significant and monotonic dampening effect of fund idiosyncratic volatility on the flow-performance sensitivity.
} 
managers or from the rational learning process of investors in the presence of high noise in performance. In the latter case, we would expect the extent of the inverse relationship between fees and investors sensitivity to decrease, after controlling for the dampening effect on this sensitivity of idiosyncratic volatility, which our model associates with higher fees. To this end, we control for the interaction terms $S_{1} \times I D V O L$ and $S_{2} \times I D V O L$. Our expectation is for these interaction variables to enter negatively, hence providing much better insights into the actual relationship between investor sensitivity and fund fee setting policies. The significantly negative loadings of MGMT on $S_{1}$ in column (ii) and $S_{2}$ in column (iii) is completely absorbed by the interaction terms $S_{1} \times I D V O L$ and $S_{2} \times I D V O L$ in Columns (vi) and (viii), respectively. ${ }^{15}$ Thus, the failure to properly control for the effect of performance noise on the performance-chasing behavior of investors could lead to the misinterpretation of the flow-performance sensitivity as an exogenous perverse incentive for fund managers to charge higher fees. Our evidence of positive, albeit not always significant, loadings of fees on the variables $S_{1}$ and $S_{2}$ run contrary to the interpretations provided by Christoffersen and Musto (2002) and Gil-Bazo and Ruiz-Verdú (2009).

\section{** INSERT TABLE VI HERE **}

Overall, the findings in Table VI provide further support to our assumption on the effect of fund idiosyncratic noise on the fee-performance relationship. Our results also highlight that we do not need to assume opportunistic behaviour on the part of fund managers in response to performance-insensitive investors, in order to explain cross-sectional variations in advisory fees.

\section{G. The Relationship Between Fees and Before-Fee Performance}

Our previous analysis was mainly concerned with the sensitivity of fees to after-fee performance, to reflect the way adviser performance is presented to existing and potential investors. ${ }^{16}$ In this section, as a robustness test, we consider how fee sensitivity varies with respect to beforefee performance. Hypothesis 4 predicts that a non-negative relationship should exist between management fees and gross performance. Like Gil-Bazo and Ruiz-Verdú (2009), we follow the two-stage procedure of Carhart (1997) to mitigate look-ahead bias in estimated gross performance, and obtain a panel of monthly abnormal return estimates from that model, where the

\footnotetext{
${ }^{15}$ In Supplement Table IX in our Internet Appendix we repeat this analysis using alternative models to estimate fund performance, flow-performance sensitivity, beta, and idiosyncratic volatility and reach similar conclusions

${ }^{16}$ As a general rule, advisory performance must be reported in the fund prospectus after the deduction of management fees, 12b-1 fees, and other minor administrative expenses. Under Rule 206(4)-1(a)(5), the SEC deems the presentation of before-fee performance alone as potentially misleading, since the average investor would make an inference about the future returns of the adviser or its skills that would not be true had the returns been presented on an after-fee basis.
} 
loadings are estimated over the previous 5 years (with a minimum of 48 months of available observations). We then estimate fund before-fee abnormal returns in month $t$ as the difference between the before-fee excess return of the fund and the lagged vector of its betas multiplied by the vectors of factor realizations in month $t$. For robustness, we repeat this two-stage procedure to estimate the Fama and French (1993) before-fee abnormal returns.

We evaluate the relationship between yearly fund fees and yearly gross abnormal returns, since published expense ratios are generally set annually by fund management companies, even though they are usually charged to investors on a daily basis. We estimate this relationship separately for advisory fees and non-advisory (i.e. 12b-1 and marketing) fees, since Malkiel (1995) indicates that those two components of the total expense ratio could have significantly different impacts on the overall relationship between the total expense ratio of a fund and its annual returns. For robustness, we use four different OLS regression specifications: yearfixed effects with standard errors clustered by fund, to account for serial correlation in the residuals; year-fixed effects, with standard errors clustered by time, to account for cross-sectional correlations in the residuals; year-fixed effects, with standard errors clustered by both fund and time (Petersen (2009)); and Fama and MacBeth (1973) cross-sectional regressions with Newey and West (1987) heteroskedasticity and autocorrelation robust standard errors. We also estimate the fee-performance sensitivity with respect to five different fee specifications: total operating expenses $(O P E X)$; management fees, which are computed as the difference between fund operating expenses and 12b-1 fees (MGMT); actual management fees provided by CRSP since 1999 (MGMT2); 12b-1 fees (12B-1); and marketing fees, which are computed as 12b-1 fees plus $1 / 7$-th of fund front-end loads $(M K T I N G) .{ }^{17}$

The coefficient estimates of fees on fund gross performance GPERF are reported in Table VII, for the two cases where performance is estimated using the four-factor risk-adjusted returns (4-Factor), and the three-factor risk-adjusted returns (3-Factor). The evidence in Table VII indicates that a negative relationship between management fees (MGMT) and beforefee alpha (4-Factor) only exists when standard errors are clustered by fund. Even without controlling for fund idiosyncratic volatility, the estimated coefficients are never significant at conventional levels in all other regression specifications, after controlling for the cross-sectional correlation in the regression residuals (see Kosowski, Timmermann, Wermers, and White (2006) and Petersen (2009)). As indicated in Models (ii)-(iv) the standard errors are almost twice (0.128) as large as those documented in Model (i) (0.066). The lack of a significant relationship

\footnotetext{
${ }^{17}$ The variable MGMT2 is the fund management fee calculated using the ratios based on the fund's Statement of Operations. Since this fee includes waivers and reimbursements, it could differ from the contractual fee reported by the fund in its prospectus.
} 
between management fees and performance is also confirmed by the use of the Fama and MacBeth (1973) two-step estimation with Newey-West standard errors (0.150) in Model (iv). Our conclusion does not change when we consider the alternative definition of fund management fees, as measured by the variable MGMT2 in Models (v)-(viii). Across all regression specifications, the negative loadings of MGMT2 on GPERF are never significant. This evidence for mutual fund management fees (as either MGMT or MGMT2) in Models (i)-(viii) supports our Hypothesis 4.

\section{** INSERT TABLE VII HERE **}

In Models (ix)-(xii) we repeat the previous analysis for fund total operating expenses (OPEX). Consistent with Gil-Bazo and Ruiz-Verdú (2009), a significantly negative sensitivity exists between fund gross performance, 4-factor, and OPEX. However, a closer look at Table VII suggests that the major driver of the negative correlation between OPEX and GPERF is not the fund advisory fee but rather its non-advisory fee component, as represented by fund 12b-1 fee (12B-1) in models (xiii)-(xvi). Since proceeds from 12b-1 fees and marketing fees are intended to compensate brokerage and distribution expenses rather than fund management costs, these findings are a further indication that advisers compensation is not inversely related to fund gross performance. We reach similar conclusions when we use fund marketing fees (MKTING) in models (xvii)-(xx). The negative relationship between non-advisory fees (either $12 B-1$ or MKTING) and gross performance is also consistent with Bergstresser, Chalmers, and Tufano (2009). They show that broker-sold mutual funds perform worse and charge significantly higher marketing fees than direct-sold mutual funds. If high 12b-1 fee funds are those mostly offered by financial intermediaries such as banks and (captive or non-captive) brokers then our evidence of a negative sensitivity of $12 \mathrm{~b}-1$ fees to performance could simply reflect the nature of the fund distribution channel (see also Christoffersen, Evans, and Musto (2013), and Guercio and Reuter (2013)). Alternatively, it is also plausible that these financial intermediaries require underperforming funds to pay higher distribution fees as a compensation for the greater reputational risk of offering poor performing funds to their clients (Gil-Bazo and Ruiz-Verdú (2009)). Both these explanations support the existence of a negative association between marketing fees and gross performance. Overall, unless investors receive other valuable services from their brokers that we are simply not able to quantify, our findings suggest that investors would be better off avoiding brokerage intermediation when buying a mutual fund. Our conclusion does not change when we estimate the variable GPERF using the three-factor model (3-Factor) as illustrated in the last three columns of Table VII. 
Why do total operating expenses (OPEX) continue to be negatively related to fund gross performance? Following the findings of our Monte Carlo experiment in Section II on the relationship between fees and gross alpha, we argue that this negative sensitivity is simply the result of a spurious relationship originated by the impact of idiosyncratic risk on performance estimation errors. As such, we would expect the loading of OPEX on the interaction term between gross performance and idiosyncratic volatility to be always negative and significant. We report the findings of this test in Table VIII for the four-factor model (4-Factor). The results for the three-factor model (3-Factor) are illustrated in our Supplementary Appendix. Starting from the findings in models (xi)-(xii) when $O P E X$ is the dependent variable, the interaction term GPERF $\times I D V O L$ is not only negative and significant $(-58.06)$ but it also explains the negative loading of $O P E X$ on GPERF. It is also interesting to notice that the same variable $G P E R F \times I D V O L$ is never significant when the dependent variable is fund advisory fee (either MGMT or MGMT2) as there exists no spurious negative relationship between this fee and estimated gross performance. On the contrary, the unsurprising evidence that idiosyncratic noise in performance does not absorb the negative estimated coefficient of 12b-1 fees or marketing fees on fund gross performance illustrates the different nature of the economic determinants of such non-advisory fees. As such, findings for non-advisory fees are consistent with those reported by Gil-Bazo and Ruiz-Verdú (2009).

\section{** INSERT TABLE VIII HERE **}

In their empirical analysis, Cheng, Massa, and Zhang (2013) regress operating expenses (but not management fees) against gross performance, and find a significant negative relationship (as do we above). ${ }^{18}$ After introducing their measure of dispersion of investor opinions, and its interaction with gross performance, as independent variables, they find that the negative dependence of operating expenses on gross performance is no longer significant. ${ }^{19}$ They interpret the significant negative loading of operating expenses on the interaction term as evidence in favour of one of their main theoretical results, namely that operating expenses and (true) gross alphas are negatively correlated, due to the indirect effect of information costs on fees. Unfortunately, as we demonstrated in Section II, the interaction term in their regression is most likely capturing nothing more than statistical noise caused by estimation errors of alphas. Consequently, this interaction term should neither be granted any economic interpretation nor be extended to the advisory fee component of fund total operating expenses.

\footnotetext{
${ }^{18}$ Using fund management fees, our results provide strong empirical evidence that advisory fees are never negatively correlated with gross performance.

${ }^{19}$ Their second proxy for investors' dispersion of opinions is the volatility of fund excess returns. This measure of fund tracking errors would be highly correlated with fund idiosyncratic volatility.
} 
Our model predictions in Section I, together with the findings presented in Tables VII and VIII, strongly suggest that there is no significant negative relationship between gross performance and advisory fees. Moreover, our detailed decomposition of total operating expenses into advisory fees (either MGMT or MGMT2) and non-advisory fees (12B-1) indicates that the marketing components of total operating expenses drive the negative relationship between OPEX and gross performance.

\section{Conclusions}

This article develops a model for mutual fund fees, in which the uncertainty of a rational investor about the performance of a fund is proportional to its idiosyncratic volatility. The model also takes account of the important institutional constraint that mutual funds cannot be sold short. Our first major contribution is to identify the unanticipated importance of idiosyncratic risk as a determinant of mutual fund fees. Second, we demonstrate that fees are insensitive to market risk. Both results are established theoretically, and demonstrated empirically.

Our third significant contribution is to show that the widely-reported negative fee-performance relationship for actively-managed mutual funds is largely attributable to the omitted dependence of fees on idiosyncratic volatility in cross-sectional regressions. With reference to our model, we argue that the empirical fee-performance relationship is compatible with investor rationality, and that it does not entail the type of managerial opportunism hypothesized in the literature. In fact, the insensitivity of fees to market risk suggests that mutual fund investors are riskaverse, and hence sensitive to performance. These observations pave the way for a somewhat less pessimistic assessment of the mutual fund industry and the rationality of its clientele, than is prevalent in the literature.

Finally, we highlight the U-shape of the empirical fee-performance relationship, and explain it in terms of the interaction between the fees charged by mutual funds and the standard errors of their estimated alphas. This has unwelcome consequences for cross-sectional regressions of mutual fund fees, which are exacerbated by the fact that the variation in managerial skills appears to be dominated by the heterogeneity of idiosyncratic risk among mutual funds. Consequently, any attempt to tease out the dependence of fees on managerial performance is handicapped by the fact that there is very little signal relative to the amount of U-shaped statistical noise.

\section{A. Proofs and Auxiliary Results}

Our first task is to derive the optimal strategy for the investor presented in Theorem 4. We begin by using (3), and the expression for the MGF of a normal random variable (see e.g. 
Johnson, Kotz, and Balakrishnan 1994), to determine the following convenient representation for the investor's value function, conditional on his estimate for the expected risk-adjusted return of the mutual fund:

$$
\begin{aligned}
L(\xi, \eta):=\mathrm{E}(\mathcal{U}(W(\xi, \eta)) \mid \widehat{\alpha}) & =1-\mathrm{E}\left(\mathrm{e}^{-\gamma W(\xi, \eta)} \mid \widehat{\alpha}\right) \\
=1-\exp (-\gamma w(1+\xi( & \left.(1-\zeta) \widehat{\alpha}-\zeta)+(\eta+\xi(1-\zeta) \beta) \mu_{\mathrm{M}}\right) \\
& \left.+\frac{1}{2}(\gamma w)^{2}\left((\eta+\xi(1-\zeta) \beta)^{2} \sigma_{\mathrm{M}}^{2}+\xi^{2}(1-\zeta)^{2} \sigma_{\varepsilon}^{2}\right)\right) .
\end{aligned}
$$

The investor's problem (2) of identifying the portfolio $\left(\xi_{*}, \eta_{*}\right)$ that maximises his expected utility of terminal wealth, without short-selling the mutual fund, may then be reformulated as follows:

$$
\left(\xi_{*}, \eta_{*}\right)=\underset{(\xi, \eta) \in \mathbb{R}_{+} \times \mathbb{R}}{\arg \max } L(\xi, \eta) .
$$

To solve it we require the following partial derivatives:

$$
\begin{aligned}
\frac{\partial L}{\partial \xi}(\xi, \eta) & =\gamma w(1-L(\xi, \eta)) A(\xi, \eta), \\
\frac{\partial L}{\partial \eta}(\xi, \eta) & =\gamma w(1-L(\xi, \eta)) B(\xi, \eta), \\
\frac{\partial^{2} L}{\partial \xi^{2}}(\xi, \eta) & =-(\gamma w)^{2}(1-L(\xi, \eta))\left((1-\zeta)^{2}\left(\beta^{2} \sigma_{\mathrm{M}}^{2}+\sigma_{\varepsilon}^{2}\right)+A^{2}(\xi, \eta)\right), \\
\frac{\partial^{2} L}{\partial \xi \partial \eta}(\xi, \eta) & =-(\gamma w)^{2}(1-L(\xi, \eta))\left((1-\zeta) \beta \sigma_{\mathrm{M}}^{2}+A(\xi, \eta) B(\xi, \eta)\right), \quad \text { and } \\
\frac{\partial^{2} L}{\partial \eta^{2}}(\xi, \eta) & =-(\gamma w)^{2}(1-L(\xi, \eta))\left(\sigma_{\mathrm{M}}^{2}+B^{2}(\xi, \eta)\right) .
\end{aligned}
$$

In these expressions

$$
\begin{aligned}
& A(\xi, \eta):=\left(\widehat{\alpha}+\beta \mu_{\mathrm{M}}\right)(1-\zeta)-\zeta-\gamma w(1-\zeta)\left((\eta+\xi(1-\zeta) \beta) \beta \sigma_{\mathrm{M}}^{2}+\xi(1-\zeta) \sigma_{\varepsilon}^{2}\right), \quad \text { and } \\
& B(\xi, \eta):=\mu_{\mathrm{M}}-\gamma w(\eta+\xi(1-\zeta) \beta) \sigma_{\mathrm{M}}^{2} .
\end{aligned}
$$

The next result, which establishes the concavity of the investor's value function (A.1), is a crucial ingredient in the proof of Theorem 4:

Lemma A.1. The investor's value function $L(\xi, \eta)$ is concave.

Proof: Establishing the concavity of $L(\xi, \eta)$ is equivalent to demonstrating that the Hessian matrix

$$
\nabla^{2} L(\xi, \eta)=\left(\begin{array}{cc}
\frac{\partial^{2} L}{\partial \xi^{2}}(\xi, \eta) & \frac{\partial^{2} L}{\partial \xi \partial \eta}(\xi, \eta) \\
\frac{\partial^{2} L}{\partial \xi \partial \eta}(\xi, \eta) & \frac{\partial^{2} L}{\partial \eta^{2}}(\xi, \eta)
\end{array}\right)
$$


is negative semidefinite. This, in turn, is equivalent to showing that neither eigenvalue of $\nabla^{2} L(\xi, \eta)$ is positive. Now, since $L(\xi, \eta) \leq 1$, by inspection of (A.1), it follows that the partial derivatives (A.5) and (A.7) are both non-positive, whence $\operatorname{tr}\left(\nabla^{2} L(\xi, \eta)\right) \leq 0$. Consequently, since the eigenvalues of $\nabla^{2} L(\xi, \eta)$ are given by

$$
\frac{\operatorname{tr}\left(\nabla^{2} L(\xi, \eta)\right) \pm \sqrt{\operatorname{tr}^{2}\left(\nabla^{2} L(\xi, \eta)\right)-4 \operatorname{det}\left(\nabla^{2} L(\xi, \eta)\right)}}{2}
$$

we conclude that $L(\xi, \eta)$ is concave if and only if $\operatorname{det}\left(\nabla^{2} L(\xi, \eta)\right) \geq 0$. To verify the latter condition, we observe that

$$
\begin{aligned}
\operatorname{det}\left(\nabla^{2} L(\xi, \eta)\right)=\frac{\partial^{2} L}{\partial \xi^{2}}(\xi, \eta) \frac{\partial^{2} L}{\partial \eta^{2}}(\xi, \eta)-\left(\frac{\partial^{2} L}{\partial \xi \partial \eta}(\xi, \eta)\right)^{2} \\
=(\gamma w)^{4}(1-L(\xi, \eta))^{2}\left(\left((1-\zeta)^{2}\left(\beta^{2} \sigma_{\mathrm{M}}^{2}+\sigma_{\varepsilon}^{2}\right)+A^{2}(\xi, \eta)\right)\left(\sigma_{\mathrm{M}}^{2}+B^{2}(\xi, \eta)\right)\right. \\
\left.\quad-\left((1-\zeta) \beta \sigma_{\mathrm{M}}^{2}+A(\xi, \eta) B(\xi, \eta)\right)^{2}\right) \\
\geq(\gamma w)^{4}(1-L(\xi, \eta))^{2}\left(\left((1-\zeta)^{2} \beta^{2} \sigma_{\mathrm{M}}^{2}+A^{2}(\xi, \eta)\right)\left(\sigma_{\mathrm{M}}^{2}+B^{2}(\xi, \eta)\right)\right. \\
\left.\quad-\left((1-\zeta) \beta \sigma_{\mathrm{M}}^{2}+A(\xi, \eta) B(\xi, \eta)\right)^{2}\right) \\
=(\gamma w)^{4}(1-L(\xi, \eta))^{2}(A(\xi, \eta)-(1-\zeta) \beta B(\xi, \eta))^{2} \sigma_{\mathrm{M}}^{2},
\end{aligned}
$$

by virtue of (A.5)-(A.7). In particular, $\operatorname{det}\left(\nabla^{2} L(\xi, \eta)\right) \geq 0$, as required.

Before continuing with the proof of Theorem 4, let us consider briefly the situation when the investor is not confronted with a short-selling constraint on the mutual fund. In that case Lemma A.1 ensures that he has recourse to the globally optimal strategy $\left(\xi_{* *}, \eta_{* *}\right)$. Moreover, according to (A.3) and (A.4), this strategy is determined by the first-order conditions $A\left(\xi_{* *}, \eta_{* *}\right)=0$ and $B\left(\xi_{* *}, \eta_{* *}\right)=0$. By solving the second of these equations for $\eta_{* *}$, and then substituting that expression into the first equation, we obtain

$$
\xi_{* *}=\frac{1}{\gamma w} \frac{(1-\zeta) \widehat{\alpha}-\zeta}{(1-\zeta)^{2} \sigma_{\varepsilon}^{2}} \quad \text { and } \quad \eta_{* *}=\frac{1}{\gamma w} \frac{\mu_{\mathrm{M}}}{\sigma_{\mathrm{M}}^{2}}-\xi_{* *}(1-\zeta) \beta
$$

Returning to the investor's problem with short-selling of the mutual fund disallowed, the natural candidate for the constrained optimal strategy is obtained by replacing $\xi_{* *}$ with $\xi_{* *}^{+} \equiv$ $\max \left\{\xi_{* *}, 0\right\}$ in the two expressions above, thereby yielding the portfolio fractions $\left(\xi_{*}, \eta_{*}\right)$ given by (4). In other words, the investor should choose the globally optimal strategy, if it is admissible. Failing that, if the globally optimal strategy involves a short position in the mutual 
fund, the investor should construct the best portfolio consisting exclusively of holdings in the money-market account and the market portfolio. Below, we demonstrate formally that this strategy does indeed solve the investor's problem:

Proof of Theorem 4: Consider the portfolio strategy $\left(\xi_{*}, \eta_{*}\right)$ determined by (4). According to Borwein and Lewis (2006), Proposition 2.1.2, if the investor's value function $L(\xi, \eta)$ is concave then the condition

$$
\left\langle\nabla L\left(\xi_{*}, \eta_{*}\right),\left(\xi-\xi_{*}, \eta-\eta_{*}\right)^{\prime}\right\rangle \equiv \frac{\partial L}{\partial \xi}\left(\xi_{*}, \eta_{*}\right)\left(\xi-\xi_{*}\right)+\frac{\partial L}{\partial \eta}\left(\xi_{*}, \eta_{*}\right)\left(\eta-\eta_{*}\right) \leq 0,
$$

for all $(\xi, \eta) \in \mathbb{R}_{+} \times \mathbb{R}$, is sufficient to ensure that $\left(\xi_{*}, \eta_{*}\right)$ solves his expected utility maximization problem (A.2). Of course, Lemma A.1 has already established the concavity of $L(\xi, \eta)$. Moreover, (A.4) yields $\frac{\partial L}{\partial \eta}\left(\xi_{*}, \eta_{*}\right)=0$, since

$B\left(\xi_{*}, \eta_{*}\right)=\mu_{\mathrm{M}}-\gamma w\left(\eta_{*}+\xi_{*}(1-\zeta) \beta\right) \sigma_{\mathrm{M}}^{2}=\mu_{\mathrm{M}}-\gamma w\left(\frac{1}{\gamma w} \frac{\mu_{\mathrm{M}}}{\sigma_{\mathrm{M}}^{2}}-\xi_{*}(1-\zeta)+\xi_{*}(1-\zeta) \beta\right) \sigma_{\mathrm{M}}^{2}=0$.

Our task therefore is to demonstrate that $\frac{\partial L}{\partial \xi}\left(\xi_{*}, \eta_{*}\right)\left(\xi-\xi_{*}\right) \leq 0$, for all $\xi \geq 0$. Alternatively, since inspection of (A.1) yields $L\left(\xi_{*}, \eta_{*}\right) \leq 1$, (A.3) indicates that we must show that $A\left(\xi_{*}, \eta_{*}\right)(\xi-$ $\left.\xi_{*}\right) \leq 0$, for all $\xi \geq 0$. There are two cases to consider:

(i) $\left(\xi_{*}>0\right)$ : In this case the constraint prohibiting short sales of the mutual fund is not binding, and $\left(\xi_{*}, \eta_{*}\right)$ must be identical to the unconstrained globally optimal portfolio strategy (A.8). This implies that the first-order condition $A\left(\xi_{*}, \eta_{*}\right)=0$ is satisfied, whence $A\left(\xi_{*}, \eta_{*}\right)\left(\xi-\xi_{*}\right)=0$, for all $\xi \geq 0$.

(ii) $\left(\xi_{*}=0\right)$ : In this case the constraint prohibiting short sales of the mutual fund is binding, and we may deduce from (4) that

$$
(1-\zeta) \widehat{\alpha}-\zeta \leq 0 \quad \text { and } \quad \eta_{*}=\frac{1}{\gamma w} \frac{\mu_{\mathrm{M}}}{\sigma_{\mathrm{M}}^{2}}
$$

From these relations we obtain

$$
\begin{aligned}
A\left(\xi_{*}, \eta_{*}\right) & =\left(\widehat{\alpha}+\beta \mu_{\mathrm{M}}\right)(1-\zeta)-\zeta-\gamma w(1-\zeta)\left(\left(\eta_{*}+\xi_{*}(1-\zeta) \beta\right) \beta \sigma_{\mathrm{M}}^{2}+\xi_{*}(1-\zeta) \sigma_{\varepsilon}^{2}\right) \\
& =\left(\widehat{\alpha}+\beta \mu_{\mathrm{M}}\right)(1-\zeta)-\zeta-\gamma w(1-\zeta) \frac{1}{\gamma w} \frac{\mu_{\mathrm{M}}}{\sigma_{\mathrm{M}}^{2}} \beta \sigma_{\mathrm{M}}^{2} \\
& =(1-\zeta) \widehat{\alpha}-\zeta \leq 0
\end{aligned}
$$

whence $A\left(\xi_{*}, \eta_{*}\right)\left(\xi-\xi_{*}\right)=A\left(\xi_{*}, \eta_{*}\right) \xi \leq 0$, for all $\xi \geq 0$. 
The lemma below establishes some interesting inequalities involving the PDF and CDF of a standard normal random variable. These inequalities are apparently original, and may be of independent interest. We appeal to them repeatedly in the proofs of Lemmas 6 and A.3, Propositions 9 and 12, and Theorem 9:

Lemma A.2. The following inequalities always hold:

$$
0<z \Phi(z)+\varphi(z)<\frac{\Phi^{2}(z)}{\varphi(z)} .
$$

Proof: To justify the first inequality, we use integration by parts to get

$$
\begin{aligned}
z \Phi(z)+\varphi(z) & =\int_{-\infty}^{z} \zeta \varphi(\zeta) \mathrm{d} \zeta+\int_{-\infty}^{z} \int_{-\infty}^{\zeta} \varphi(\xi) \mathrm{d} \xi \mathrm{d} \zeta+\varphi(z) \\
& =\int_{\infty}^{\frac{1}{2} z^{2}} \frac{1}{\sqrt{2 \pi}} \mathrm{e}^{-\xi} \mathrm{d} \xi+\int_{-\infty}^{z} \Phi(\zeta) \mathrm{d} \zeta+\varphi(z) \\
& =\int_{-\infty}^{z} \Phi(\zeta) \mathrm{d} \zeta>0
\end{aligned}
$$

with the aid of the transformation of variables $\frac{1}{2} \zeta^{2} \mapsto \xi$. Next, Komatsu's inequality for Mill's ratio (see e.g. Dudley 1999) yields

$$
\frac{\Phi(z)}{\varphi(z)}=\frac{\Phi(z)}{\varphi(-z)}>\frac{1}{\sqrt{1+\frac{1}{4} z^{2}}-\frac{1}{2} z}=\sqrt{1+\frac{1}{4} z^{2}}+\frac{1}{2} z .
$$

From this we obtain

$$
\Phi(z)-\frac{1}{2} z \varphi(z)>\sqrt{1+\frac{1}{4} z^{2}} \varphi(z),
$$

whence

$$
\Phi^{2}(z)-z \Phi(z) \varphi(z)>\varphi^{2}(z),
$$

and the second inequality follows.

Next, we prove Lemma 6 , which states that the optimum fee charged by the fund manager is both non-negative and less than the total value of the fund:

Proof of Lemma 6: After rewriting (6) as

$$
\begin{array}{r}
F\left(\alpha, \sigma_{\varepsilon}, \zeta\right)=\frac{1+\alpha+\beta \mu_{\mathrm{M}}}{\gamma \kappa \sigma_{\varepsilon}^{3}} \frac{\zeta}{(1-\zeta)^{3}}\left(\frac{(1-\zeta) \alpha-\zeta}{(1-\zeta) \kappa \sigma_{\varepsilon}} \Phi\left(\frac{(1-\zeta) \alpha-\zeta}{(1-\zeta) \kappa \sigma_{\varepsilon}}\right)\right. \\
\left.+\varphi\left(\frac{(1-\zeta) \alpha-\zeta}{(1-\zeta) \kappa \sigma_{\varepsilon}}\right)\right)
\end{array}
$$

Assumption 5 and the first inequality in (A.9) yield the following: $F\left(\alpha, \sigma_{\varepsilon}, \zeta\right) \leq 0$ if $\zeta \leq 0$; 
$F\left(\alpha, \sigma_{\varepsilon}, \zeta\right)>0$ if $0<\zeta<1 ; F\left(\alpha, \sigma_{\varepsilon}, 1-\right)=0 ; F\left(\alpha, \sigma_{\varepsilon}, 1+\right)=-\infty$; and $F\left(\alpha, \sigma_{\varepsilon}, \zeta\right)<0$ if $\zeta>1$. In particular, $F\left(\alpha, \sigma_{\varepsilon}, \zeta\right)>0$ if and only if $0<\zeta<1$.

The following technical result establishes an interesting property of the inverse of Mill's ratio. It is the crucial ingredient in the proof of Lemma 8:

Lemma A.3. The function

$$
z \mapsto z+\frac{\varphi(z)}{\Phi(z)}
$$

is monotonically increasing.

Proof: With the help of the second inequality in (A.9) we obtain

$$
\frac{d}{d z}\left(z+\frac{\varphi(z)}{\Phi(z)}\right)=1-\frac{\varphi(z)}{\Phi^{2}(z)}(z \Phi(z)+\varphi(z))>0
$$

Lemma 6 established very coarse bounds on the optimal fee charged by the fund manager. More refined bounds are obtained by Lemma 8:

Proof of Lemma 8: Since $\zeta_{*}<1$, by Lemma 6, the first-order condition $G\left(\alpha, \sigma_{\varepsilon}, \zeta_{*}\right)=0$ allows us to infer that $\left(1-\zeta_{*}\right) \alpha-2 \zeta_{*}<0$ from (7). From this inequality we obtain $\zeta_{*}>\frac{\alpha}{2+\alpha}$, if $\alpha>0$, while Lemma 6 ensures that $\zeta_{*}>0$, in general. Combining these two observations produces the lower bound in (8). Next, with reference to (7), we may rewrite the first-order condition $G\left(\alpha, \sigma_{\varepsilon}, \zeta_{*}\right)=0$ as follows:

$$
\begin{aligned}
\frac{\zeta_{*}}{\left(1-\zeta_{*}\right) \kappa \sigma_{\varepsilon}}=\frac{\left(1-\zeta_{*}\right) \alpha-\zeta_{*}}{\left(1-\zeta_{*}\right) \kappa \sigma_{\varepsilon}}+\frac{\varphi\left(\frac{\left(1-\zeta_{*}\right) \alpha-\zeta_{*}}{\left(1-\zeta_{*}\right) \kappa \sigma_{\varepsilon}}\right)}{\Phi\left(\frac{\left(1-\zeta_{*}\right) \alpha-\zeta_{*}}{\left(1-\zeta_{*}\right) \kappa \sigma_{\varepsilon}}\right)} & =\frac{\alpha-\frac{\zeta_{*}}{1-\zeta_{*}}}{\kappa \sigma_{\varepsilon}}+\frac{\varphi\left(\frac{\alpha-\frac{\zeta_{*}}{1-\zeta_{*}}}{\kappa \sigma_{\varepsilon}}\right)}{\Phi\left(\frac{\alpha-\frac{\zeta_{*}}{1-\zeta_{*}}}{\kappa \sigma_{\varepsilon}}\right)} \\
& <\frac{\alpha-\frac{\alpha^{+}}{2}}{\kappa \sigma_{\varepsilon}}+\frac{\varphi\left(\frac{\alpha-\frac{\alpha^{+}}{2}}{\kappa \sigma_{\varepsilon}}\right)}{\Phi\left(\frac{\alpha-\frac{\alpha+}{2}}{\kappa \sigma_{\varepsilon}}\right)}
\end{aligned}
$$

by an application of Lemma A.3, since $\frac{\zeta_{*}}{1-\zeta_{*}}>\frac{\alpha^{+}}{2}$ by virtue of the previously established bound $\zeta_{*}>\frac{\alpha^{+}}{2+\alpha^{+}}$. From this we may deduce that

$$
\frac{\zeta_{*}}{1-\zeta_{*}}<\alpha-\frac{\alpha^{+}}{2}+\kappa \sigma_{\varepsilon} \frac{\varphi\left(\frac{\alpha-\frac{\alpha^{+}}{2}}{\kappa \sigma_{\varepsilon}}\right)}{\Phi\left(\frac{\alpha-\frac{\alpha+}{2}}{\kappa \sigma_{\varepsilon}}\right)}=\alpha \wedge \frac{\alpha}{2}+\kappa \sigma_{\varepsilon} \frac{\varphi\left(\frac{\alpha \wedge \frac{\alpha}{2}}{\kappa \sigma_{\varepsilon}}\right)}{\Phi\left(\frac{\alpha \wedge \frac{\alpha}{2}}{\kappa \sigma_{\varepsilon}}\right)},
$$

which establishes the upper bound in (8), after some easy manipulation. Finally, taking limits 
in (8) yields

$$
\frac{\alpha^{+}}{2+\alpha^{+}}<\lim _{\sigma_{\varepsilon} \downarrow 0} \zeta_{*}<\lim _{\sigma_{\varepsilon} \downarrow 0} \frac{\alpha \wedge \frac{\alpha}{2}+\kappa \sigma_{\varepsilon} \frac{\varphi\left(\frac{\alpha \wedge \frac{\alpha}{2}}{\kappa \sigma_{\varepsilon}}\right)}{\Phi\left(\frac{\alpha \wedge \frac{\alpha}{2}}{\kappa \sigma_{\varepsilon}}\right)}}{1+\alpha \wedge \frac{\alpha}{2}+\kappa \sigma_{\varepsilon} \frac{\varphi\left(\frac{\alpha \wedge \frac{\alpha}{2}}{\kappa \sigma_{\varepsilon}}\right)}{\Phi\left(\frac{\alpha \wedge \frac{\alpha}{2}}{\kappa \sigma_{\varepsilon}}\right)}}=\frac{\alpha^{+}}{2+\alpha^{+}},
$$

which establishes the identity $\left.\zeta_{*}\right|_{\sigma_{\varepsilon}=0+}=\frac{\alpha^{+}}{2+\alpha^{+}}$.

Before continuing, we pause briefly to compute expressions for the partial derivatives of (7), which will be required in the proofs of Theorems 9 and 12, and Proposition 10:

$$
\begin{aligned}
\frac{\partial G}{\partial \alpha}\left(\alpha, \sigma_{\varepsilon}, \zeta\right) & =(1-\zeta) \Phi\left(\frac{(1-\zeta) \alpha-\zeta}{(1-\zeta) \kappa \sigma_{\varepsilon}}\right)-\frac{\zeta}{\kappa \sigma_{\varepsilon}} \varphi\left(\frac{(1-\zeta) \alpha-\zeta}{(1-\zeta) \kappa \sigma_{\varepsilon}}\right), \\
\frac{\partial G}{\partial \sigma_{\varepsilon}}\left(\alpha, \sigma_{\varepsilon}, \zeta\right) & =\frac{1}{\sigma_{\varepsilon}}\left((1-\zeta) \kappa \sigma_{\varepsilon}+\zeta \frac{(1-\zeta) \alpha-\zeta}{(1-\zeta) \kappa \sigma_{\varepsilon}}\right) \varphi\left(\frac{(1-\zeta) \alpha-\zeta}{(1-\zeta) \kappa \sigma_{\varepsilon}}\right), \quad \text { and } \\
\frac{\partial G}{\partial \zeta}\left(\alpha, \sigma_{\varepsilon}, \zeta\right)= & \frac{1}{1-\zeta}\left(\frac{\zeta}{(1-\zeta) \kappa \sigma_{\varepsilon}}-(1-\zeta) \kappa \sigma_{\varepsilon}\right) \varphi\left(\frac{(1-\zeta) \alpha-\zeta}{(1-\zeta) \kappa \sigma_{\varepsilon}}\right) \\
& -(2+\alpha) \Phi\left(\frac{(1-\zeta) \alpha-\zeta}{(1-\zeta) \kappa \sigma_{\varepsilon}}\right),
\end{aligned}
$$

and these expressions are well-defined and continuous, for $\sigma_{\varepsilon}>0$ and $0<\zeta<1$.

Theorem 9 reveals that the optimal fee charged by the manager of the mutual fund is monotonically increasing with respect to its idiosyncratic volatility:

Proof of Theorem 9: We derive the following inequalities from $G\left(\alpha, \sigma_{\varepsilon}, \zeta_{*}\right)=0$ and (7), together with the fact that $0<\zeta_{*}<1$, according to Lemma 6 , and an application of the second inequality in (A.9):

$$
\begin{aligned}
0 & <\frac{\zeta_{*}}{\left(1-\zeta_{*}\right) \kappa \sigma_{\varepsilon}} \Phi\left(\frac{\left(1-\zeta_{*}\right) \alpha-\zeta_{*}}{\left(1-\zeta_{*}\right) \kappa \sigma_{\varepsilon}}\right) \\
& =\frac{\left(1-\zeta_{*}\right) \alpha-\zeta_{*}}{\left(1-\zeta_{*}\right) \kappa \sigma_{\varepsilon}} \Phi\left(\frac{\left(1-\zeta_{*}\right) \alpha-\zeta_{*}}{\left(1-\zeta_{*}\right) \kappa \sigma_{\varepsilon}}\right)+\varphi\left(\frac{\left(1-\zeta_{*}\right) \alpha-\zeta_{*}}{\left(1-\zeta_{*}\right) \kappa \sigma_{\varepsilon}}\right)<\frac{\Phi^{2}\left(\frac{\left(1-\zeta_{*}\right) \alpha-\zeta_{*}}{\left(1-\zeta_{*}\right) \kappa \sigma_{\varepsilon}}\right)}{\varphi\left(\frac{\left(1-\zeta_{*}\right) \alpha-\zeta_{*}}{\left(1-\zeta_{*}\right) \kappa \sigma_{\varepsilon}}\right)} .
\end{aligned}
$$

From this we deduce that

$$
0<\frac{\zeta_{*}}{\left(1-\zeta_{*}\right) \kappa \sigma_{\varepsilon}} \varphi\left(\frac{\left(1-\zeta_{*}\right) \alpha-\zeta_{*}}{\left(1-\zeta_{*}\right) \kappa \sigma_{\varepsilon}}\right)<\Phi\left(\frac{\left(1-\zeta_{*}\right) \alpha-\zeta_{*}}{\left(1-\zeta_{*}\right) \kappa \sigma_{\varepsilon}}\right) .
$$

Next, we combine (A.13) with $G\left(\alpha, \sigma_{\varepsilon}, \zeta_{*}\right)=0$ and (7) to get

$$
\frac{\partial G}{\partial \zeta}\left(\alpha, \sigma_{\varepsilon}, \zeta_{*}\right)=\frac{1}{1-\zeta_{*}}\left(\frac{\zeta_{*}}{\left(1-\zeta_{*}\right) \kappa \sigma_{\varepsilon}}-\left(1-\zeta_{*}\right) \kappa \sigma_{\varepsilon}\right) \varphi\left(\frac{\left(1-\zeta_{*}\right) \alpha-\zeta_{*}}{\left(1-\zeta_{*}\right) \kappa \sigma_{\varepsilon}}\right)
$$




$$
\begin{aligned}
&-(2+\alpha) \Phi\left(\frac{\left(1-\zeta_{*}\right) \alpha-\zeta_{*}}{\left(1-\zeta_{*}\right) \kappa \sigma_{\varepsilon}}\right) \\
&= \frac{\zeta_{*}}{\left(1-\zeta_{*}\right)^{2} \kappa \sigma_{\varepsilon}} \varphi\left(\frac{\left(1-\zeta_{*}\right) \alpha-\zeta_{*}}{\left(1-\zeta_{*}\right) \kappa \sigma_{\varepsilon}}\right)+\left(\frac{\left(1-\zeta_{*}\right) \alpha-2 \zeta_{*}}{1-\zeta_{*}}-(2+\alpha)\right) \Phi\left(\frac{\left(1-\zeta_{*}\right) \alpha-\zeta_{*}}{\left(1-\zeta_{*}\right) \kappa \sigma_{\varepsilon}}\right) \\
&= \frac{\zeta_{*}}{\left(1-\zeta_{*}\right)^{2} \kappa \sigma_{\varepsilon}} \varphi\left(\frac{\left(1-\zeta_{*}\right) \alpha-\zeta_{*}}{\left(1-\zeta_{*}\right) \kappa \sigma_{\varepsilon}}\right)-\frac{2}{1-\zeta_{*}} \Phi\left(\frac{\left(1-\zeta_{*}\right) \alpha-\zeta_{*}}{\left(1-\zeta_{*}\right) \kappa \sigma_{\varepsilon}}\right) \\
&<-\frac{1}{1-\zeta_{*}} \Phi\left(\frac{\left(1-\zeta_{*}\right) \alpha-\zeta_{*}}{\left(1-\zeta_{*}\right) \kappa \sigma_{\varepsilon}}\right)<0,
\end{aligned}
$$

by an application of (A.14). Since $\frac{\partial G}{\partial \zeta}\left(\alpha, \sigma_{\varepsilon}, \zeta_{*}\right) \neq 0$, we may employ the Implicit Function Theorem and (A.12)-(A.13) to derive (9), as follows:

$$
\begin{aligned}
\frac{\partial \zeta_{*}}{\partial \sigma_{\varepsilon}} & =-\frac{\frac{\partial G}{\partial \sigma_{\varepsilon}}\left(\alpha, \sigma_{\varepsilon}, \zeta_{*}\right)}{\frac{\partial G}{\partial \zeta}\left(\alpha, \sigma_{\varepsilon}, \zeta_{*}\right)} \\
& =-\frac{\frac{1}{\sigma_{\varepsilon}}\left(\left(1-\zeta_{*}\right) \kappa \sigma_{\varepsilon}+\zeta_{*} \frac{\left(1-\zeta_{*}\right) \alpha-\zeta_{*}}{\left(1-\zeta_{*}\right) \kappa \sigma_{\varepsilon}}\right) \varphi\left(\frac{\left(1-\zeta_{*}\right) \alpha-\zeta_{*}}{\left(1-\zeta_{*}\right) \kappa \sigma_{\varepsilon}}\right)}{\frac{1}{1-\zeta_{*}}\left(\frac{\zeta_{*}}{\left(1-\zeta_{*}\right) \kappa \sigma_{\varepsilon}}-\left(1-\zeta_{*}\right) \kappa \sigma_{\varepsilon}\right) \varphi\left(\frac{\left(1-\zeta_{*}\right) \alpha-\zeta_{*}}{\left(1-\zeta_{*}\right) \kappa \sigma_{\varepsilon}}\right)-(2+\alpha) \Phi\left(\frac{\left(1-\zeta_{*}\right) \alpha-\zeta_{*}}{\left(1-\zeta_{*}\right) \kappa \sigma_{\varepsilon}}\right)} \\
& =-\frac{\frac{1}{\sigma_{\varepsilon}}\left(\left(1-\zeta_{*}\right) \kappa \sigma_{\varepsilon}+\zeta_{*} \frac{\left(1-\zeta_{*}\right) \alpha-\zeta_{*}}{\left(1-\zeta_{*}\right) \kappa \sigma_{\varepsilon}}\right)}{\frac{1}{1-\zeta_{*}}\left(\frac{\zeta_{*}}{\left(1-\zeta_{*}\right) \kappa \sigma_{\varepsilon}}-\left(1-\zeta_{*}\right) \kappa \sigma_{\varepsilon}\right)+(2+\alpha) \frac{\left(1-\zeta_{*}\right) \kappa \sigma_{\varepsilon}}{\left(1-\zeta_{*}\right) \alpha-2 \zeta_{*}}} \\
& =\frac{\left(1-\zeta_{*}\right)\left(2 \zeta_{*}-\left(1-\zeta_{*}\right) \alpha\right)\left(\left(1-\zeta_{*}\right) \zeta_{*} \alpha-\zeta_{*}^{2}+\left(1-\zeta_{*}\right)^{2} \kappa^{2} \sigma_{\varepsilon}^{2}\right)}{\sigma_{\varepsilon}\left(\left(1-\zeta_{*}\right) \zeta_{*} \alpha-2 \zeta_{*}^{2}+2\left(1-\zeta_{*}\right)^{2} \kappa^{2} \sigma_{\varepsilon}^{2}\right)}
\end{aligned}
$$

where the third equality follows from $G\left(\alpha, \sigma_{\varepsilon}, \zeta_{*}\right)=0$ and (7). Next, to demonstrate that $\frac{\partial \zeta_{*}}{\partial \sigma_{\varepsilon}}>0$, we must establish the inequality $\frac{\partial G}{\partial \sigma_{\varepsilon}}\left(\alpha, \sigma_{\varepsilon}, \zeta_{*}\right)>0$. Suppose, on the contrary, that $\frac{\partial G}{\partial \sigma_{\varepsilon}}\left(\alpha, \sigma_{\varepsilon}, \zeta_{*}\right) \leq 0$. In that case, since $0<\zeta_{*}<1$, by virtue of Lemma 6 , it follows from (A.12) that $\left(1-\zeta_{*}\right) \alpha-\zeta_{*}<0$. By combining this inequality with (A.14) we get

$$
0>\zeta_{*} \frac{\left(1-\zeta_{*}\right) \alpha-\zeta_{*}}{\left(1-\zeta_{*}\right) \kappa \sigma_{\varepsilon}} \varphi\left(\frac{\left(1-\zeta_{*}\right) \alpha-\zeta_{*}}{\left(1-\zeta_{*}\right) \kappa \sigma_{\varepsilon}}\right)>\left(\left(1-\zeta_{*}\right) \alpha-\zeta_{*}\right) \Phi\left(\frac{\left(1-\zeta_{*}\right) \alpha-\zeta_{*}}{\left(1-\zeta_{*}\right) \kappa \sigma_{\varepsilon}}\right)
$$

Next, $G\left(\alpha, \sigma_{\varepsilon}, \zeta_{*}\right)=0$ and (7), together with an application of the inequality above to (A.12), yields

$$
\begin{aligned}
& \frac{\partial G}{\partial \sigma_{\varepsilon}}\left(\alpha, \sigma_{\varepsilon}, \zeta_{*}\right)> \frac{1}{\sigma_{\varepsilon}}\left(\left(1-\zeta_{*}\right) \kappa \sigma_{\varepsilon} \varphi\left(\frac{\left(1-\zeta_{*}\right) \alpha-\zeta_{*}}{\left(1-\zeta_{*}\right) \kappa \sigma_{\varepsilon}}\right)\right. \\
&\left.+\left(\left(1-\zeta_{*}\right) \alpha-\zeta_{*}\right) \Phi\left(\frac{\left(1-\zeta_{*}\right) \alpha-\zeta_{*}}{\left(1-\zeta_{*}\right) \kappa \sigma_{\varepsilon}}\right)\right) \\
&\left.=\frac{1}{\sigma_{\varepsilon}}\left(2 \zeta_{*}-\left(1-\zeta_{*}\right) \alpha+\left(1-\zeta_{*}\right) \alpha-\zeta_{*}\right) \Phi\left(\frac{\left(1-\zeta_{*}\right) \alpha-\zeta_{*}}{\left(1-\zeta_{*}\right) \kappa \sigma_{\varepsilon}}\right)\right) \\
&=\frac{\zeta_{*}}{\sigma_{\varepsilon}} \Phi\left(\frac{\left(1-\zeta_{*}\right) \alpha-\zeta_{*}}{\left(1-\zeta_{*}\right) \kappa \sigma_{\varepsilon}}\right)>0,
\end{aligned}
$$


since $0<\zeta_{*}<1$, by virtue of Lemma 6 . This contradicts our initial assumption that $\frac{\partial G}{\partial \sigma_{\varepsilon}}\left(\alpha, \sigma_{\varepsilon}, \zeta_{*}\right) \leq 0$, and so we may conclude that $\frac{\partial G}{\partial \sigma_{\varepsilon}}\left(\alpha, \sigma_{\varepsilon}, \zeta_{*}\right)>0$. Finally, since we already established that $\frac{\partial G}{\partial \zeta}\left(\alpha, \sigma_{\varepsilon}, \zeta_{*}\right)<0$ in (A.16), the Implicit Function Theorem gives

$$
\frac{\partial \zeta_{*}}{\partial \sigma_{\varepsilon}}=-\frac{\frac{\partial G}{\partial \sigma_{\varepsilon}}\left(\alpha, \sigma_{\varepsilon}, \zeta_{*}\right)}{\frac{\partial G}{\partial \zeta}\left(\alpha, \sigma_{\varepsilon}, \zeta_{*}\right)}>0,
$$

as required.

Proposition 10 establishes that the optimal fee charged by the mutual fund manager is a concave function of its idiosyncratic volatility, in the canonical case when its gross alpha is zero:

Proof of Proposition 10: From (10) we obtain

$$
\frac{\partial^{2} \zeta_{*}}{\partial \sigma_{\varepsilon}^{2}}=\frac{\left(1-2 \zeta_{*}\right) \frac{\mathrm{d} \zeta_{*}}{\mathrm{~d} \sigma_{\varepsilon}}-\left(1-\zeta_{*}\right) \zeta_{*}}{\sigma_{\varepsilon}^{2}}=-\frac{2\left(1-\zeta_{*}\right) \zeta_{*}^{2}}{\sigma_{\varepsilon}^{2}}<0,
$$

since $0<\zeta_{*}<1$, by virtue of Lemma 6 .

In the special case when the gross alpha of the mutual fund is zero, it is in fact possible to obtain an explicit expression for the optimal fee charged by the fund manager. This expression is presented in Proposition 11, which we now prove:

Proof of Proposition 11: By integrating (10) we obtain

$$
\int \frac{1}{\left(1-\zeta_{*}\right) \zeta_{*}} \mathrm{~d} \zeta_{*}=c+\int \frac{1}{\sigma_{\varepsilon}} \mathrm{d} \sigma_{\varepsilon}=c+\ln \sigma_{\varepsilon}
$$

where $c$ is an arbitrary constant. The integral on the left-hand side may be computed as follows:

$$
\int \frac{1}{\left(1-\zeta_{*}\right) \zeta_{*}} \mathrm{~d} \zeta_{*}=\int \frac{1-\zeta_{*}}{\zeta_{*}} \frac{1}{\left(1-\zeta_{*}\right)^{2}} \mathrm{~d} \zeta_{*}=\int \frac{1}{z} \mathrm{~d} z=\ln z=\ln \frac{\zeta_{*}}{1-\zeta_{*}}
$$

with the aid of the transformation of variables $\frac{\zeta_{*}}{1-\zeta_{*}} \mapsto z$. Putting everything together yields

$$
\zeta_{*}=\frac{k \sigma_{\varepsilon}}{1+k \sigma_{\varepsilon}},
$$

where $k:=\mathrm{e}^{c}>0$. Substituting this into (7), and using the fact that $G\left(0, \sigma_{\varepsilon}, \zeta_{*}\right)=0$, then gives

$$
\frac{k}{\kappa} \Phi\left(\frac{k}{\kappa}\right)+\frac{1}{2} \varphi\left(\frac{k}{\kappa}\right)=\frac{k}{\kappa}
$$

as required. Numerical solution of this equation gives $k \approx 0.6120 \kappa$. 
Theorem 12 establishes a positive relationship between the optimal fee charged by the fund manager and the gross alpha of the mutual fund. It also indicates that the fund manager passes some portion of any increase in performance on to the investor:

Proof of Theorem 12: Using (A.11) and (A.15), the Implicit Function Theorem gives

$$
\begin{aligned}
\frac{\partial \zeta_{*}}{\partial \alpha}=-\frac{\frac{\partial G}{\partial \alpha}\left(\alpha, \sigma_{\varepsilon}, \zeta_{*}\right)}{\frac{\partial G}{\partial \zeta}\left(\alpha, \sigma_{\varepsilon}, \zeta_{*}\right)} & =-\frac{\left(1-\zeta_{*}\right)\left(\Phi\left(\frac{\left(1-\zeta_{*}\right) \alpha-\zeta_{*}}{\left(1-\zeta_{*}\right) \kappa \sigma_{\varepsilon}}\right)-\frac{\zeta_{*}}{\left(1-\zeta_{*}\right) \kappa \sigma_{\varepsilon}} \varphi\left(\frac{\left(1-\zeta_{*}\right) \alpha-\zeta_{*}}{\left(1-\zeta_{*}\right) \kappa \sigma_{\varepsilon}}\right)\right)}{\frac{\zeta_{*}}{\left(1-\zeta_{*}\right)^{2} \kappa \sigma_{\varepsilon}} \varphi\left(\frac{\left(1-\zeta_{*}\right) \alpha-\zeta_{*}}{\left(1-\zeta_{*}\right) \kappa \sigma_{\varepsilon}}\right)-\frac{2}{\left(1-\zeta_{*}\right)} \Phi\left(\frac{\left(1-\zeta_{*}\right) \alpha-\zeta_{*}}{\left(1-\zeta_{*}\right) \kappa \sigma_{\varepsilon}}\right)} \\
& =\left(1-\zeta_{*}\right)^{2} \frac{\Phi\left(\frac{\left(1-\zeta_{*}\right) \alpha-\zeta_{*}}{\left(1-\zeta_{*}\right) \kappa \sigma_{\varepsilon}}\right)-\frac{\zeta_{*}}{\left(1-\zeta_{*}\right) \kappa \sigma_{\varepsilon}} \varphi\left(\frac{\left(1-\zeta_{*}\right) \alpha-\zeta_{*}}{\left(1-\zeta_{*}\right) \kappa \sigma_{\varepsilon}}\right)}{2 \Phi\left(\frac{\left(1-\zeta_{*}\right) \alpha-\zeta_{*}}{\left(1-\zeta_{*}\right) \kappa \sigma_{\varepsilon}}\right)-\frac{\zeta_{*}}{\left(1-\zeta_{*}\right) \kappa \sigma_{\varepsilon}} \varphi\left(\frac{\left(1-\zeta_{*}\right) \alpha-\zeta_{*}}{\left(1-\zeta_{*}\right) \kappa \sigma_{\varepsilon}}\right)} \\
& =\left(1-\zeta_{*}\right)^{2} \frac{\left(\left(1-\zeta_{*}\right) \alpha-2 \zeta_{*}\right) \zeta_{*}+\left(1-\zeta_{*}\right)^{2} \kappa^{2} \sigma_{\varepsilon}^{2}}{\left(\left(1-\zeta_{*}\right) \alpha-2 \zeta_{*}\right) \zeta_{*}+2\left(1-\zeta_{*}\right)^{2} \kappa^{2} \sigma_{\varepsilon}^{2}}
\end{aligned}
$$

by virtue of $G\left(\alpha, \sigma_{\varepsilon}, \zeta_{*}\right)=0$ and (7). Finally, applying (A.14) to (A.17) yields

$$
0<\frac{\partial \zeta_{*}}{\partial \alpha}<\left(1-\zeta_{*}\right)^{2}<1,
$$

since $0<\zeta_{*}<1$, according to Lemma 6 .

We conclude by proving Theorem 13, which derives an expression for the sensitivity of the equilibrium investment flow into the mutual fund with respect to its gross alpha. In particular, we demonstrate that the flow-performance sensitivity is positive:

Proof of Theorem 13: Using (12) and (A.17), we get

$$
\begin{aligned}
& \frac{\partial \omega_{*}}{\partial \alpha}=\frac{\zeta_{*}}{\gamma\left(1-\zeta_{*}\right)^{2} \kappa \sigma_{\varepsilon}^{3}}\left(1-\frac{\frac{\partial \zeta_{*}}{\partial \alpha}}{\left(1-\zeta_{*}\right)^{2}}\right) \varphi\left(\frac{\left(1-\zeta_{*}\right) \alpha-\zeta_{*}}{\left(1-\zeta_{*}\right) \kappa \sigma_{\varepsilon}}\right) \\
& +\frac{1+\zeta_{*}}{\gamma\left(1-\zeta_{*}\right)^{3} \sigma_{\varepsilon}^{2}} \Phi\left(\frac{\left(1-\zeta_{*}\right) \alpha-\zeta_{*}}{\left(1-\zeta_{*}\right) \kappa \sigma_{\varepsilon}}\right) \frac{\partial \zeta_{*}}{\partial \alpha} \\
& =\frac{\zeta_{*}}{\gamma\left(1-\zeta_{*}\right)^{2} \kappa \sigma_{\varepsilon}^{3}} \frac{\Phi\left(\frac{\left(1-\zeta_{*}\right) \alpha-\zeta_{*}}{\left(1-\zeta_{*}\right) \kappa \sigma_{\varepsilon}}\right) \varphi\left(\frac{\left(1-\zeta_{*}\right) \alpha-\zeta_{*}}{\left(1-\zeta_{*}\right) \kappa \sigma_{\varepsilon}}\right)}{2 \Phi\left(\frac{\left(1-\zeta_{*}\right) \alpha-\zeta_{*}}{\left(1-\zeta_{*}\right) \kappa \sigma_{\varepsilon}}\right)-\frac{\zeta_{*}}{\left(1-\zeta_{*}\right) \kappa \sigma_{\varepsilon}} \varphi\left(\frac{\left(1-\zeta_{*}\right) \alpha-\zeta_{*}}{\left(1-\zeta_{*}\right) \kappa \sigma_{\varepsilon}}\right)} \\
& +\frac{1+\zeta_{*}}{\gamma\left(1-\zeta_{*}\right) \sigma_{\varepsilon}^{2}} \Phi\left(\frac{\left(1-\zeta_{*}\right) \alpha-\zeta_{*}}{\left(1-\zeta_{*}\right) \kappa \sigma_{\varepsilon}}\right) \frac{\Phi\left(\frac{\left(1-\zeta_{*}\right) \alpha-\zeta_{*}}{\left(1-\zeta_{*}\right) \kappa \sigma_{\varepsilon}}\right)-\frac{\zeta_{*}}{\left(1-\zeta_{*}\right) \kappa \sigma_{\varepsilon}} \varphi\left(\frac{\left(1-\zeta_{*}\right) \alpha-\zeta_{*}}{\left(1-\zeta_{*}\right) \kappa \sigma_{\varepsilon}}\right)}{2 \Phi\left(\frac{\left(1-\zeta_{*}\right) \alpha-\zeta_{*}}{\left(1-\zeta_{*}\right) \kappa \sigma_{\varepsilon}}\right)-\frac{\zeta_{*}}{\left(1-\zeta_{*}\right) \kappa \sigma_{\varepsilon}} \varphi\left(\frac{\left(1-\zeta_{*}\right) \alpha-\zeta_{*}}{\left(1-\zeta_{*}\right) \kappa \sigma_{\varepsilon}}\right)} \\
& =\frac{1+\zeta_{*}}{\gamma\left(1-\zeta_{*}\right) \sigma_{\varepsilon}^{2}} \frac{\Phi^{2}\left(\frac{\left(1-\zeta_{*}\right) \alpha-\zeta_{*}}{\left(1-\zeta_{*}\right) \kappa \sigma_{\varepsilon}}\right)}{2 \Phi\left(\frac{\left(1-\zeta_{*}\right) \alpha-\zeta_{*}}{\left(1-\zeta_{*}\right) \kappa \sigma_{\varepsilon}}\right)-\frac{\zeta_{*}}{\left(1-\zeta_{*}\right) \kappa \sigma_{\varepsilon}} \varphi\left(\frac{\left(1-\zeta_{*}\right) \alpha-\zeta_{*}}{\left(1-\zeta_{*}\right) \kappa \sigma_{\varepsilon}}\right)} \\
& -\frac{\zeta_{*}^{2}}{\gamma\left(1-\zeta_{*}\right)^{2} \kappa \sigma_{\varepsilon}^{3}} \frac{\Phi\left(\frac{\left(1-\zeta_{*}\right) \alpha-\zeta_{*}}{\left(1-\zeta_{*}\right) \kappa \sigma_{\varepsilon}}\right) \varphi\left(\frac{\left(1-\zeta_{*}\right) \alpha-\zeta_{*}}{\left(1-\zeta_{*}\right) \kappa \sigma_{\varepsilon}}\right)}{2 \Phi\left(\frac{\left(1-\zeta_{*}\right) \alpha-\zeta_{*}}{\left(1-\zeta_{*}\right) \kappa \sigma_{\varepsilon}}\right)-\frac{\zeta_{*}}{\left(1-\zeta_{*}\right) \kappa \sigma_{\varepsilon}} \varphi\left(\frac{\left(1-\zeta_{*}\right) \alpha-\zeta_{*}}{\left(1-\zeta_{*}\right) \kappa \sigma_{\varepsilon}}\right)}
\end{aligned}
$$




$$
\begin{aligned}
& =\frac{\zeta_{*}}{\gamma\left(1-\zeta_{*}\right) \sigma_{\varepsilon}^{2}} \frac{\frac{1+\zeta_{*}}{\zeta_{*}} \Phi\left(\frac{\left(1-\zeta_{*}\right) \alpha-\zeta_{*}}{\left(1-\zeta_{*}\right) \kappa \sigma_{\varepsilon}}\right)-\frac{\zeta_{*}}{\left(1-\zeta_{*}\right) \kappa \sigma_{\varepsilon}} \varphi\left(\frac{\left(1-\zeta_{*}\right) \alpha-\zeta_{*}}{\left(1-\zeta_{*}\right) \kappa \sigma_{\varepsilon}}\right)}{2 \Phi\left(\frac{\left(1-\zeta_{*}\right) \alpha-\zeta_{*}}{\left(1-\zeta_{*}\right) \kappa \sigma_{\varepsilon}}\right)-\frac{\zeta_{*}}{\left(1-\zeta_{*}\right) \kappa \sigma_{\varepsilon}} \varphi\left(\frac{\left(1-\zeta_{*}\right) \alpha-\zeta_{*}}{\left(1-\zeta_{*}\right) \kappa \sigma_{\varepsilon}}\right)} \Phi\left(\frac{\left(1-\zeta_{*}\right) \alpha-\zeta_{*}}{\left(1-\zeta_{*}\right) \kappa \sigma_{\varepsilon}}\right) \\
& =\frac{\zeta_{*}}{\gamma\left(1-\zeta_{*}\right) \sigma_{\varepsilon}^{2}} \frac{\frac{1+\zeta_{*}}{\zeta_{*}}\left(1-\zeta_{*}\right)^{2} \kappa^{2} \sigma_{\varepsilon}^{2}+\left(\left(1-\zeta_{*}\right) \alpha-2 \zeta_{*}\right)}{2\left(1-\zeta_{*}\right)^{2} \kappa^{2} \sigma_{\varepsilon}^{2}+\left(\left(1-\zeta_{*}\right) \alpha-2 \zeta_{*}\right)} \Phi\left(\frac{\left(1-\zeta_{*}\right) \alpha-\zeta_{*}}{\left(1-\zeta_{*}\right) \kappa \sigma_{\varepsilon}}\right),
\end{aligned}
$$

where the final equality follows from $G\left(\alpha, \sigma_{\varepsilon}, \zeta_{*}\right)=0$ and (7). Finally, applying (A.14) to (A.18) yields

$$
\frac{\partial \omega_{*}}{\partial \alpha}>\frac{\zeta_{*}}{\gamma\left(1-\zeta_{*}\right) \sigma_{\varepsilon}^{2}} \Phi\left(\frac{\left(1-\zeta_{*}\right) \alpha-\zeta_{*}}{\left(1-\zeta_{*}\right) \kappa \sigma_{\varepsilon}}\right)=\left(1-\zeta_{*}\right) \omega_{*}>0
$$

by virtue of (12), and the fact that $0<\zeta_{*}<1$, according to Lemma 6 . 


\section{References}

Aggarwal, Rajesh K., and Andrew A. Samwick, 1999, The other side of the trade-off: The impact of risk on executive compensation, Journal of Political Economy 107, 65-105.

Barber, Brad M., and Terrance Odean, 2001, Boys will be boys: Gender, overconfidence, and common stock investment, Quarterly Journal of Economics 116, 261-292.

Barber, Brad M., Terrance Odean, and Lu Zheng, 2005, Out of sight, out of mind: The effects of expenses on mutual fund flows, Journal of Business 78, 2095-2120.

Bergstresser, Daniel, John M. R. Chalmers, and Peter Tufano, 2009, Assessing the costs and benefits of brokers in the mutual fund industry, Review of Financial Studies 22, 4129-4156.

Berk, Jonathan B., and Richard C. Green, 2004, Mutual fund flows and performance in rational markets, Journal of Political Economy 112, 1269-1295.

Borwein, Jonathan M., and Adrian S. Lewis, 2006, Convex Analysis and Nonlinear Optimization: Theory and Examples. (Springer, New York) second edn.

Brown, Keith C., W. V. Harlow, and Laura T. Starks, 1996, Of tournaments and temptations: An analysis of managerial incentives in the mutual fund industry, Journal of Finance 51, $85-110$.

Capon, Noel, Gavan J. Fitzsimons, and Russ Alan Prince, 1996, An individual level analysis of the mutual fund investment decision, Journal of Financial Services Research 10, 59-82.

Carhart, Mark M., 1997, On persistence in mutual fund performance, Journal of Finance 52, $57-82$.

Chalmers, John, Roger M. Edelen, and Gregory B. Kadlec, 1999, An Analysis of Mutual Fund Trading Costs, Working paper, University of Oregon.

Chen, Joseph, Harrison G. Hong, Ming Huang, and Jeffrey D. Kubik, 2004, Does fund size erode mutual fund performance? The role of liquidity and organization, American Economic Review 94, 1276-1302.

Cheng, Si, Massimo Massa, and Hong Zhang, 2013, Short-sale constraints and the pricing of managerial skills: The case of mutual funds, INSEAD Working Paper No. 2013/06/FIN.

Chevalier, Judith, and Glenn Ellison, 1997, Risk taking by mutual funds as a response to incentives, Journal of Political Economy 105, 1167-1200.

Chordia, Tarun, 1996, The structure of mutual fund charges, Journal of Financial Economics $41,3-39$. 
Christoffersen, Susan E. K., Richard Evans, and David K. Musto, 2013, What Do Consumers Fund Flows Maximize? Evidence from Their Brokers Incentives, Journal of Finance 68, 201-235.

Christoffersen, Susan E. K., and David K. Musto, 2002, Demand curves and the pricing of money management, Review of Financial Studies 15, 1499-1524.

Cremers, K. J. Martijn, and Antti Petajisto, 2009, How active is your fund manager? A new measure that predicts performance, Review of Financial Studies 22, 3329-3365.

Deli, Daniel N., 2002, Mutual Fund Advisory Contracts: An Empirical Investigation, Journal of Finance 57, 109-133.

Dudley, Richard M., 1999, Uniform Central Limit Theorems. (Cambridge University Press, Cambridge).

Elton, Edwin J., Martin J. Gruber, and Christopher R. Blake, 2012, Does mutual fund size matter? The relationship between size and performance, Review of Asset Pricing Studies 2, $31-55$

Evans, Richard B., 2010, Mutual fund incubation, Journal of Finance 65, 1581-1611.

Fama, Eugene F., and Kenneth R. French, 1993, Common risk factors in the returns on stocks and bonds, Journal of Financial Economics 33, 3-56.

Fama, Eugene F., and Kenneth R. French, 2010, Luck versus skill in the cross section of mutual fund returns, Journal of Finance 65, 1915-1947.

Fama, Eugene F., and James D. MacBeth, 1973, Risk, return, and equilibrium: Empirical tests, Journal of Political Economy 81, 607-636.

French, Kenneth R., 2008, Presidential address: The cost of active investing, Journal of Finance 63, 1537-1573.

Garen, John E., 1994, Executive compensation and principal-agent theory, Journal of Political Economy 102, 1175-1199.

Gil-Bazo, Javier, and Pablo Ruiz-Verdú, 2008, When cheaper is better: Fee determination in the market for equity mutual funds, Journal of Economic Behavior and Organization 67, $871-885$.

Gil-Bazo, Javier, and Pablo Ruiz-Verdú, 2009, The relation between price and performance in the mutual fund industry, Journal of Finance 64, 2153-2183.

Golec, Joseph H., 1992, Empirical tests of a principal-agent model of the investor-investment advisor relationship, Journal of Financial and Quantitative Analysis 20, 145-158. 
Gruber, Martin J., 1996, Another puzzle: The growth in actively managed mutual funds, Journal of Finance 51, 783-810.

Guercio, Diane Del, and Jonathan Reuter, 2013, Mutual fund performance and the incentive to generate alpha, Journal of Finance, forthcoming.

Harless, David W., and Steven P. Peterson, 1998, Investor behavior and the persistence of poorly-performing mutual funds, Journal of Economic Behavior and Organization 37, 257276.

Hortacsu, Ali, and Chad Syverson, 2004, Product differentiation, search costs, and competition in the mutual fund industry: A case study of S\&P 500 index funds, Quarterly Journal of Economics 119, 403-456.

Huang, Jennifer, Kelsey D. Wei, and Hong Yan, 2007, Participation costs and the sensitivity of fund flows to past performance, Journal of Finance 62, 1273-1311.

Huang, Jennifer, Kelsey D. Wei, and Hong Yan, 2012, Investor Learning and Mutual Fund Flows, Working paper, McCombs School of Business.

Hugonnier, Julien, and Ron Kaniel, 2010, Mutual fund portfolio choice in the presence of dynamic flows, Mathematical Finance 20, 187-227.

Ippolito, Richard A., 1992, Consumer reaction to measures of poor quality: Evidence from the mutual fund industry, Journal of Law and Economics 35, 45-70.

Jeffrey L. Coles, Jose Suay, and Denise Woodbury, 2000, Fund advisor compensation in closedend funds, Journal of Finance 55, 1385-1414.

Jin, Li, 2002, CEO compensation, diversification, and incentives, Journal of Financial Economics 66, 29-63.

Johnson, Norman L., Samuel Kotz, and N. Balakrishnan, 1994, Continuous Univariate Distributions: Volume 1. (Wiley, New York) second edn.

Khorana, Ajay, 1996, Top management turnover an empirical investigation of mutual fund managers, Journal of Financial Economics 40, 403-427.

Kosowski, Robert, Allan Timmermann, Russ Wermers, and Hal White, 2006, Can mutual fund "stars" really pick stocks? New evidence from a bootstrap analysis, Journal of Finance 61, $2551-2595$.

Kuhnen, Camelia M., 2005, Dynamic contracting in the mutual fund industry, Working Paper, Northwestern University. 
Lynch, Anthony W., and David K. Musto, 2003, How investors interpret past fund returns, Journal of Finance 58, 2033-2058.

Malkiel, Burton G., 1995, Returns from investing in equity mutual funds 1971 to 1991, Journal of Finance 50, 549-572.

Miller, Edward M., 1977, Risk, Uncertainty, and Divergence of Opinion, Journal of Finance 32, $1151-1168$.

Newey, Whitney K., and Kenneth D. West, 1987, A simple positive definite heteroscedasticity and autocorrelation consistent covariance matrix, Econometrica 55, 703-705.

Petersen, Mitchell A., 2009, Estimating standard errors in finance panel data sets: Comparing approaches, Review of Financial Studies 22, 435-480.

Sirri, Erik R., and Peter Tufano, 1998, Costly search and mutual fund flows, Journal of Finance 53.

Tufano, Peter, and Matthew Sevick, 1997, Board structure and fee-setting in the U.S. mutual fund industry, Journal of Financial Economics 46, 321-355.

Warner, Jerold B., and Joanna S. Wu, 2001, Why do mutual fund advisory contracts change? Performance, growth, and spillover effects, Journal of Finance 66, 271-306.

Wermers, Russ, 2000, Mutual fund performance: An empirical decomposition into stock-picking talent, style, transaction costs, and expenses, Journal of Finance 55, 1655-1703.

Wermers, Russ, 2003, Is money really "smart"? New evidence on the relation between mutual fund flows, manager behavior, and performance persistence, Working Paper, University of Maryland. 
(a)

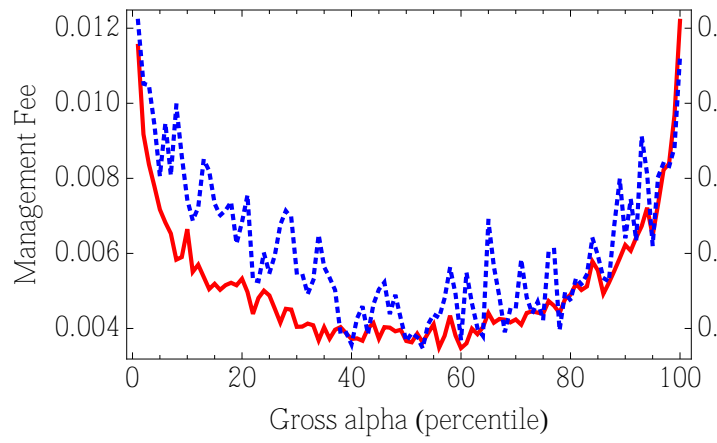

(b)

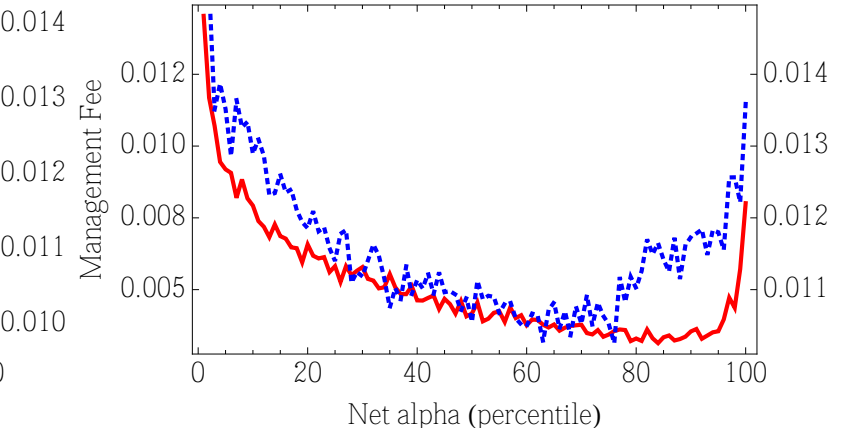

(c)

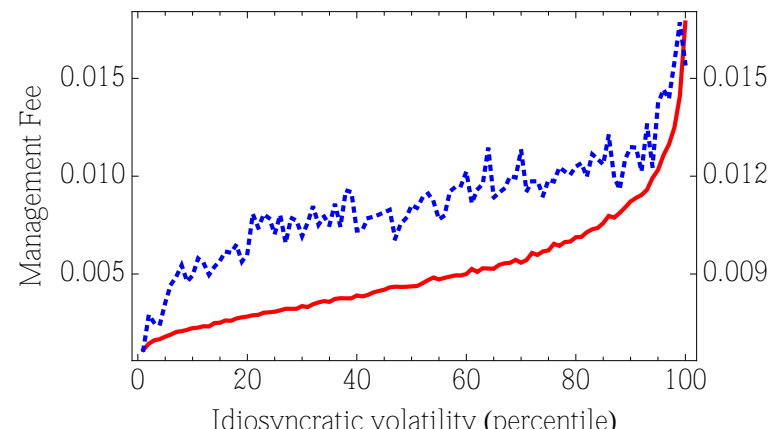

(d)

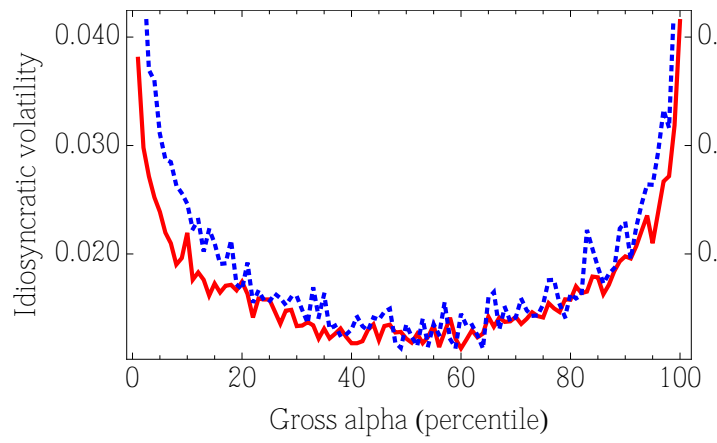

(e)

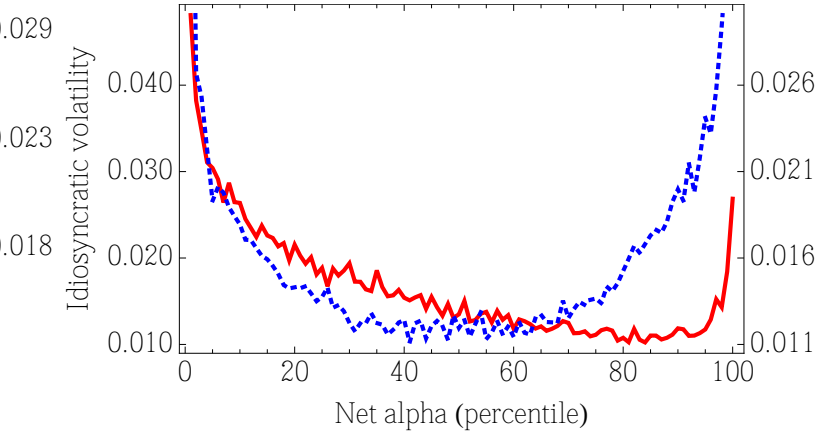

Figure 1. Decomposition of the simulated fee-performance relationship. In each of the subfigures above, the solid curves describe relationships for the simulated data generated by our model, with $\sigma_{\alpha}=0$ and $\kappa=0.5$, while the dotted curves describe the corresponding empirical relationships. In each case, the vertical scale on the left applies to the simulated data, while the vertical scale on the right applies to the empirical data. The following relationships are illustrated: (a) fees versus gross alphas; (b) fees versus net alphas; (c) fees versus gross idiosyncratic volatilities; (d) gross idiosyncratic volatilities versus gross alphas; and (e) gross idiosyncratic volatilities versus net alphas. 
(a)

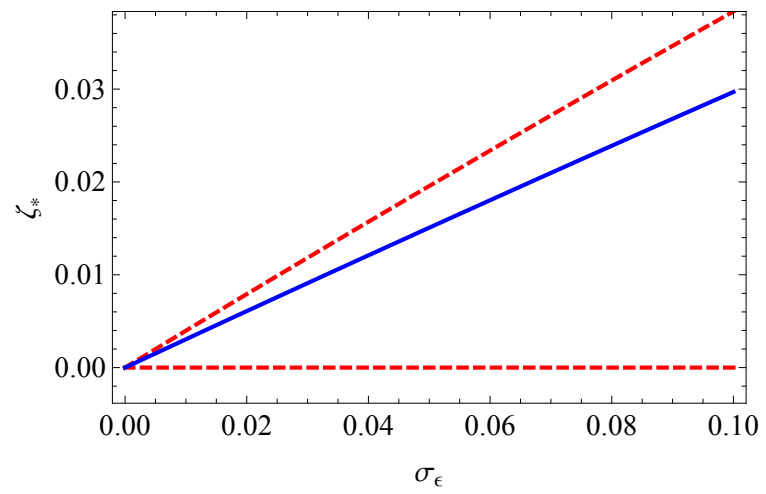

(b)

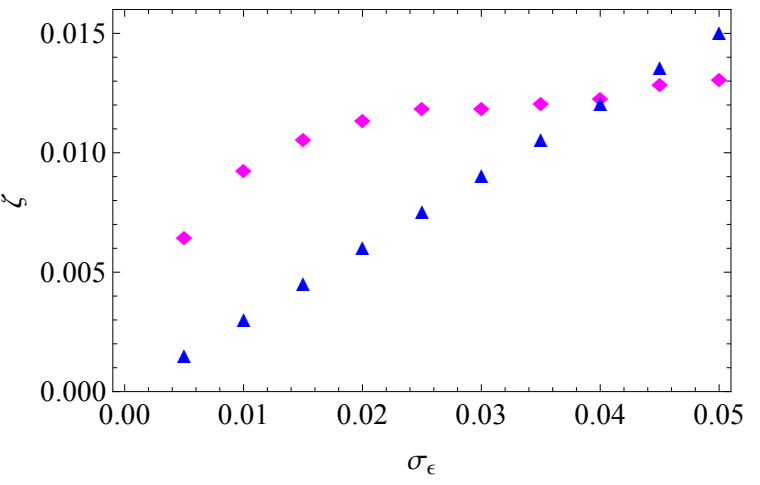

Figure 2. The relationship between fees and gross idiosyncratic volatilities. (a) The optimal fee $\zeta_{*}$ charged by the mutual fund manager, as a function of the idiosyncratic volatility $\sigma_{\varepsilon}$ of the fund, for $\alpha=0$ and $\kappa=0.5$, together with the upper and lower bounds from Lemma 8; and (b) the optimal fee $\zeta_{*}$ charged by the mutual fund manager as a function of the idiosyncratic volatility $\sigma_{\varepsilon}$ of the fund (triangles), for the same parameter values as before, together with the empirically observed relationship between mutual fund fees and idiosyncratic volatility (diamonds).

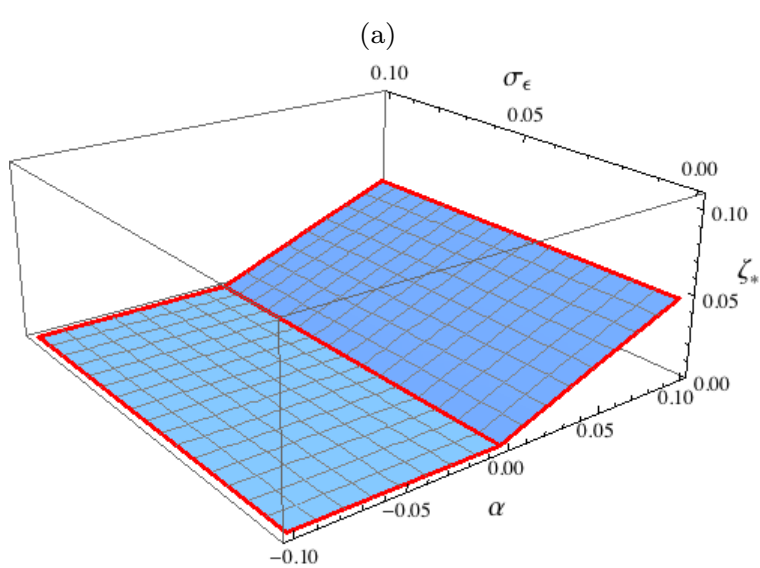

(c)

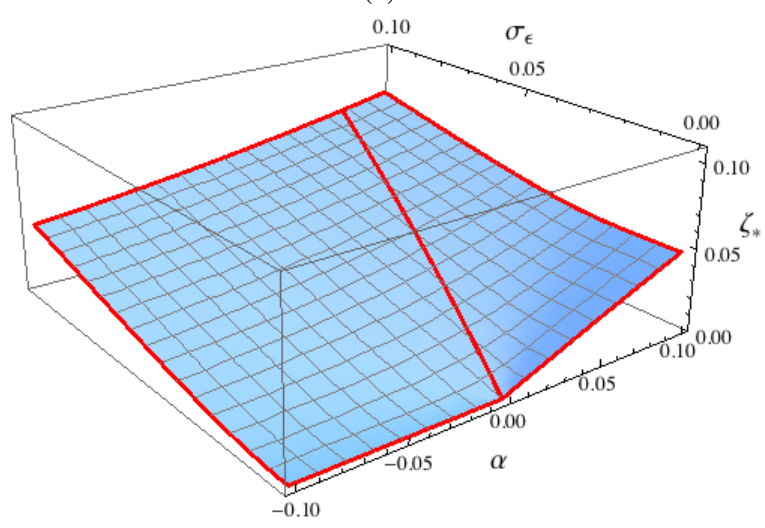

(b)

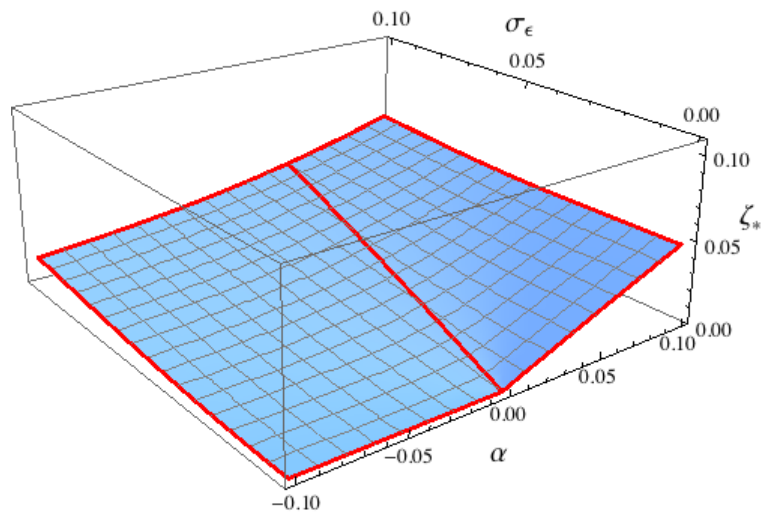

(d)

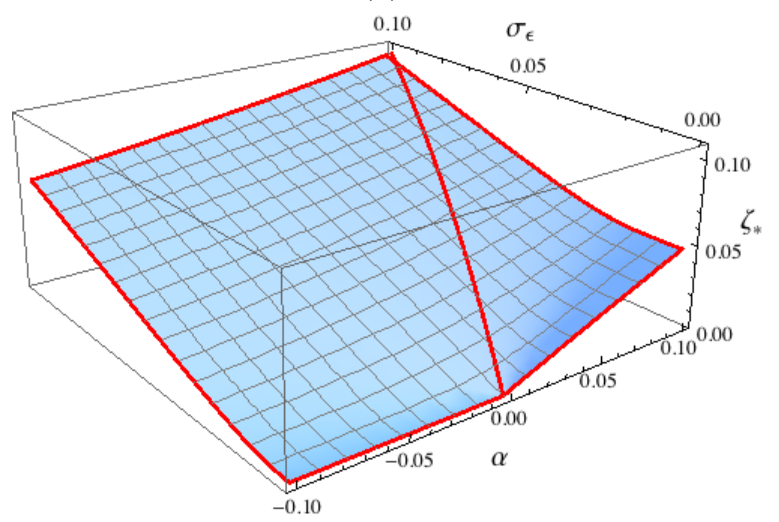

Figure 3. Fees for different levels of investor expertise. Each subfigure plots the optimal fee $\zeta_{*}$ charged by the manager of the mutual fund, as a function of its gross alpha $\alpha$ and its idiosyncratic volatility $\sigma_{\varepsilon}$, for different levels of investor expertise: (a) $\kappa=0$; (b) $\kappa=0.5$; (c) $\kappa=1$; and (d) $\kappa=1.5$. In each case, the bold curve indicates where the fee equals the gross alpha, which implies that the net alpha offered by the fund is zero along that curve. 
(a)

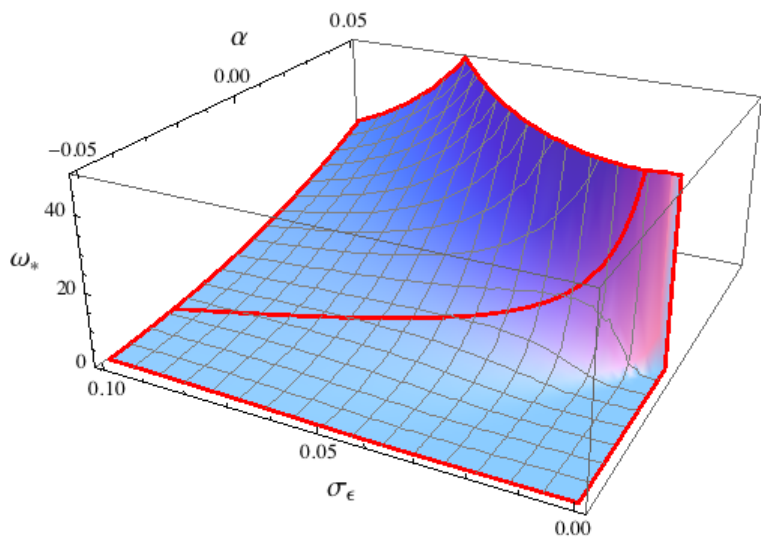

(b)

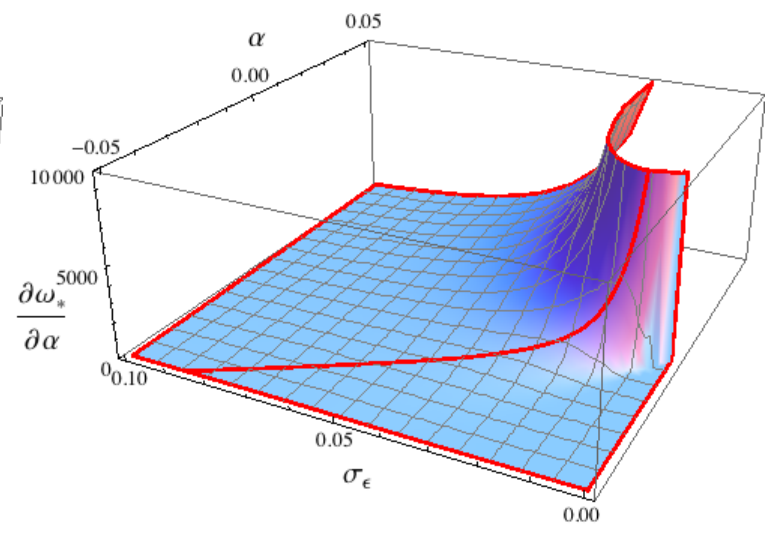

Figure 4. Flows and the sensitivity of flows to performance.(a) The equilibrium flow into the mutual fund, as a function of its gross alpha $\alpha$ and its gross idiosyncratic volatility $\sigma_{\varepsilon}$; and (b) the equilibrium flowperformance sensitivity of the fund, as a function of the same variables. The bold curves indicate where the functions achieve their maxima.

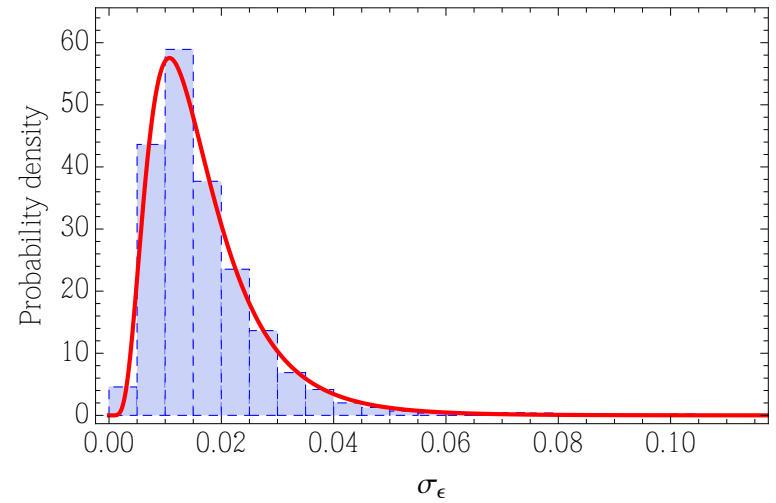

Figure 5. The empirical volatility distribution. The empirical distribution of the idiosyncratic volatilities described in Section III, together with the best-fitting log-normal distribution, based on maximum likelihood. Its log-scale and shape parameters are $\mu \approx-4.2263$ and $\sigma \approx 0.5532$, respectively. 


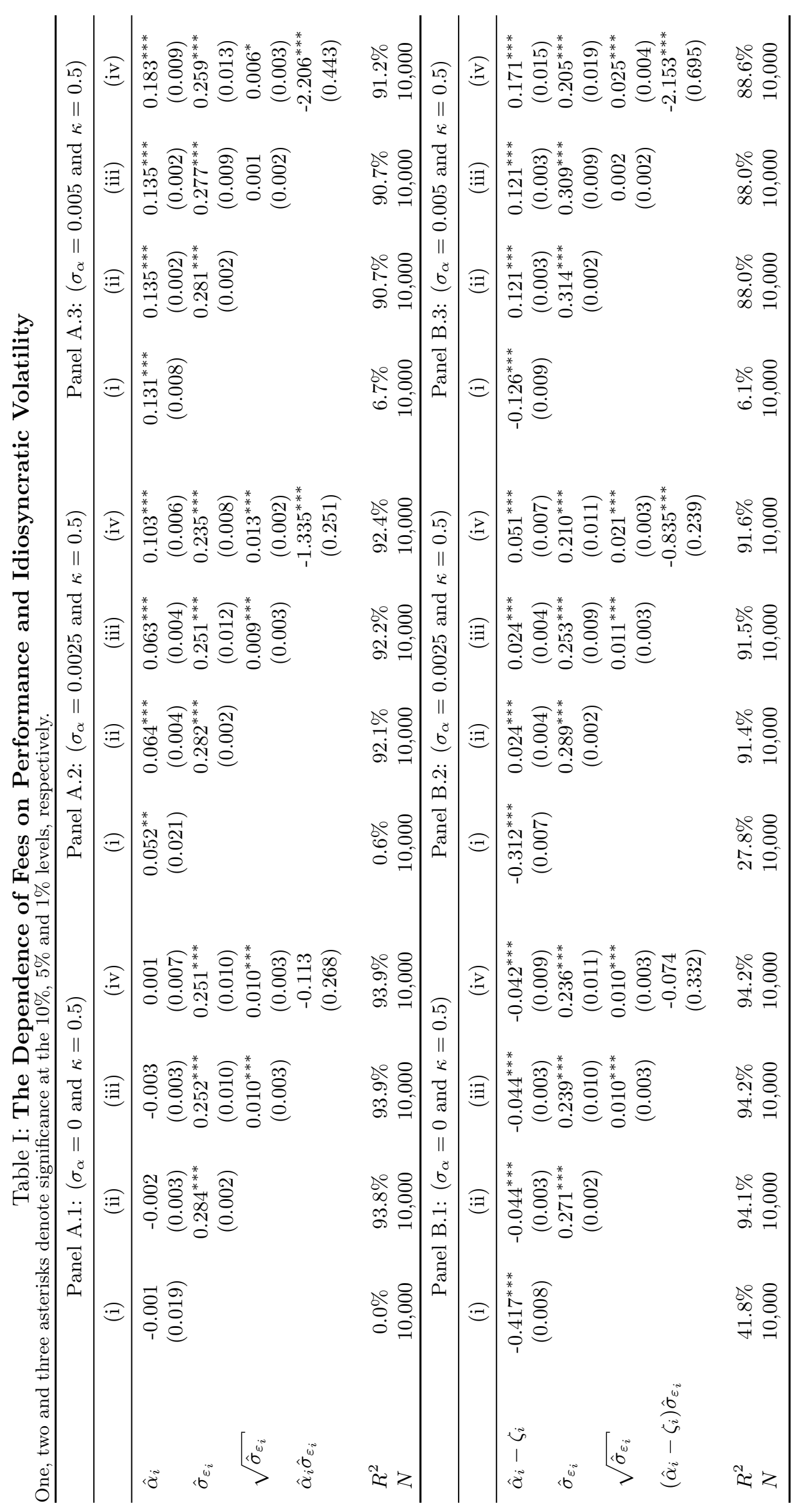


Table II

Correlations Between Estimated Alphas and Estimated Volatilities

Sample correlations between estimated gross and net alphas and estimated gross volatilities, for three simulations with $\sigma_{\alpha}=0, \sigma_{\alpha}=0.0025$, and $\sigma_{\alpha}=0.005$. One, two and three asterisks denote significance at the $10 \%, 5 \%$ and $1 \%$ levels, respectively.

\begin{tabular}{lccc}
\hline & $\sigma_{\alpha}=0.0000$ & $\sigma_{\alpha}=0.0025$ & $\sigma_{\alpha}=0.0050$ \\
$\widehat{\widehat{\operatorname{Corr}}\left(\hat{\alpha}_{i}, \hat{\sigma}_{\varepsilon_{i}}\right)}$ & 0.0018 & -0.0187 & -0.0085 \\
& $(0.8539)$ & $(0.1235)$ & $(0.3937)$ \\
$\widehat{\operatorname{Corr}}\left(\hat{\alpha}_{i}-\zeta_{i}, \hat{\sigma}_{\varepsilon_{i}}\right)$ & $-0.6240^{* * *}$ & $-0.5805^{* * *}$ & $-0.4730^{* * *}$ \\
& $(0.0000)$ & $(0.0000)$ & $(0.0000)$ \\
\hline
\end{tabular}




\section{Table III}

\section{Idiosyncratic Volatility and Other Mutual Fund Characteristics}

This table presents average management fees $(M G M T)$ for quintile portfolios of idiosyncratic volatility and other selected fund characteristics, for the period from 1994 to 2007. Funds are sorted according to their lagged idiosyncratic volatilities (IDVOL), and then assigned to quintile portfolios. The portfolio with the lowest (highest) idiosyncratic volatility funds is denoted IDVOL.Low (IDVOL.High). We also allocate funds to quintile portfolios, based on each of the following characteristics: the logarithm of fund total net assets (FNDSIZE), in Panel A; the logarithm of fund family total net assets (FAMSIZE), in Panel B; fund portfolio turnover, computed as the minimum of aggregated sales and aggregated purchases of securities (TRNOVR), in Panel C; and the logarithm of the number of years since fund inception (FNDAGE), in Panel D. For each panel, we report the difference between the two extreme quintile portfolios (High - Low or Old - Young). Levels of significance are denoted by asterisks, with one, two, and three asterisks indicating significance at the $10 \%, 5 \%$, and $1 \%$ levels, respectively.

\begin{tabular}{|c|c|c|c|c|c|c|}
\hline & \multicolumn{6}{|c|}{ Panel A: Quintile Portfolios of Fund TNA } \\
\hline & FNDSIZE.Low & FNDSIZE.2 & FNDSIZE.3 & FNDSIZE.4 & FNDSIZE.High & High - Low \\
\hline IDVOL.Low & 1.042 & 1.035 & 0.966 & 0.908 & 0.748 & $-0.294^{* * *}$ \\
\hline IDVOL.2 & 1.209 & 1.155 & 1.068 & 1.013 & 0.838 & $-0.371^{* * *}$ \\
\hline IDVOL.3 & 1.321 & 1.254 & 1.148 & 1.091 & 0.944 & $-0.377^{* * *}$ \\
\hline IDVOL.4 & 1.416 & 1.305 & 1.239 & 1.167 & 1.001 & $-0.415^{* * *}$ \\
\hline IDVOL.High & 1.691 & 1.516 & 1.386 & 1.251 & 1.078 & $-0.613^{* * *}$ \\
\hline \multirow[t]{3}{*}{ High-Low } & $0.649^{* * *}$ & $0.482^{* * *}$ & $0.420^{* * *}$ & $0.343^{* * *}$ & $0.330^{* * *}$ & \\
\hline & \multicolumn{6}{|c|}{ Panel B: Quintile Portfolios of Fund Family TNA } \\
\hline & FAMSIZE.Low & FAMSIZE.2 & FAMSIZE.3 & FAMSIZE.4 & FAMSIZE.High & High - Low \\
\hline IDVOL.Low & 1.056 & 1.017 & 0.947 & 0.867 & 0.751 & $-0.305^{* * *}$ \\
\hline IDVOL. 2 & 1.213 & 1.122 & 1.053 & 0.976 & 0.852 & $-0.361^{* * *}$ \\
\hline IDVOL.3 & 1.302 & 1.219 & 1.136 & 1.062 & 0.979 & $-0.323^{* * *}$ \\
\hline IDVOL.4 & 1.393 & 1.278 & 1.224 & 1.133 & 1.040 & $-0.353^{* * *}$ \\
\hline IDVOL.High & 1.634 & 1.469 & 1.354 & 1.217 & 1.150 & $-0.484^{* * *}$ \\
\hline \multirow[t]{3}{*}{ High-Low } & $0.578^{* * *}$ & $0.452^{* * *}$ & $0.407^{* * *}$ & $0.350^{* * *}$ & $0.399^{* * *}$ & \\
\hline & \multicolumn{6}{|c|}{ Panel C: Quintile Portfolios of Fund Portfolio Turnover } \\
\hline & TRNOVR.Low & TRNOVR.2 & TRNOVR.3 & TRNOVR.4 & TRNOVR.High & High - Low \\
\hline IDVOL.Low & 0.816 & 0.919 & 0.931 & 0.953 & 1.032 & $0.216^{* * *}$ \\
\hline IDVOL.2 & 0.978 & 1.031 & 1.068 & 1.043 & 1.062 & $0.084^{* * *}$ \\
\hline IDVOL.3 & 1.106 & 1.127 & 1.123 & 1.167 & 1.196 & $0.091^{* * *}$ \\
\hline IDVOL.4 & 1.145 & 1.176 & 1.203 & 1.271 & 1.234 & $0.089^{* * *}$ \\
\hline IDVOL.High & 1.260 & 1.322 & 1.374 & 1.395 & 1.444 & $0.184^{* * *}$ \\
\hline \multirow[t]{3}{*}{ High-Low } & $0.445^{* * *}$ & $0.403^{* * *}$ & $0.443^{* * *}$ & $0.441^{* * *}$ & $0.413^{* * *}$ & \\
\hline & \multicolumn{6}{|c|}{ Panel D: Quintile Portfolios of Fund Age } \\
\hline & FNDAGE.Young & FNDAGE.2 & FNDAGE.3 & FNDAGE.4 & FNDAGE.Old & Old - Young \\
\hline IDVOL.Low & 0.780 & 0.928 & 0.935 & 0.947 & 0.827 & 0.047 \\
\hline IDVOL.2 & 1.006 & 1.079 & 1.080 & 1.037 & 0.924 & -0.082 \\
\hline IDVOL.3 & 1.177 & 1.190 & 1.152 & 1.122 & 1.058 & -0.119 \\
\hline IDVOL.4 & 1.285 & 1.268 & 1.238 & 1.176 & 1.139 & -0.146 \\
\hline IDVOL.High & 1.358 & 1.396 & 1.378 & 1.382 & 1.279 & -0.079 \\
\hline High-Low & $0.578^{*}$ & $0.467^{* * *}$ & $0.443^{* * *}$ & $0.435^{* * *}$ & $0.452^{* * *}$ & \\
\hline
\end{tabular}




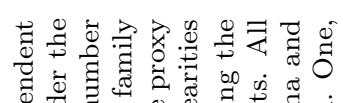

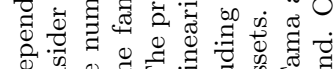

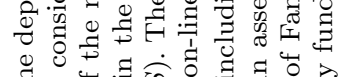

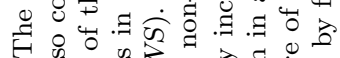

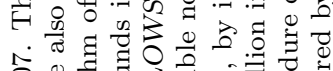

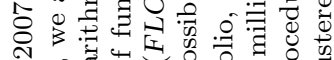
No

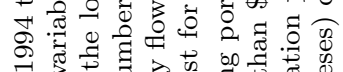

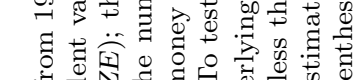

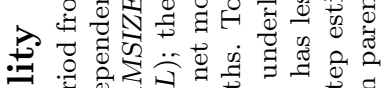

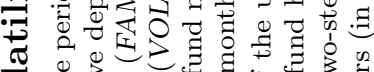
O

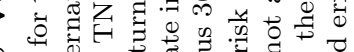

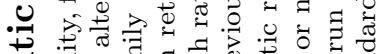

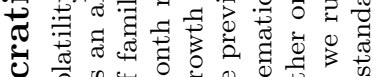

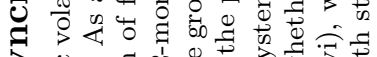

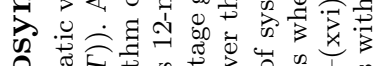

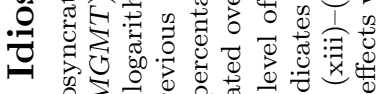

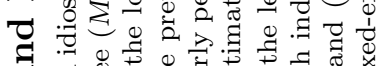
ส

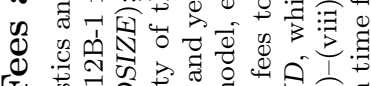

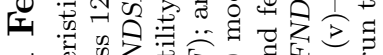

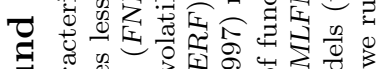

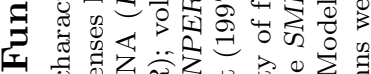
质

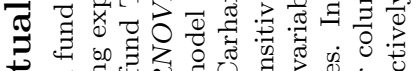

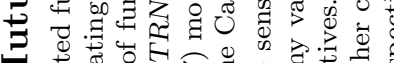

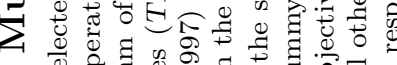
5 क

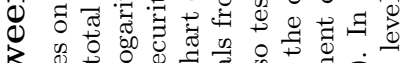

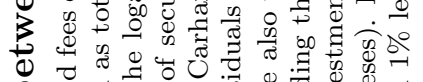

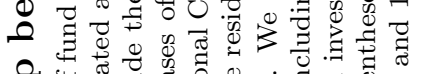

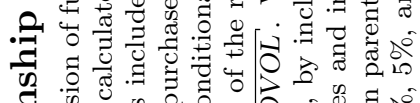

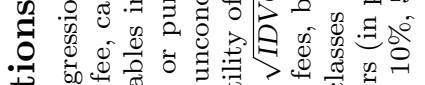

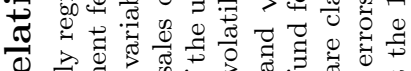
Q

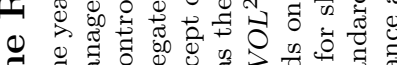

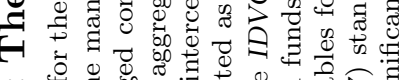

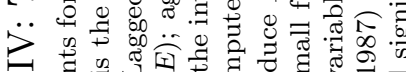

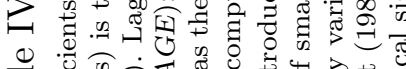

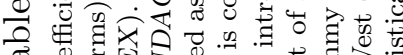

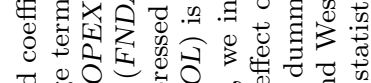
政

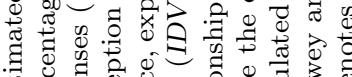

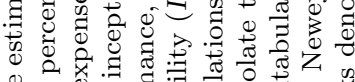

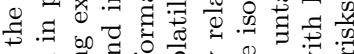

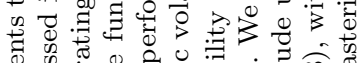

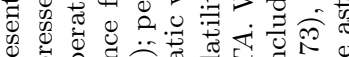

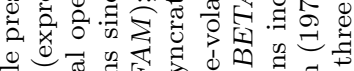
等

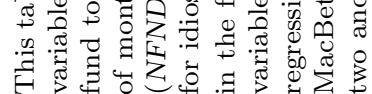

亩畧长

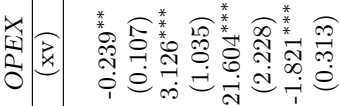

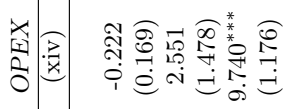

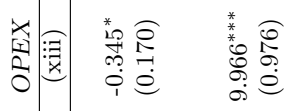

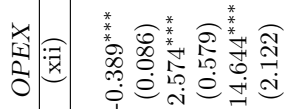

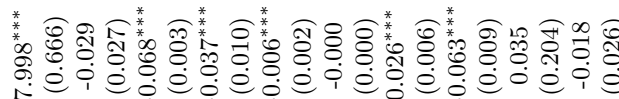

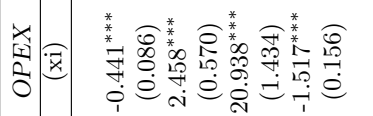

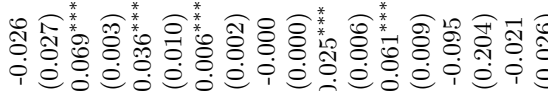

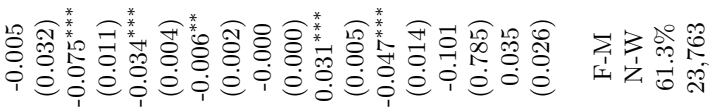

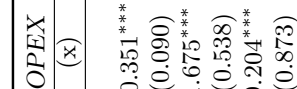

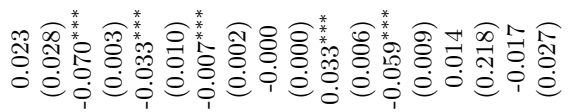

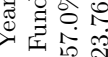

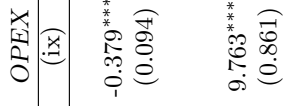

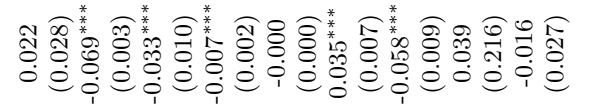

돌

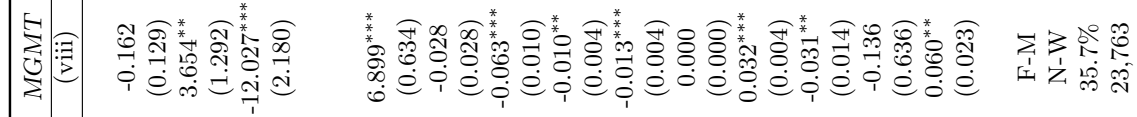

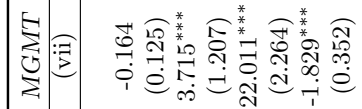

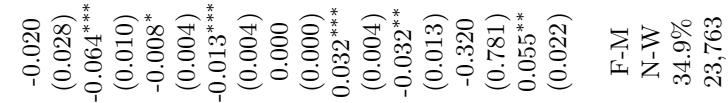

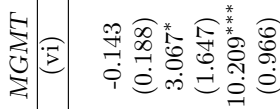

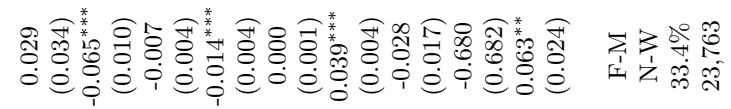

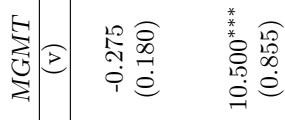

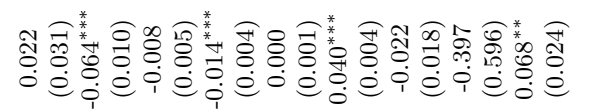

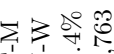

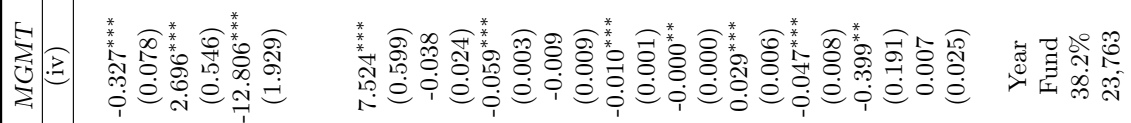

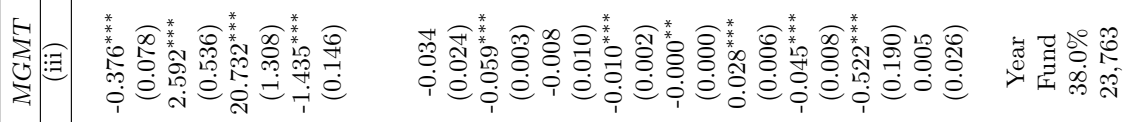

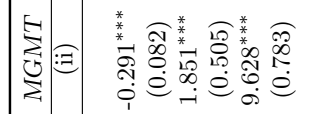

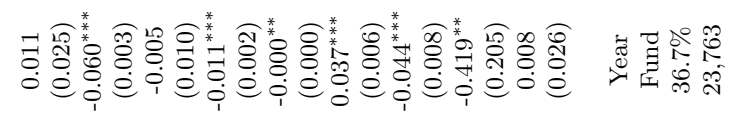

E)

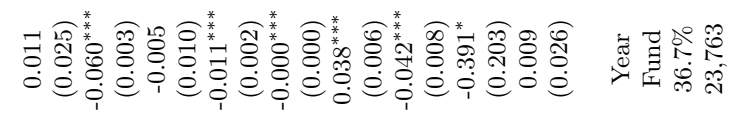

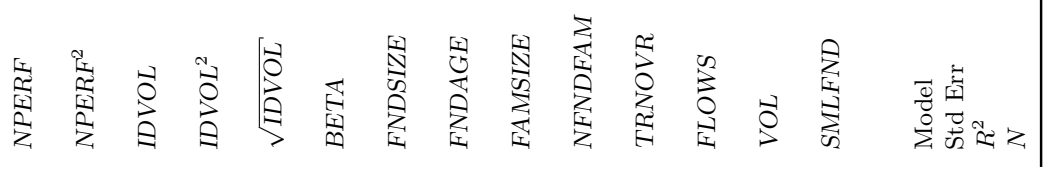




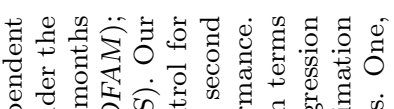

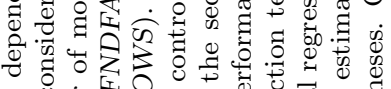

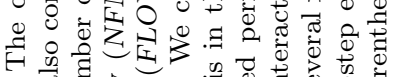

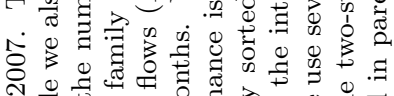

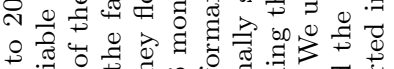

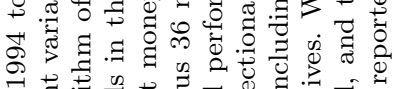

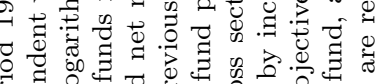

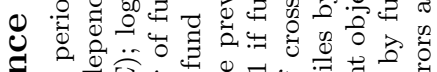
สี

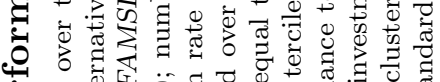

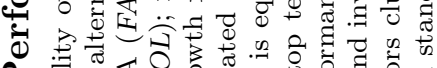

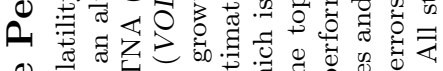
\& 0

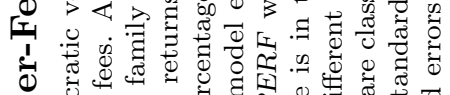

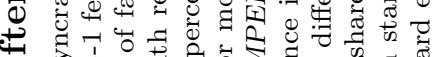
定

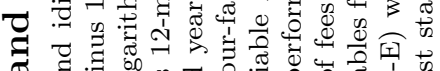
สิ ส

讨

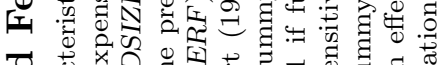

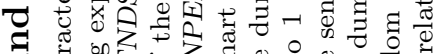

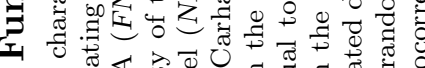

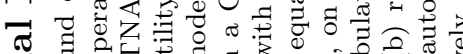

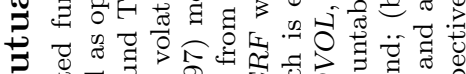

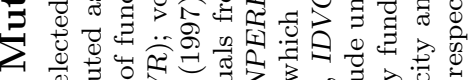

व 0 \%

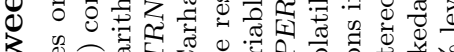

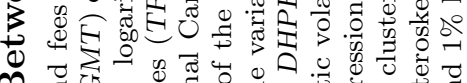

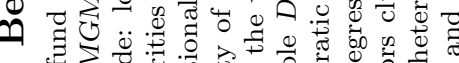

응

Th

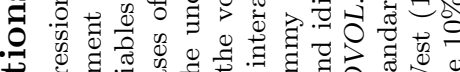

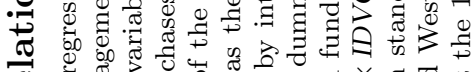

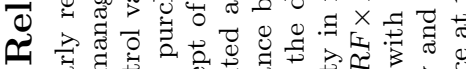

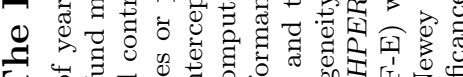

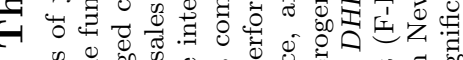

$\ddot{>}$

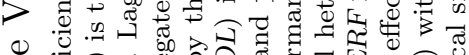

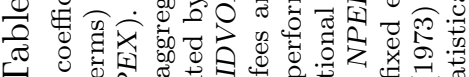

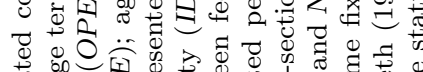

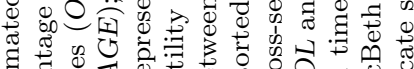

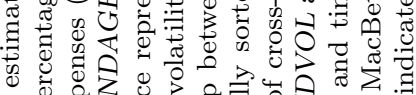

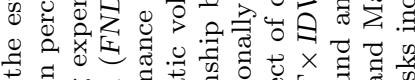

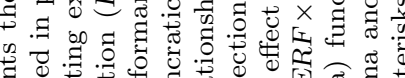

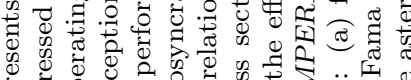

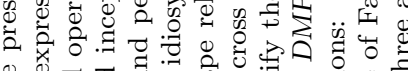

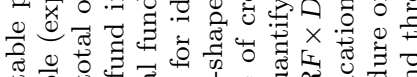

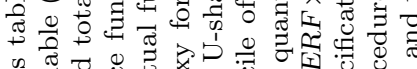

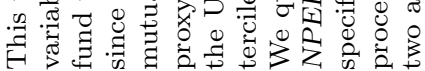

|甾展

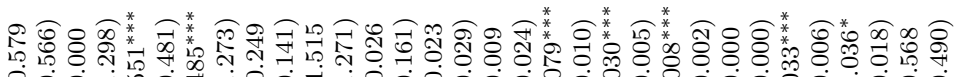

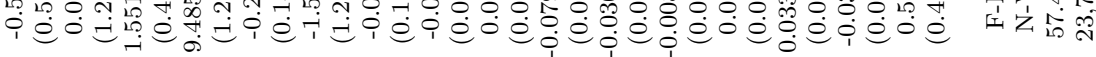

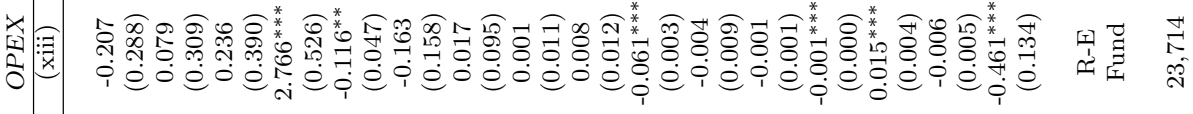

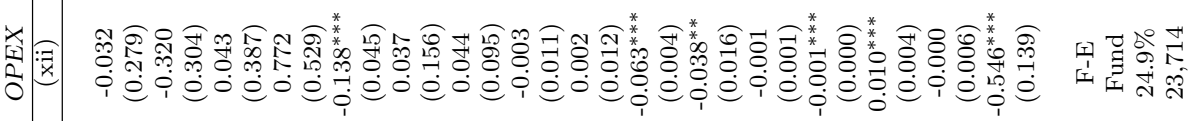

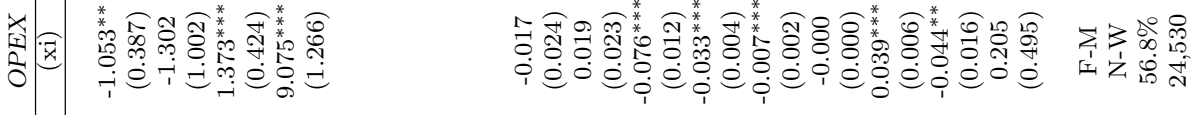

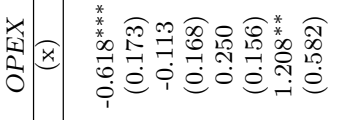

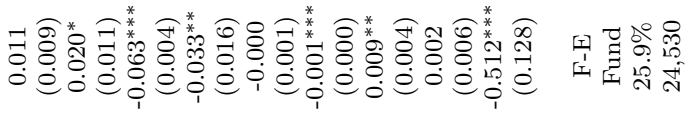

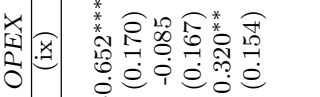

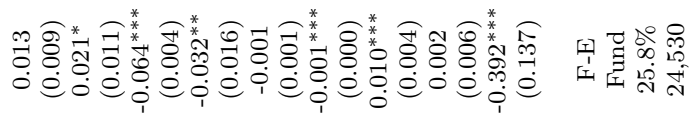

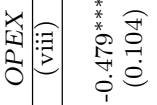

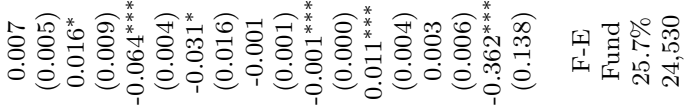

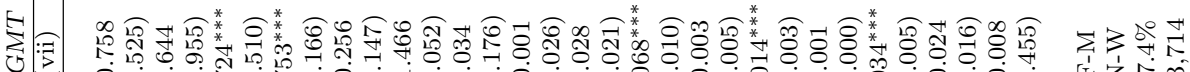

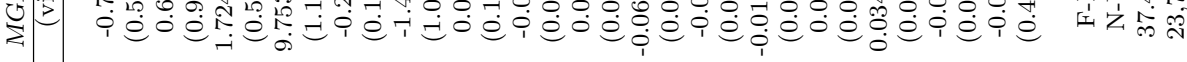

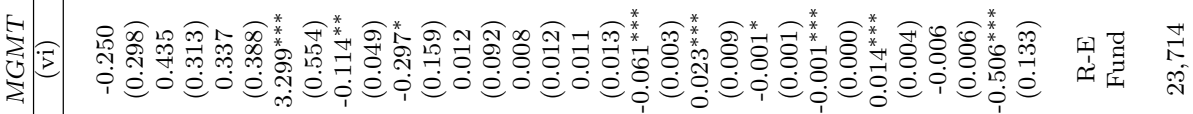

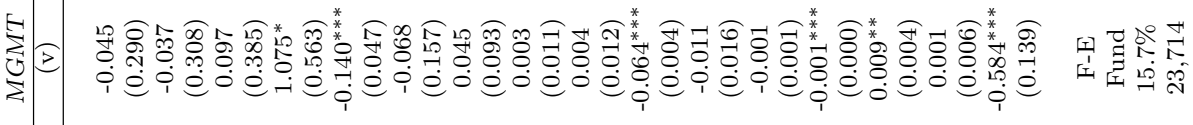

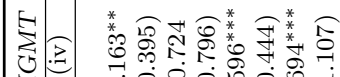

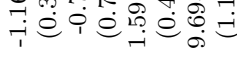

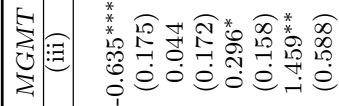

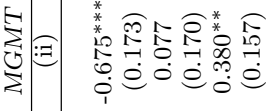

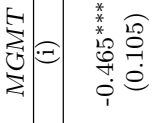

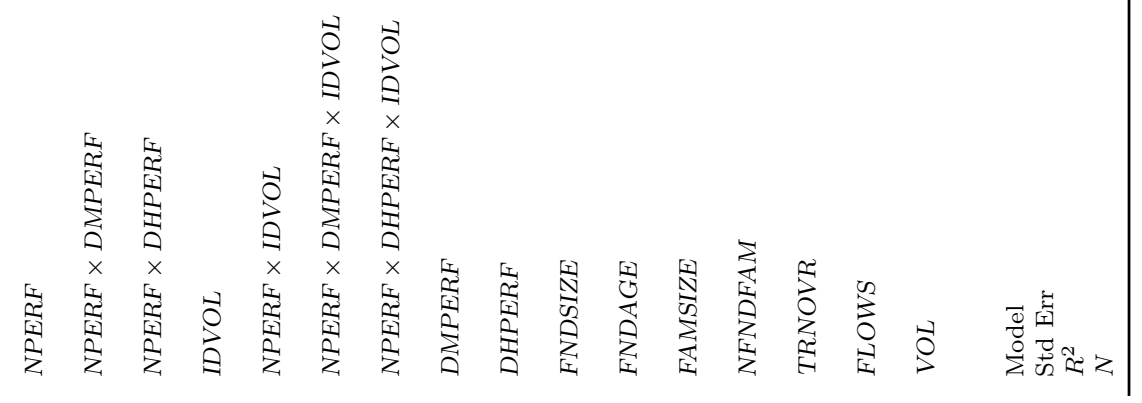

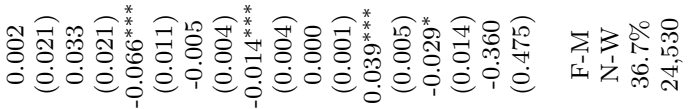

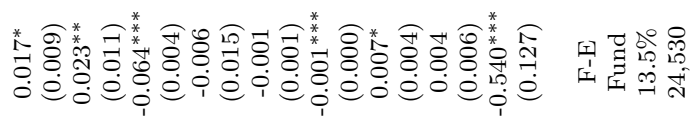

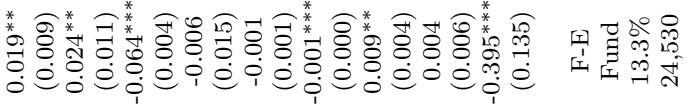

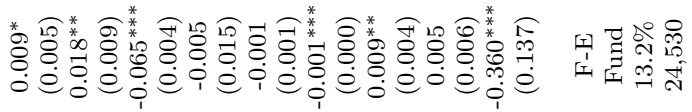




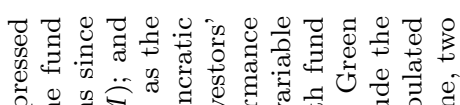

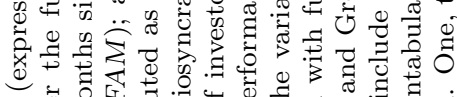

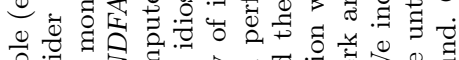

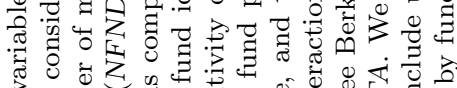

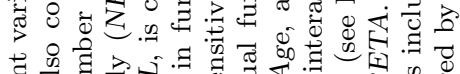

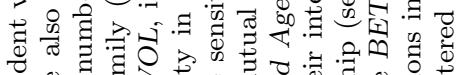

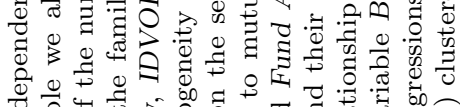

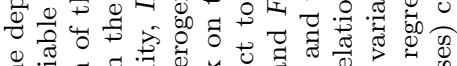

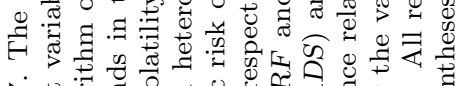

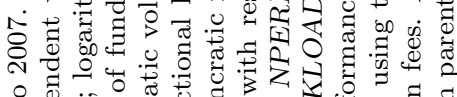

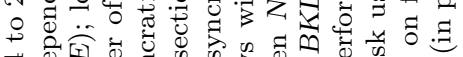

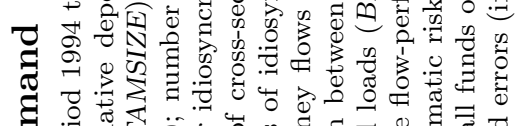

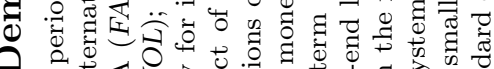

等

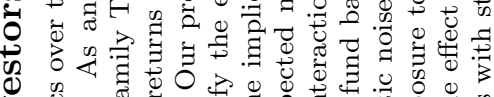

等

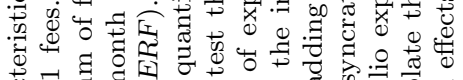

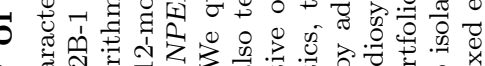

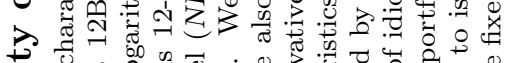

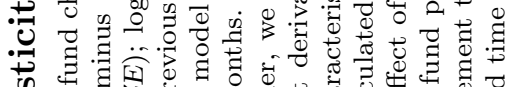

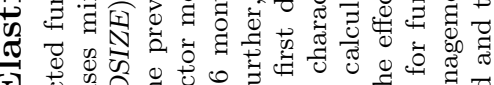

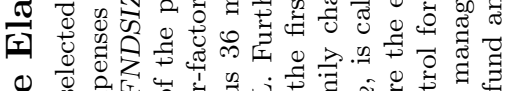

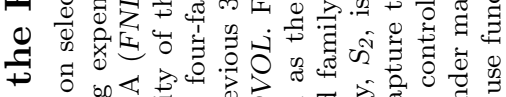

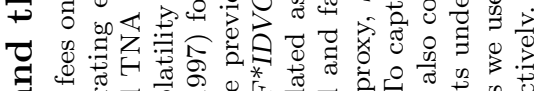

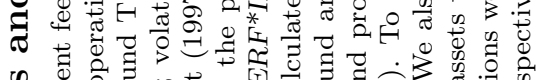

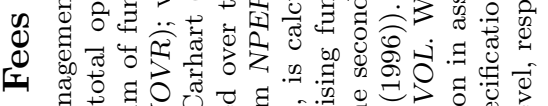

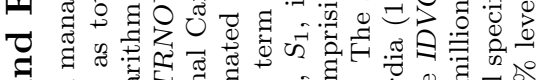

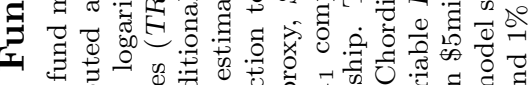

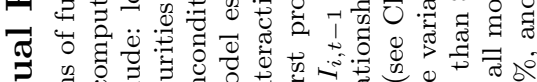

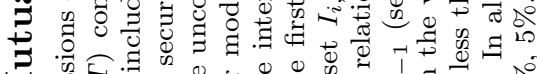

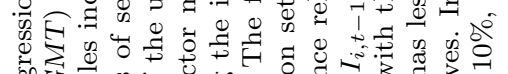

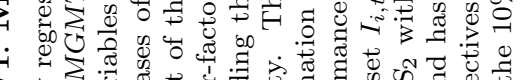

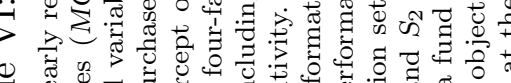

응

元

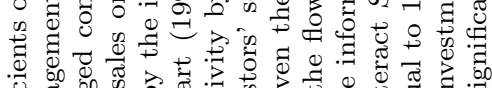

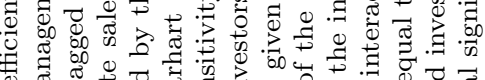

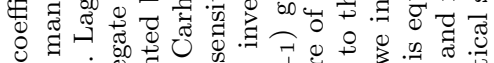

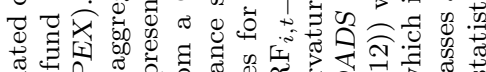

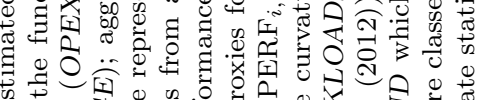

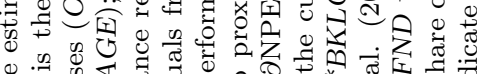

等

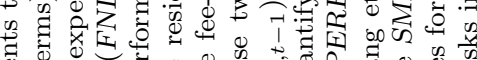

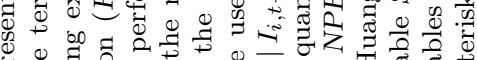

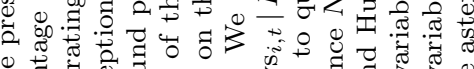

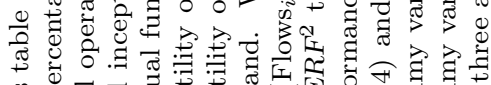

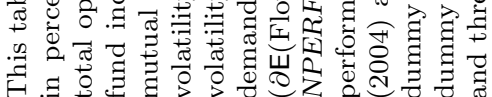

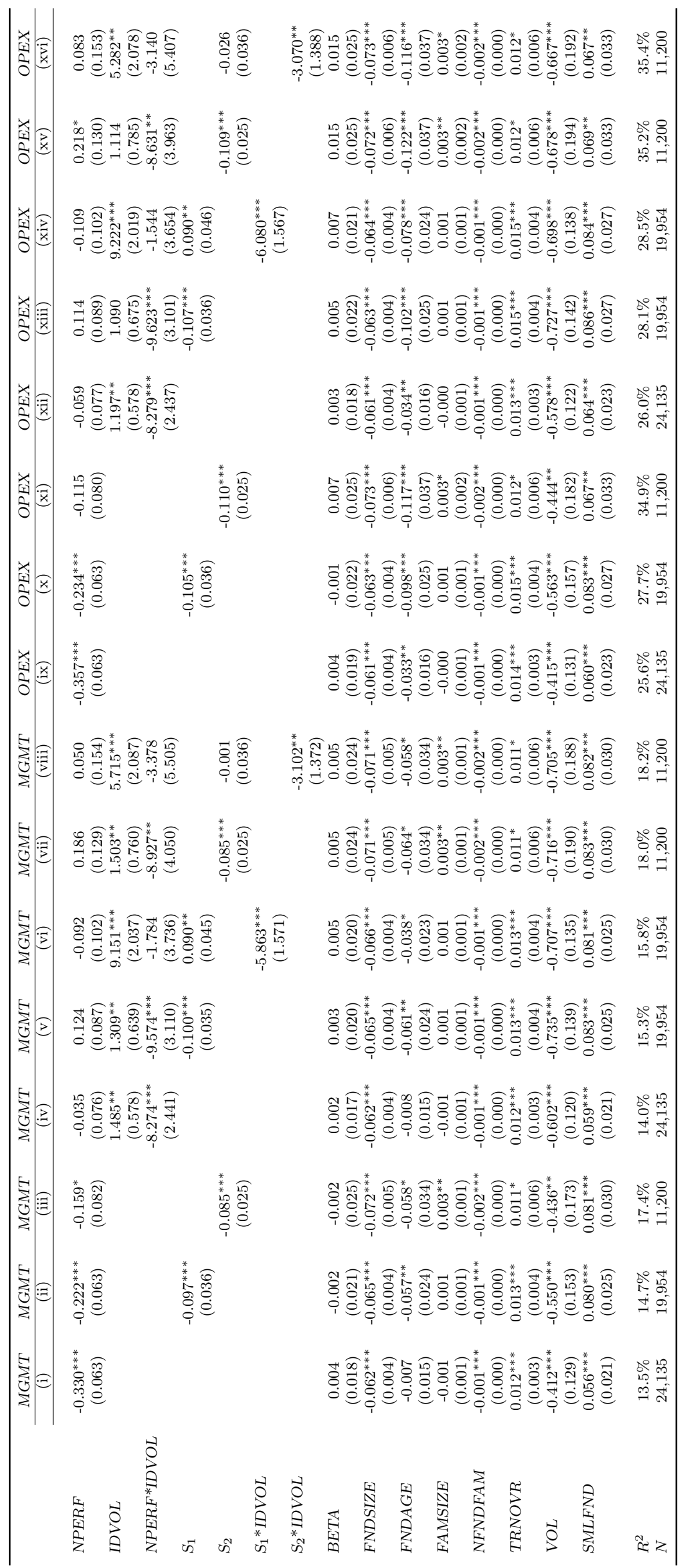




\section{Table VII}

\section{Mutual Fund Fees and Before-Fee Performance}

This table examines the relationship between different mutual fund fees and before-fee risk-adjusted performance over the period from January 1994 to December 2007. We estimate the fee-performance sensitivity using as dependent variable five different fee specifications: (a) management fees (MGMT) computed as total operating expenses minus 12b-1 fees; (b) actual management fee reported by the fund in its statement of operations and available over the period from 1999 through 2007 (MGMT2); (c) total operating expenses (OPEX); (d) 12b-1 fees (12b-1); and (e) marketing fees (MKTING) which are computed as $12 \mathrm{~b}-1$ fees plus $1 / 7$ th of fund front-end loads. The independent variable is the fund gross expected performance, GPERF, estimated using the two-stage procedure of Carhart (1997) to mitigate look-ahead bias. First, we obtain a panel of monthly risk-adjusted return estimates from the four-factor model where the loadings are estimated over the previous 60 months (with a minimum of 48 months of available observations). We then estimate fund before-fee abnormal returns in month $t$ as the difference between the fund's before-fee excess return and the lagged vector of betas multiplied by the vectors of factor realizations in month $t$. We also repeat this two-stage procedure to estimate the Fama and French (1993) before-fee risk-adjusted returns. The coefficient estimates of fees on fund gross performance GPERF are reported for the two cases where performance is estimated using the four-factor model (4-Factor), and the three-factor model (3-Factor). For each fund fee we estimate the fee-performance sensitivity using four different OLS specifications: (1) year fixed effects with standard errors clustered by fund (Fund); (2) year fixed effects with standard errors clustered by time (Time); (3) year fixed effects with standard errors clustered by both fund and time (Fund-Time); and (4) the Fama and MacBeth (1973) cross-sectional regression with Newey and West (1987) heteroskedasticity and autocorrelation robust standard errors (Newey-West). All standard errors are reported in parentheses. One, two and three asterisks indicate statistical significance at the $10 \%, 5 \%$, and $1 \%$ level, respectively.

\begin{tabular}{|c|c|c|c|c|c|c|c|c|c|}
\hline & Fee Type & Std. Err. & Obs. & GPERF & Coeff. & $R^{2}$ & GPERF & Coeff. & $R^{2}$ \\
\hline (i) & MGMT & Fund & 10,934 & 4-Factor & $\begin{array}{c}-0.175^{* * *} \\
(0.066)\end{array}$ & $4.9 \%$ & 3-Factor & $\begin{array}{c}-0.113^{*} \\
(0.061)\end{array}$ & $4.8 \%$ \\
\hline (ii) & $M G M T$ & Time & 10,934 & 4-Factor & $\begin{array}{l}-0.175 \\
(0.128)\end{array}$ & $4.9 \%$ & 3-Factor & $\begin{array}{l}-0.113 \\
(0.134)\end{array}$ & $4.8 \%$ \\
\hline (iii) & MGMT & Fund-Time & 10,934 & 4-Factor & $\begin{array}{l}-0.175 \\
(0.127)\end{array}$ & $4.9 \%$ & 3-Factor & $\begin{array}{l}-0.113 \\
(0.133)\end{array}$ & $4.8 \%$ \\
\hline (iv) & $M G M T$ & Newey-West & 10,934 & 4-Factor & $\begin{array}{l}-0.192 \\
(0.150)\end{array}$ & $0.8 \%$ & 3-Factor & $\begin{array}{l}-0.138 \\
(0.123)\end{array}$ & $0.6 \%$ \\
\hline$(\mathrm{v})$ & MGMT2 & Fund & 9,359 & 4-Factor & $\begin{array}{l}-0.092 \\
(0.076)\end{array}$ & $0.1 \%$ & 3-Factor & $\begin{array}{l}-0.051 \\
(0.064)\end{array}$ & $0.1 \%$ \\
\hline (vi) & MGMT2 & Time & 9,359 & 4-Factor & $\begin{array}{l}-0.092 \\
(0.102)\end{array}$ & $0.1 \%$ & 3-Factor & $\begin{array}{c}-0.051 \\
(0.086)\end{array}$ & $0.1 \%$ \\
\hline (vii) & MGMT2 & Fund-Time & 9,359 & 4-Factor & $\begin{array}{l}-0.092 \\
(0.114)\end{array}$ & $0.1 \%$ & 3-Factor & $\begin{array}{l}-0.051 \\
(0.095)\end{array}$ & $0.1 \%$ \\
\hline (viii) & MGMT2 & Newey-West & 9,359 & 4-Factor & $\begin{array}{l}-0.132 \\
(0.150)\end{array}$ & $0.2 \%$ & 3-Factor & $\begin{array}{l}-0.108 \\
(0.129)\end{array}$ & $0.3 \%$ \\
\hline (ix) & OPEX & Fund & 10,934 & 4-Factor & $\begin{array}{c}-0.527^{* * *} \\
(0.080)\end{array}$ & $3.1 \%$ & 3-Factor & $\begin{array}{c}-0.396^{* * *} \\
(0.071)\end{array}$ & $2.9 \%$ \\
\hline$(\mathrm{x})$ & OPEX & Time & 10,934 & 4-Factor & $\begin{array}{c}-0.527^{* * *} \\
(0.153)\end{array}$ & $3.1 \%$ & 3-Factor & $\begin{array}{c}-0.396^{* * *} \\
(0.139)\end{array}$ & $2.9 \%$ \\
\hline$(x i)$ & OPEX & Fund-Time & 10,934 & 4-Factor & $\begin{array}{c}-0.527^{* * *} \\
(0.155)\end{array}$ & $3.1 \%$ & 3-Factor & $\begin{array}{c}-0.396^{* * *} \\
(0.141)\end{array}$ & $2.9 \%$ \\
\hline (xii) & OPEX & Newey-West & 10,934 & 4-Factor & $\begin{array}{c}-0.460^{* *} \\
(0.207)\end{array}$ & $1.1 \%$ & 3-Factor & $\begin{array}{c}-0.370^{* *} \\
(0.177)\end{array}$ & $0.8 \%$ \\
\hline (xiii) & $12 B-1$ & Fund & 10,934 & 4-Factor & $\begin{array}{c}-0.352^{* * *} \\
(0.047)\end{array}$ & $11.4 \%$ & 3-Factor & $\begin{array}{c}-0.283^{* * *} \\
(0.045)\end{array}$ & $11.2 \%$ \\
\hline (xiv) & $12 B-1$ & Time & 10,934 & 4-Factor & $\begin{array}{c}-0.352^{* * *} \\
(0.085)\end{array}$ & $11.4 \%$ & 3-Factor & $\begin{array}{c}-0.283^{* * *} \\
(0.093)\end{array}$ & $11.2 \%$ \\
\hline$(\mathrm{xv})$ & $12 B-1$ & Fund-Time & 10,934 & 4-Factor & $\begin{array}{c}-0.352^{* * *} \\
(0.086)\end{array}$ & $11.4 \%$ & 3-Factor & $\begin{array}{c}-0.283^{* * *} \\
(0.094)\end{array}$ & $11.2 \%$ \\
\hline (xvi) & $12 B-1$ & Newey-West & 10,934 & 4-Factor & $\begin{array}{c}-0.268^{* *} \\
(0.098)\end{array}$ & $0.8 \%$ & 3-Factor & $\begin{array}{c}-0.232^{* *} \\
(0.096)\end{array}$ & $0.8 \%$ \\
\hline (xvii) & MKTING & Fund & 10,934 & 4-Factor & $\begin{array}{c}-0.200^{* * *} \\
(0.056)\end{array}$ & $8.9 \%$ & 3-Factor & $\begin{array}{c}-0.195^{* * *} \\
(0.055)\end{array}$ & $8.9 \%$ \\
\hline (xviii) & MKTING & Time & 10,934 & 4-Factor & $\begin{array}{c}-0.200^{* * *} \\
(0.061)\end{array}$ & $8.9 \%$ & 3-Factor & $\begin{array}{c}-0.195^{* * *} \\
(0.055)\end{array}$ & $8.9 \%$ \\
\hline$(x i x)$ & MKTING & Fund-Time & 10,934 & 4-Factor & $\begin{array}{c}-0.200^{* * *} \\
(0.064)\end{array}$ & $8.9 \%$ & 3-Factor & $\begin{array}{c}-0.195^{* * *} \\
(0.059)\end{array}$ & $8.9 \%$ \\
\hline$(\mathrm{xx})$ & MKTING & Newey-West & 10,934 & 4-Factor & $\begin{array}{c}-0.368^{* *} \\
(0.164)\end{array}$ & $0.7 \%$ & 3-Factor & $\begin{array}{c}-0.393^{* *} \\
(0.154)\end{array}$ & $0.7 \%$ \\
\hline
\end{tabular}




\section{Table VIII}

\section{Mutual Fund Fees and Before-Fee Performance}

This table examines the sensitivity of different mutual fund fees to gross risk-adjusted returns while controlling for cross-sectional variations in fund idiosyncratic volatility from January 1994 to December 2007. We estimate the fee-performance sensitivity using as dependent variable five different fee specifications: (a) management fees (MGMT) computed as total operating expenses minus 12b-1 fees; (b) actual management fee reported by the fund in its statement of operations and available over the period from 1999 through 2007 (MGMT2); (c) total operating expenses (OPEX); (d) 12b-1 fees (12b-1); and (e) marketing fees (MKTING) which are computed as $12 \mathrm{~b}-1$ fees plus $1 / 7$-th of fund front-end loads. Our main independent variable is the fund before-fee abnormal returns, GPERF, computed as the difference between the fund's before-fee excess return and the lagged vector of betas multiplied by the vectors of factor realizations in month $t$. Fund gross abnormal returns are estimated using the Carhart (1997) before-fee risk-adjusted returns over the previous five years (requiring a minimum of 48 months of available observations). To test our model prediction on the relationship between fees and fund idiosyncratic volatility we include the variable $I D V O L$. To account for possible non-linearities in the fee-volatility relationship we introduce the variable $\sqrt{I D V O L}$. We isolate the effect on the fee-performance sensitivity of $I D V O L$ using the interaction term GPERF $\times I D V O L$. All regression models are estimated using the Fama and MacBeth (1973) approach with Newey and West (1987) heteroskedasticity and autocorrelation consistent standard errors (in parentheses). One, two and three asterisks indicate statistical significance at the $10 \%, 5 \%$, and $1 \%$ level, respectively.

\begin{tabular}{|c|c|c|c|c|c|c|c|}
\hline & Fee & GPERF & IDVOL & $G P E R F \times I D V O L$ & $\sqrt{I D V O L}$ & $R^{2}$ & Obs. \\
\hline (i) & $M G M T$ & $\begin{array}{l}-0.192 \\
(0.150)\end{array}$ & & & & $0.8 \%$ & 10,934 \\
\hline (ii) & $M G M T$ & $\begin{array}{l}-0.186 \\
(0.152)\end{array}$ & $\begin{array}{c}13.381^{* * *} \\
(1.292)\end{array}$ & & & $11.2 \%$ & 10,934 \\
\hline (iii) & $M G M T$ & $\begin{array}{l}-0.057 \\
(0.137)\end{array}$ & $\begin{array}{c}15.152^{* * *} \\
(1.684)\end{array}$ & $\begin{array}{l}-36.494 \\
(22.082)\end{array}$ & & $15.4 \%$ & 10,934 \\
\hline (iv) & $M G M T$ & $\begin{array}{l}-0.050 \\
(0.144)\end{array}$ & $\begin{array}{l}-9.476 \\
(5.566)\end{array}$ & $\begin{array}{l}-33.361 \\
(20.237)\end{array}$ & $\begin{array}{c}7.761^{* * *} \\
(1.341)\end{array}$ & $16.3 \%$ & 10,934 \\
\hline (v) & MGMT2 & $\begin{array}{l}-0.132 \\
(0.150)\end{array}$ & & & & $0.2 \%$ & 9,359 \\
\hline (vi) & MGMT2 & $\begin{array}{l}-0.142 \\
(0.151)\end{array}$ & $\begin{array}{c}5.560^{* * *} \\
(1.493)\end{array}$ & & & $2.4 \%$ & 9,359 \\
\hline (vii) & MGMT2 & $\begin{array}{l}-0.100 \\
(0.136)\end{array}$ & $\begin{array}{c}5.622^{* *} \\
(1.836)\end{array}$ & $\begin{array}{l}-14.572 \\
(9.158)\end{array}$ & & $2.4 \%$ & 9,359 \\
\hline (viii) & MGMT2 & $\begin{array}{l}-0.051 \\
(0.136)\end{array}$ & $\begin{array}{l}-1.064 \\
(2.562)\end{array}$ & $\begin{array}{r}-7.994^{*} \\
(4.008)\end{array}$ & $\begin{array}{c}6.628^{* * *} \\
(0.906)\end{array}$ & $3.7 \%$ & 9,359 \\
\hline (ix) & OPEX & $\begin{array}{c}-0.460^{* *} \\
(0.207)\end{array}$ & & & & $1.1 \%$ & 10,934 \\
\hline$(\mathrm{x})$ & OPEX & $\begin{array}{c}-0.459^{* *} \\
(0.205)\end{array}$ & $\begin{array}{c}11.924^{* * *} \\
(1.197)\end{array}$ & & & $6.9 \%$ & 10,934 \\
\hline (xi) & OPEX & $\begin{array}{l}-0.249 \\
(0.146)\end{array}$ & $\begin{array}{c}13.566^{* * *} \\
(1.686)\end{array}$ & $\begin{array}{c}-58.062^{* *} \\
(27.744)\end{array}$ & & $10.4 \%$ & 10,934 \\
\hline (xii) & OPEX & $\begin{array}{l}-0.245^{*} \\
(0.133)\end{array}$ & $\begin{array}{c}-11.371^{*} \\
(6.187)\end{array}$ & $\begin{array}{c}-58.757^{* *} \\
(25.774)\end{array}$ & $\begin{array}{c}7.891^{* * *} \\
(1.498)\end{array}$ & $11.4 \%$ & 10,934 \\
\hline (xiii) & $12 B-1$ & $\begin{array}{c}-0.268^{* *} \\
(0.098)\end{array}$ & & & & $0.8 \%$ & 10,934 \\
\hline (xiv) & $12 B-1$ & $\begin{array}{c}-0.273^{* *} \\
(0.098)\end{array}$ & $\begin{array}{c}-1.457^{*} \\
(0.711)\end{array}$ & & & $1.1 \%$ & 10,934 \\
\hline$(\mathrm{xv})$ & $12 B-1$ & $\begin{array}{c}-0.192^{* *} \\
(0.083)\end{array}$ & $\begin{array}{c}-1.586^{* *} \\
(0.627)\end{array}$ & $\begin{array}{c}-21.568^{* * *} \\
(6.490)\end{array}$ & & $1.9 \%$ & 10,934 \\
\hline (xvi) & $12 B-1$ & $\begin{array}{c}-0.195^{* *} \\
(0.085)\end{array}$ & $\begin{array}{l}-1.895 \\
(2.912)\end{array}$ & $\begin{array}{c}-25.395^{* * *} \\
(7.025)\end{array}$ & $\begin{array}{c}0.130 \\
(0.827)\end{array}$ & $2.3 \%$ & 10,934 \\
\hline (xvii) & MKTING & $\begin{array}{c}-0.368^{* *} \\
(0.164)\end{array}$ & & & & $0.7 \%$ & 10,934 \\
\hline (xviii) & MKTING & $\begin{array}{l}-0.180 \\
(0.177)\end{array}$ & $\begin{array}{c}3.146 \\
(4.032)\end{array}$ & & & $3.3 \%$ & 10,934 \\
\hline$(\mathrm{xix})$ & MKTING & $\begin{array}{c}0.072 \\
(0.276)\end{array}$ & $\begin{array}{c}3.730 \\
(5.073)\end{array}$ & $\begin{array}{c}-66.705^{* *} \\
(30.169)\end{array}$ & & $4.5 \%$ & 10,934 \\
\hline$(\mathrm{xx})$ & MKTING & $\begin{array}{c}0.124 \\
(0.279)\end{array}$ & $\begin{array}{l}-33.311 \\
(22.718)\end{array}$ & $\begin{array}{c}-74.537^{* *} \\
(32.926)\end{array}$ & $\begin{array}{l}10.344 \\
(7.475)\end{array}$ & $3.8 \%$ & 10,934 \\
\hline
\end{tabular}




\section{SUPPLEMENTARY APPENDIX FOR “THE IMPACT OF IDIOSYNCRATIC RISK ON MUTUAL FUND FEES"}

\section{A. Data: Sample Selection and Descriptive Statistics}

\section{A.1 Investment Objectives, Policy Codes, and Share Classes}

Since CRSP uses different providers of mutual fund investment objectives at different times, we combine the information supplied by a number of different providers to stratify our sample according to the investment objective codes of its constituent funds. In particular, we used the Wiesenberger objective codes "GCI," "LTG," "MCG," and "SCG," for the period from 1990 to 1992; the Standard \& Poor's detailed objective codes "AGG," "GRI," "GRO," "ING," "SCG," and "GMC" for the period from 1993 to 1998; and the Lipper investment objective codes of "G," "GI," "LSE," "MC," "MR," and "SG" for the period from 1998 to 2007. We removed funds whose names contained strings that were inconsistent with our selected policy codes. The following filters were employed for this purpose: "B\&P," "Bal," "Bonds," "C\&I," "GS," "Leases," "MM," and "TFM." Collectively, the filters based on policy codes contributed to the elimination of 353 fund share classes from the sample. In addition, we separated the mutual funds in our sample into their various share classes, by recursively searching for share class identifiers in their names. This name search is necessary as CRSP does not provide a fund share class identifier before the year 2003. In addition to the automated procedure for separating funds into share classes, based on the class identifier in their names, we also carefully check by-hand their classification. This manual check increased the size of the final sample by about $3 \%$.

\section{A.2 Index Funds and Institutional Funds}

The CRSP database does not provide a flag for distinguishing between passively-managed funds and actively-managed funds before June 2008. To overcome this obstacle, we exclude from the final sample all funds whose names contain the following strings: "Index," "Idx," "Ix," "Indx," "Nasdaq," "Dow," "Mkt," "DJ," "S\&P," "Barra," "100," "400," "500," "1000," "ETF," "Exchange," "Vanguard," and "Balanced.". The task of removing institutional funds is partly facilitated by the fact that the CRSP database provides a flag for identifying institutional funds. However, since this flag is not sufficient as it is sometimes missing in the CRSP dataset, we exclude all funds whose names contain the following strings: "/Y," "/I," "Class Y," and "Class I." In total, the process of filtering out index funds and institutional funds by coding the mutual fund names further reduced the size of our sample by 2,369 fund share classes. 


\section{A.3 Descriptive Statistics}

In Supplement Table I we present the summary statistics of our sample of U.S. diversified equity mutual funds. The values reported there agree with the findings of previous studies, and describe our sample prior to the elimination of funds with fewer than 36 months of observations. Those funds were subsequently removed to decrease the likelihood of our results being affected by incubation funds (see Evans (2010)).

The average TNA of the funds in our sample is around $\$ 860$ million, with a standard deviation of approximately $\$ 3.6$ billion, and their average age is almost 10 years in excess of their first filing with the SEC, with a percentile deviation between 4 years and 67 years. We observe that the number of funds per family (NFNDFAM) has a skewed distribution, due to the prevalence of single-fund families; the average family contains about 24 funds.

With respect to fees, we see that the average management fee $(M G M T)$ for the funds in our sample is $1.12 \%$, with a standard deviation of $0.40 \%$, while fund total operating expenses average $1.56 \%$, with a standard deviation of $0.55 \%$. These figures are based on 29,553 fund-year observations.

The statistics for Carhart (1997) expected risk-adjusted after-fee returns (NPERF) in Supplement Table I suggest that mutual funds under-perform their benchmarks to the extent of their fees, on average (see e.g. Carhart (1997), Wermers (2000), Kosowski, Timmermann, Wermers, and White (2006), and Fama and French (2010)). Similar statistics are provided for the CAPM, for comparison. We also observe that although a small number of funds appear to deliver positive after-fee performance, their impact is overwhelmed by poor performers.

According to Supplement Table I, the average before-fee idiosyncratic volatility (IDVOL) of the funds in our sample is $1.6 \%$, with a standard deviation of $1.18 \%$. Comparing the average idiosyncratic volatility with the average total volatility of $4.33 \%$ suggests that the funds in our sample are not particularly well-diversified. 


\section{Supplement Table. I \\ Summary Statistics}

This table presents descriptive statistics for our sample of diversified U.S. equity mutual funds, for the period from 1994 to 2007. We provide descriptive statistics for the following fund and family characteristics: fund total net assets, in \$ million (FNDTNA); fund family total net assets, in \$ billion (FAMTNA); fund age, expressed as years since inception (FNDAGE); the average number of funds per family (NFNDFAM); fund portfolio turnover (TRNOVR); annual management fees, calculated as the difference between total operating expenses and $12 \mathrm{~b}-1$ fees (MGMT); annual total operating expenses (OPEX); fund annual after-fee returns (RETRN); and the volatility of fund returns over the previous 12 months (VOL); and the average active share of fund portfolio (ACTIVESHR) which is computed as half of the difference between the holdings of a mutual fund and the holdings of its benchmark (see Cremers and Petajisto (2009) for more details on the construction of this variable). We estimate the intercepts for the CAPM model $\left(N P E R F_{C A P M}\right)$ and the Carhart (1997) model (NPERF), as proxies for fund risk-adjusted returns. The levels of systematic risk of funds are measured by the estimated betas for the CAPM model $\left(B E T A_{C A P M}\right)$ and the Carhart (1997) model (BETA). Finally, the idiosyncratic volatilities of funds are expressed as the standard devitions of the previous 36 monthly residuals for the CAPM (IDVOL $\left.L_{C A P M}\right)$ and the Carhart (1997) model (IDVOL).

\begin{tabular}{|c|c|c|c|c|c|c|c|c|}
\hline & \multirow[b]{2}{*}{ Obs. } & \multirow[b]{2}{*}{ Mean } & \multirow[b]{2}{*}{ Std.Dev. } & \multicolumn{5}{|c|}{ Percentiles } \\
\hline & & & & $1 \%$ & $25 \%$ & $50 \%$ & $75 \%$ & $99 \%$ \\
\hline FNDTNA & 29,482 & 856.5 & $3,663.6$ & 0.4 & 22.6 & 99.3 & 441.1 & $13,408.9$ \\
\hline FNDAGE & 29,491 & 10.10 & 1.95 & 4.00 & 6.00 & 8.83 & 14.00 & 66.83 \\
\hline FAMTNA & 29,656 & 21.96 & 72.40 & 0.00 & 0.00 & 1.31 & 10.81 & 426.44 \\
\hline NFNDFAM & 29,656 & 23.75 & 29.59 & 1.00 & 1.00 & 12.00 & 37.00 & 135.00 \\
\hline TRNOVR & 29,377 & 0.92 & 1.03 & 0.03 & 0.38 & 0.69 & 1.16 & 4.40 \\
\hline$N P E R F_{C A P M}$ & 29,656 & -0.56 & 7.20 & -19.11 & -4.26 & -0.96 & 2.43 & 20.44 \\
\hline NPERF & 29,656 & -1.36 & 5.43 & -15.81 & -3.87 & -1.42 & 1.08 & 14.24 \\
\hline RETRN & 29,656 & 8.67 & 19.52 & -41.88 & -0.34 & 9.59 & 18.74 & 62.15 \\
\hline$M G M T$ & 29,553 & 1.12 & 0.40 & 0.22 & 0.90 & 1.08 & 1.29 & 2.50 \\
\hline OPEX & 29,553 & 1.56 & 0.55 & 0.45 & 1.15 & 1.50 & 1.98 & 2.96 \\
\hline VOL & 29,656 & 4.20 & 2.29 & 1.04 & 2.69 & 3.66 & 5.16 & 12.68 \\
\hline ACTIVESHR & 14,037 & 75.99 & 15.77 & 35.10 & 65.10 & 78.40 & 89.50 & 98.20 \\
\hline$B E T A_{C A P M}$ & 29,656 & 0.99 & 0.34 & 0.09 & 0.81 & 0.97 & 1.17 & 1.91 \\
\hline BETA & 29,656 & 0.97 & 0.24 & 0.12 & 0.88 & 0.98 & 1.07 & 1.56 \\
\hline$I D V O L_{C A P M}$ & 29,656 & 2.27 & 1.66 & 0.46 & 1.16 & 1.80 & 2.87 & 8.55 \\
\hline IDVOL & 29,656 & 1.57 & 1.18 & 0.37 & 0.88 & 1.26 & 1.89 & 6.61 \\
\hline
\end{tabular}

\section{B. Idiosyncratic Volatility and Fund Characteristics}

In Supplement Table II we examine the characteristics of funds grouped according to their Strategic Insights investment objective codes of "ING", "GRI", "GRO", "GMS", "SCG", and "AGG". We repeat the analysis using the CDA Spectrum investment objective codes of "Growth \& Income", "Growth", and "Aggressive Growth". In Supplement Table III we summarize the average fund characteristics and factor loadings of quintile portfolios of funds sorted by IDVOL. We then compute the return of each portfolio as the equally-weighted average return of all constituent funds over the next month after portfolio formation to guard against potential endogeneity issues. On the resulting time series of monthly portfolio returns we run the Carhart (1997) factor model. Our findings remain qualitatively similar when we consider decile portfolios of sorted IDVOL. 


\section{Supplement Table. II}

\section{Fund Idiosyncratic Volatility and Investment Objective Categories}

In this table we report some descriptive statistics for our sample of US diversified equity mutual funds from 1994 to 2007. In Panel A we separate fund descriptive statistics by investment objectives using the following Strategic Insights Codes: "ING", "GRI", "GRO", "GMS", "SCG", and "AGG". We repeat the analysis using the following CDA Spectrum Codes: "Growth \& Income" [4], "Growth" [3], and "Aggressive Growth" [2]. For each investment objective code we then calculate the following average fund characteristics: fund idiosyncratic volatility estimated using the CAPM model (IDVOL (capm)); fund idiosyncratic volatility estimated using the Carhart (1997) four-factor model (IDVOL (4-factor)); within-objective standard deviation of fund idiosyncratic volatility (IDVOL StdDev); fund portfolio turnover (TRNOVR); percentage annual management fees (MGMT) computed as the difference between fund total operating expenses and $12 \mathrm{~b}-1$ fees; percentage annual total operating expenses (OPEX); total fund TNA in \$billion (Fund TNA); fund age (in years) since its inception (Fund Age); and average active share of fund portfolio (ACTIVE SHR) which is computed as half of the difference between the holdings of a mutual fund and the holdings of its benchmark (see Cremers and Petajisto (2009) for more details on the construction of this variable). To measure the degree of competition within each objective code we also compute the Herfindahl index (HINDEX). A lower HINDEX would be associated with a greater level of competition in the objective code.

\begin{tabular}{|c|c|c|c|c|c|c|c|c|c|c|c|}
\hline & $\begin{array}{l}\text { Num } \\
\text { Funds }\end{array}$ & $\begin{array}{l}I D V O L \\
\text { (capm) }\end{array}$ & $\begin{array}{c}I D V O L \\
(4 \text {-factor) }\end{array}$ & $\begin{array}{l}\text { IDVOL } \\
\text { StdDev }\end{array}$ & $\begin{array}{c}\text { TRNOVR } \\
\quad \text { (p.a.) }\end{array}$ & $\begin{array}{c}M G M T \\
\text { (in \%) }\end{array}$ & $\begin{array}{l}\text { OPEX } \\
\text { (in \%) }\end{array}$ & $\begin{array}{l}\text { Fund } \\
\text { TNA }\end{array}$ & $\begin{array}{c}\text { Fund } \\
\text { Age }\end{array}$ & $\begin{array}{c}\text { ACTIVE } \\
\text { SHR }\end{array}$ & $\begin{array}{c}H I N D E X \\
\text { (in \%) }\end{array}$ \\
\hline \multicolumn{12}{|c|}{ Strategic Insights Objective Codes } \\
\hline Income \& Growth (ING) & 185 & 1.47 & 1.01 & 0.35 & 0.66 & 0.89 & 1.34 & 1.23 & 11.72 & 73.70 & 6.22 \\
\hline Growth \& Income (GRI) & 545 & 1.48 & 1.07 & 0.55 & 0.73 & 0.99 & 1.34 & 1.01 & 15.06 & 69.89 & 3.87 \\
\hline Growth (GRO) & 941 & 1.88 & 1.43 & 0.82 & 0.87 & 1.11 & 1.43 & 0.81 & 12.50 & 76.15 & 2.79 \\
\hline MidCaps Growth (GMC) & 172 & 2.73 & 1.86 & 0.75 & 1.14 & 1.11 & 1.49 & 0.69 & 9.64 & 85.28 & 6.21 \\
\hline Small Cap Growth (SCG) & 425 & 2.96 & 1.87 & 0.67 & 0.92 & 1.22 & 1.53 & 0.36 & 8.66 & 91.35 & 3.50 \\
\hline Aggressive Growth (AGG) & 217 & 3.17 & 2.11 & 1.36 & 1.37 & 1.28 & 1.68 & 0.44 & 11.25 & 84.38 & 5.66 \\
\hline \multicolumn{12}{|c|}{ CDA Spectrum Objective Codes } \\
\hline Growth \& Income [4] & 718 & 1.51 & 1.08 & 0.49 & 0.68 & 0.87 & 1.39 & 1.07 & 13.8 & 65.27 & 4.51 \\
\hline Growth [3] & 2,181 & 2.21 & 1.57 & 0.89 & 0.93 & 1.17 & 1.52 & 0.49 & 9.5 & 77.86 & 3.45 \\
\hline Aggressive Growth [2] & 367 & 3.36 & 2.23 & 1.04 & 1.15 & 1.26 & 1.63 & 0.58 & 12.7 & 85.99 & 5.23 \\
\hline
\end{tabular}




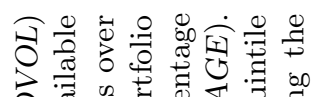

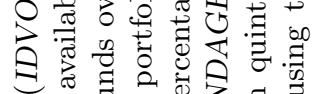

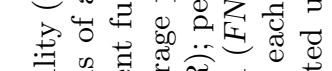

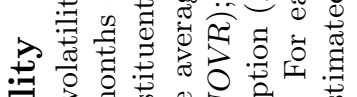
吾范

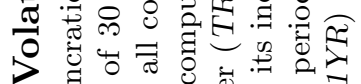

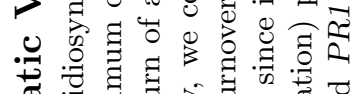
ช.

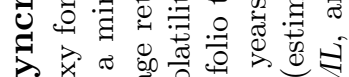

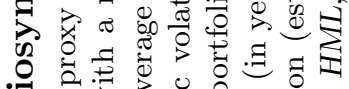
元 ○

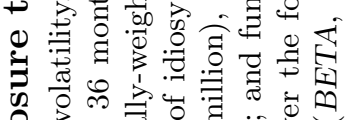
of

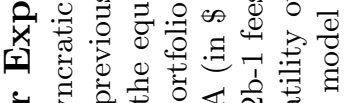

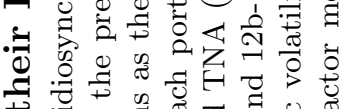

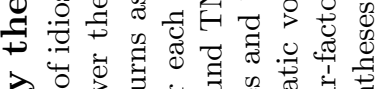

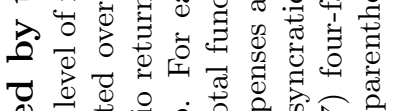

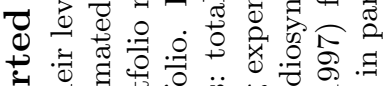

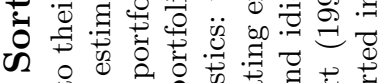
o

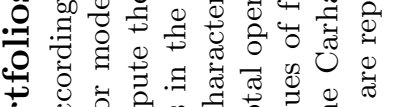

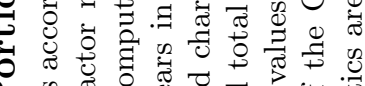

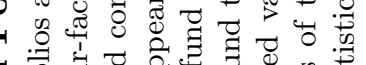

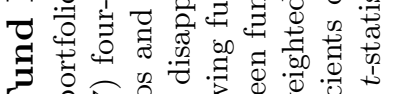
仝:。

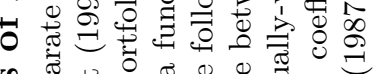
U .0.

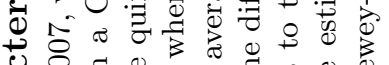

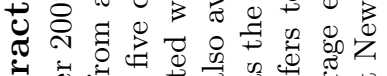

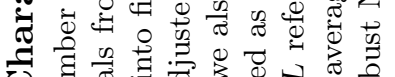
उ

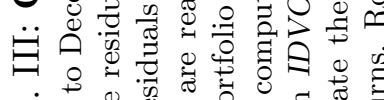

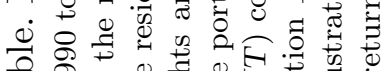

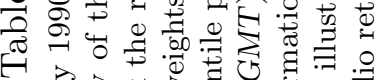

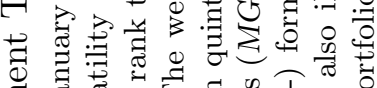

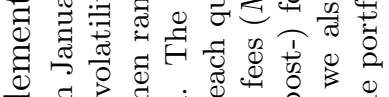

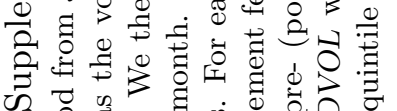

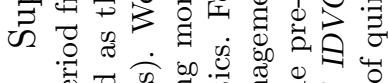

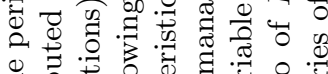

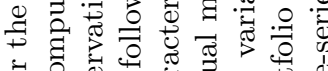

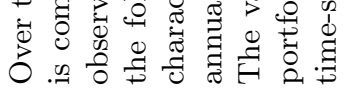

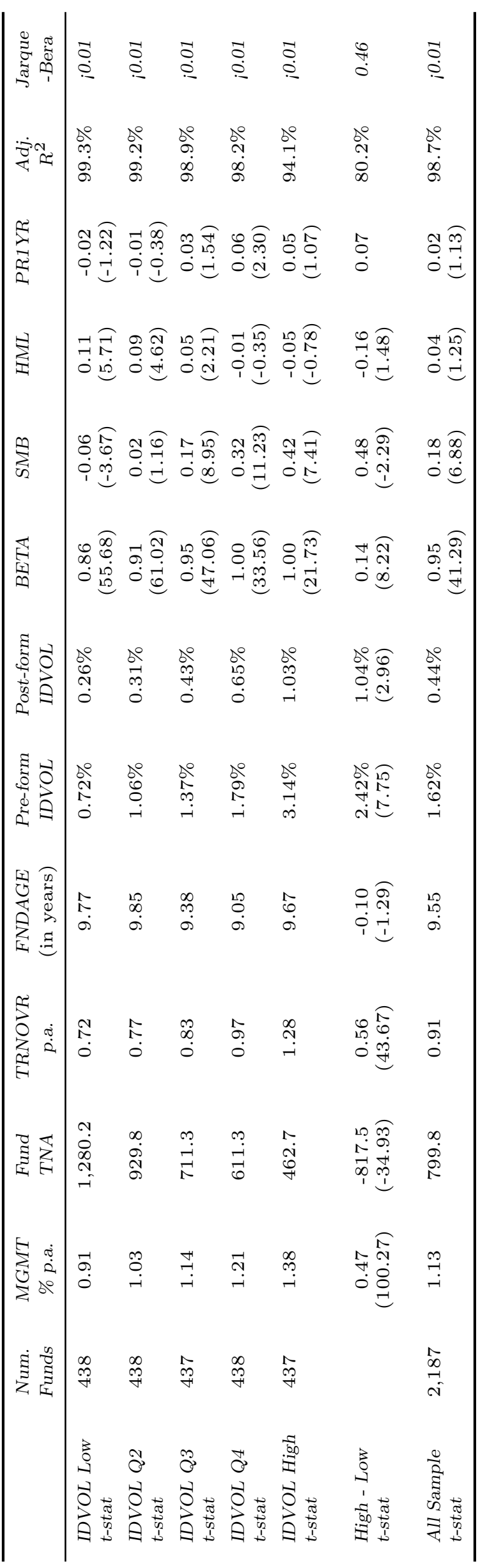




\section{Additional Tests}

Supplement Table IV illustrates the cross-sectional relationship between management fees (MGMT)and idiosyncratic volatilities in each year of our sample period from 1994 to 2007. Specifically, we sort funds in each year based on lagged fund idiosyncratic volatility estimated using the unconditional Carhart (1997) four-factor model (IDIOVOL) and allocate them to decile portfolios. Decile 1 (Decile 10) comprises funds with the lowest (highest) IDIOVOL. We then average MGMT within each decile portfolios of IDIOVOL. It is interesting to notice the existence of a remarkable stability in the level of management fees across years within each portfolio.

\section{** INSERT SUPPLEMENT TABLE IV HERE **}

Supplement Table V provides another insight into the implications of the U-shaped relationship between fund idiosyncratic risk and performance discussed in Section II and illustrated in Figure ?? of our paper. We compute the transition probabilities of fund performance, conditional on decile portfolios of idiosyncratic risk, IDVOL. Our evidence highlights that the percentage of funds persisting in the middle performance ranking $\left[P_{2, t-1} ; P_{2, t}\right]$ decreases monotonically from $31.2 \%$ for Decile 1 to just $2.82 \%$ for Decile 10 . Indeed, for the high idiosyncratic volatility portfolio (Decile 10), a greater proportion of funds tend to cluster in the tails of performance distribution. Specifically, the likelihood of funds jumping from one tail of the performance distribution to the other (either $\left[P_{1, t-1} ; P_{3, t}\right]$ or $\left[P_{3, t-1} ; P_{1, t}\right]$ ) increases in the level of IDVOL.

\section{** INSERT SUPPLEMENT TABLE V HERE **}

In Supplement Table VI we illustrate the degree of reduction in the flow-performance sensitivity caused by higher fund idiosyncratic volatility as discussed in Section IV of our paper. Higher levels of idiosyncratic noise are associated with a reduction in investors' response to fund's recent performance as indicated by the monotonically decreasing sensitivity of flows to the interaction term between NPERF and dummy variables for quintile portfolios of sorted IDVOL. This evidence is consistent with the volatility dampening effect recently documented by Huang, Wei, and Yan (2012).

\section{** INSERT SUPPLEMENT TABLE VI HERE **}




\section{Supplement Table. IV}

\section{Management Fees Versus Idiosyncratic Volatility Over Time}

This table reports average management fees for decile portfolios of idiosyncratic volatility, for the period from 1994 to 2007. Decile 1 consists of the funds with the lowest idiosyncratic volatilities, while the funds with the highest idiosyncratic volatilities are in Decile 10. We also report the inter-quartile range (IQR) and the difference between the average management fees charged by the funds in the top decile portfolio and the bottom decile portfolio (Dec10 - Dec1). These differences are significant at the $5 \%$ level.

\begin{tabular}{lccccccccccccccc}
\hline & Decile & Decile & Decile & Decile & Decile & Decile & Decile & Decile & Decile & Decile & IQR & Dec10 \\
& 1 & 2 & 3 & 4 & 5 & 6 & 7 & 8 & 9 & 10 & - Dec1 \\
\hline 1994 & 0.87 & 0.94 & 1.00 & 1.07 & 1.20 & 1.13 & 1.21 & 1.27 & 1.40 & 1.54 & 0.24 & 0.67 \\
1995 & 0.87 & 0.97 & 0.94 & 1.09 & 1.15 & 1.20 & 1.16 & 1.30 & 1.32 & 1.52 & 0.28 & 0.65 \\
1996 & 0.86 & 0.99 & 1.02 & 1.04 & 1.18 & 1.17 & 1.23 & 1.19 & 1.33 & 1.56 & 0.20 & 0.70 \\
1997 & 0.90 & 0.98 & 1.03 & 1.06 & 1.12 & 1.18 & 1.16 & 1.24 & 1.25 & 1.50 & 0.19 & 0.60 \\
1998 & 0.86 & 0.93 & 0.96 & 0.99 & 1.12 & 1.09 & 1.10 & 1.22 & 1.26 & 1.44 & 0.23 & 0.58 \\
1999 & 0.85 & 0.91 & 1.02 & 1.05 & 1.09 & 1.12 & 1.10 & 1.23 & 1.25 & 1.45 & 0.18 & 0.60 \\
2000 & 0.87 & 0.91 & 1.00 & 1.05 & 1.04 & 1.14 & 1.18 & 1.15 & 1.25 & 1.45 & 0.16 & 0.58 \\
2001 & 0.82 & 0.99 & 0.99 & 1.02 & 1.06 & 1.09 & 1.17 & 1.16 & 1.19 & 1.39 & 0.17 & 0.57 \\
2002 & 0.82 & 0.99 & 0.99 & 1.02 & 1.12 & 1.15 & 1.16 & 1.19 & 1.27 & 1.38 & 0.19 & 0.56 \\
2003 & 0.89 & 1.04 & 1.00 & 1.06 & 1.14 & 1.19 & 1.24 & 1.23 & 1.25 & 1.49 & 0.19 & 0.60 \\
2004 & 0.86 & 1.01 & 1.07 & 1.11 & 1.20 & 1.19 & 1.32 & 1.28 & 1.32 & 1.52 & 0.23 & 0.66 \\
2005 & 0.83 & 0.98 & 1.00 & 1.04 & 1.13 & 1.14 & 1.23 & 1.26 & 1.28 & 1.45 & 0.24 & 0.62 \\
2006 & 0.83 & 0.97 & 1.00 & 1.03 & 1.10 & 1.14 & 1.16 & 1.26 & 1.26 & 1.44 & 0.23 & 0.61 \\
2007 & 0.78 & 0.89 & 1.02 & 1.00 & 1.06 & 1.11 & 1.12 & 1.19 & 1.22 & 1.32 & 0.17 & 0.54 \\
$1994-2007$ & 0.85 & 0.96 & 1.00 & 1.05 & 1.12 & 1.15 & 1.18 & 1.23 & 1.28 & 1.46 & 0.20 & 0.61 \\
\hline
\end{tabular}




\section{Supplement Table. V}

\section{Annual Transition Probabilities of Mutual Fund Performance Conditional on the Level of Idiosyncratic Volatility}

The table documents the inter-tercile transition probabilities (in percentage) of fund annual realized (after-fee) returns conditional on the level of their idiosyncratic volatility (IDVOL). In each year, we first rank funds based on their level of idiosyncratic volatility and allocate them to decile portfolios. Decile 1 (Decile 10) is a portfolio of funds with the lowest (highest) level of fund idiosyncratic volatility. We then sort and separate fund annual realized returns in three tercile portfolios, $P_{1}, P_{2}$, and $P_{3}$, with portfolio $P_{1}\left(P_{3}\right)$ comprising funds with the worst (best) annual performance. The sample is subsequently divided in nine groups based on the year-on-year inter-tercile performance transition. For instance, a fund moving from the lowest tercile portfolio $\left(P_{1, t-1}\right)$ to the highest tercile portfolio $\left(P_{3, t}\right)$ from year $t-1$ to year $t$ is indicated as $\left[P_{1, t-1} ; P_{3, t}\right]$. For each decile portfolio of idiosyncratic volatility we then compute the distribution of fund transition probabilities. We also document the number of funds that populate each decile together with the interquartile ranges ( $I$ - $Q$ range ) and the differences in transition probabilities between the top and the bottom deciles of IDVOL (Dec10 - Dec1). In Panel B, we repeat this analysis by computing the fund transition probabilities from year $t-2$ to year $t$.

\begin{tabular}{|c|c|c|c|c|c|c|c|c|c|c|}
\hline & $\begin{array}{l}\text { Num. } \\
\text { obs. }\end{array}$ & $\begin{array}{l}{\left[P_{1, t-1}\right.} \\
\left.\quad P_{1, t}\right]\end{array}$ & $\begin{array}{c}{\left[P_{1, t-1}\right.} \\
\left.\quad P_{2, t}\right]\end{array}$ & $\begin{array}{l}{\left[P_{1, t-1} ;\right.} \\
\left.\quad P_{3, t}\right]\end{array}$ & $\begin{array}{l}{\left[P_{2, t-1}\right.} \\
\left.\quad P_{1, t}\right]\end{array}$ & $\begin{array}{c}{\left[P_{2, t-1}\right.} \\
\left.\quad P_{2, t}\right]\end{array}$ & $\begin{array}{c}{\left[P_{2, t-1} ;\right.} \\
\left.\quad P_{3, t}\right]\end{array}$ & $\begin{array}{c}{\left[P_{3, t-1}\right.} \\
\left.\quad P_{1, t}\right]\end{array}$ & $\begin{array}{c}{\left[P_{3, t-1}\right.} \\
\left.\quad P_{2, t}\right]\end{array}$ & $\begin{array}{c}{\left[P_{3, t-1}\right.} \\
\left.\quad P_{3, t}\right]\end{array}$ \\
\hline & & (i) & (ii) & (iii) & (iv) & (v) & (vi) & (vii) & (viii) & (ix) \\
\hline Decile 1 & 3,261 & 9.41 & 13.03 & 3.77 & 14.19 & 31.18 & 7.11 & 4.69 & 8.43 & 8.19 \\
\hline Decile 2 & 3,257 & 12.80 & 11.18 & 4.21 & 14.06 & 22.08 & 9.89 & 5.43 & 11.67 & 8.69 \\
\hline Decile 3 & 3,263 & 14.47 & 10.09 & 6.41 & 12.75 & 17.96 & 11.01 & 6.65 & 9.96 & 10.70 \\
\hline Decile 4 & 3,257 & 14.37 & 9.92 & 6.75 & 12.19 & 13.79 & 11.08 & 6.54 & 11.15 & 14.22 \\
\hline Decile 5 & 3,261 & 13.58 & 8.80 & 7.02 & 9.01 & 13.24 & 10.73 & 9.04 & 12.07 & 16.52 \\
\hline Decile 6 & 3,259 & 12.92 & 9.42 & 9.73 & 10.56 & 9.63 & 10.52 & 8.41 & 10.65 & 18.17 \\
\hline Decile 7 & 3,258 & 13.57 & 9.18 & 9.64 & 10.68 & 8.75 & 10.59 & 10.68 & 8.66 & 18.26 \\
\hline Decile 8 & 3,263 & 14.81 & 9.14 & 12.02 & 9.38 & 7.66 & 10.15 & 11.31 & 10.36 & 15.17 \\
\hline Decile 9 & 3,268 & 14.30 & 9.92 & 11.48 & 7.96 & 5.51 & 9.92 & 14.79 & 8.48 & 17.64 \\
\hline Decile 10 & 3,258 & 22.58 & 7.55 & 14.97 & 5.43 & 2.82 & 6.29 & 16.94 & 6.66 & 16.75 \\
\hline$I-Q$ range & & 1.36 & 0.90 & 4.55 & 3.51 & 8.99 & 0.80 & 4.59 & 2.50 & 5.84 \\
\hline $10-1$ & & 13.17 & -5.48 & 11.20 & -8.76 & $\begin{array}{c}- \\
28.36\end{array}$ & -0.82 & 12.25 & -1.77 & 8.56 \\
\hline
\end{tabular}

\begin{tabular}{|c|c|c|c|c|c|c|c|c|c|c|}
\hline & $\begin{array}{c}\text { Num. } \\
\text { obs. }\end{array}$ & $\begin{array}{c}{\left[P_{1, t-2}\right.} \\
\left.\quad P_{1, t}\right]\end{array}$ & $\begin{array}{l}{\left[P_{1, t-2} ;\right.} \\
\left.\quad P_{2, t}\right]\end{array}$ & $\begin{array}{l}{\left[P_{1, t-2}\right.} \\
\left.\quad P_{3, t}\right]\end{array}$ & $\begin{array}{c}{\left[P_{2, t-2}\right.} \\
\left.\quad P_{1, t}\right]\end{array}$ & $\begin{array}{c}{\left[P_{2, t-2}\right.} \\
\left.\quad P_{2, t}\right]\end{array}$ & $\begin{array}{l}{\left[P_{2, t-2}\right.} \\
\left.\quad P_{3, t}\right]\end{array}$ & $\begin{array}{c}{\left[P_{3, t-2}\right.} \\
\left.\quad P_{1, t}\right]\end{array}$ & $\begin{array}{c}{\left[P_{3, t-2}\right.} \\
\left.\quad P_{2, t}\right]\end{array}$ & $\begin{array}{c}{\left[P_{3, t-2}\right.} \\
\left.\quad P_{3, t}\right]\end{array}$ \\
\hline & & (i) & (ii) & (iii) & (iv) & (v) & (vi) & (vii) & (viii) & (ix) \\
\hline Decile 1 & 3,004 & 9.55 & 12.45 & 4.46 & 13.98 & 30.39 & 9.45 & 4.73 & 9.62 & 5.36 \\
\hline Decile 2 & 3,025 & 11.31 & 12.13 & 3.97 & 15.57 & 20.96 & 10.74 & 6.05 & 11.44 & 7.83 \\
\hline Decile 3 & 3,043 & 12.65 & 10.12 & 7.69 & 12.91 & 17.35 & 10.71 & 8.31 & 10.22 & 10.02 \\
\hline Decile 4 & 3,028 & 10.96 & 9.68 & 7.83 & 11.36 & 14.00 & 12.09 & 10.14 & 11.33 & 12.62 \\
\hline Decile 5 & 3,032 & 10.32 & 8.34 & 8.15 & 10.69 & 12.76 & 11.38 & 10.62 & 12.90 & 14.84 \\
\hline Decile 6 & 3,032 & 10.39 & 8.71 & 11.31 & 9.80 & 10.09 & 11.54 & 11.51 & 11.05 & 15.60 \\
\hline Decile 7 & 3,008 & 12.30 & 8.51 & 12.27 & 10.80 & 7.81 & 11.07 & 11.77 & 10.24 & 15.23 \\
\hline Decile 8 & 3,014 & 14.07 & 9.42 & 12.08 & 8.16 & 7.80 & 9.95 & 12.74 & 10.25 & 15.53 \\
\hline Decile 9 & 3,036 & 13.41 & 8.23 & 13.67 & 7.58 & 4.94 & 8.14 & 16.34 & 10.77 & 16.93 \\
\hline Decile 10 & 3,032 & 19.06 & 7.59 & 15.70 & 6.46 & 2.87 & 6.04 & 19.36 & 6.13 & 16.79 \\
\hline$I-Q$ range & & 2.69 & 1.63 & 4.50 & 3.95 & 8.71 & 1.73 & 3.73 & 1.04 & 4.91 \\
\hline $10-1$ & & 9.51 & -4.86 & 11.24 & -7.52 & $\begin{array}{c}- \\
27.52\end{array}$ & -3.41 & 14.63 & -3.49 & 11.43 \\
\hline
\end{tabular}




\section{Supplement Table. VI \\ The Dampening Effect of Fund Idiosyncratic Volatility on the Flow-Performance Relationship}

This table reports the results of the regression of investors net money flows on fund performance with and without controlling for the extent of idiosyncratic risk-taking in the period from January 1994 to December 2007. The dependent variable is the yearly percentage growth rate in fund net money flows (Flows). Lagged control variables include: logarithm of fund TNA (FNDSIZE); logarithm of family TNA (FAMSIZE); logarithm of the number of months since fund inception (FNDAGE); aggregate sales or purchases of securities (TRNOVR); volatility of the previous 12-month returns (VOL); number of funds in the family (NFNDFAM); mutual fund performance represented by the intercept of the unconditional Carhart (1997) four-factor model (NPERF); and fund total operating expenses (OPEX). To capture the non-linearity in the flow-performance relationship, in column (ii) we separate fund performance using the Sirri and Tufano (1998) piece-wise fractional rankings of performance (LOWPERF, MEDPERF, HIGHPERF). We also control for the sensitivity of the dependent variable to different levels of idiosyncratic risk-taking by using dummies of quintile portfolios of sorted fund idiosyncratic volatility, where the dummy $I D V O L_{Q 1}$ equals 1 for funds in the quintile portfolio of low idiosyncratic volatility, while the dummy $I D V O L_{Q 5}$ equals 1 for funds in the quintile portfolio of high idiosyncratic volatility. We illustrate the results of different estimation models: Fama-Macbeth $(F-M)$ with Newey-West standard errors, Fixed-Effect $(F-$ $E)$ with standard errors clustered by fund and time, and Random-Effect $(R-E)$ with standard errors clustered by fund. All standard errors are reported in parentheses. One, two and three asterisks indicate statistical significance at the $10 \%, 5 \%$, and $1 \%$ level, respectively.

\begin{tabular}{|c|c|c|c|c|c|c|}
\hline & (i) & (ii) & (iii) & (iv) & (v) & (vi) \\
\hline NPERF & $\begin{array}{c}1.646^{* * *} \\
(0.143)\end{array}$ & & $\begin{array}{c}1.738^{* * *} \\
(0.148)\end{array}$ & $\begin{array}{c}2.988^{* * *} \\
(0.307)\end{array}$ & $\begin{array}{c}2.633^{* * *} \\
(0.288)\end{array}$ & $\begin{array}{c}2.409^{* * *} \\
(0.216)\end{array}$ \\
\hline LOWPERF & & $\begin{array}{c}0.432^{* * *} \\
(0.092)\end{array}$ & & & & \\
\hline MEDPERF & & $\begin{array}{c}0.357^{* * *} \\
(0.074)\end{array}$ & & & & \\
\hline HIGHPERF & & $\begin{array}{c}1.528^{* * *} \\
(0.139)\end{array}$ & & & & \\
\hline$N P E R F * I D V O L_{Q 2}$ & & & & $\begin{array}{c}-0.376 \\
(0.422)\end{array}$ & $\begin{array}{c}-0.257 \\
(0.231)\end{array}$ & $\begin{array}{l}-0.291 \\
(0.228)\end{array}$ \\
\hline$N P E R F * I D V O L_{Q 3}$ & & & & $\begin{array}{l}-0.534 \\
(0.373)\end{array}$ & $\begin{array}{l}-0.379 \\
(0.376)\end{array}$ & $\begin{array}{l}-0.331 \\
(0.238)\end{array}$ \\
\hline$N P E R F * I D V O L_{Q 4}$ & & & & $\begin{array}{c}-1.144^{* * *} \\
(0.201)\end{array}$ & $\begin{array}{c}-1.055^{* * *} \\
(0.371)\end{array}$ & $\begin{array}{c}-1.076^{* * *} \\
(0.234)\end{array}$ \\
\hline$N P E R F * I D V O L_{Q 5}$ & & & & $\begin{array}{c}-1.572^{* * *} \\
(0.439)\end{array}$ & $\begin{array}{c}-1.717^{* * *} \\
(0.263)\end{array}$ & $\begin{array}{c}-1.604^{* * *} \\
(0.221)\end{array}$ \\
\hline IDVOL & & & $\begin{array}{c}0.411 \\
(1.364)\end{array}$ & $\begin{array}{c}-0.276 \\
(1.262)\end{array}$ & $\begin{array}{c}1.261 \\
(1.085)\end{array}$ & $\begin{array}{c}0.253 \\
(0.525)\end{array}$ \\
\hline FNDSIZE & $\begin{array}{c}-0.025^{* * *} \\
(0.004)\end{array}$ & $\begin{array}{c}-0.038^{* * *} \\
(0.005)\end{array}$ & $\begin{array}{c}-0.025^{* * *} \\
(0.004)\end{array}$ & $\begin{array}{c}-0.027^{* * *} \\
(0.004)\end{array}$ & $\begin{array}{c}-0.025^{* * *} \\
(0.004)\end{array}$ & $\begin{array}{c}-0.043^{* * *} \\
(0.003)\end{array}$ \\
\hline FNDAGE & $\begin{array}{c}-0.049^{* * *} \\
(0.006)\end{array}$ & $\begin{array}{c}-0.082^{* * *} \\
(0.008)\end{array}$ & $\begin{array}{c}-0.050^{* * *} \\
(0.004)\end{array}$ & $\begin{array}{c}-0.048^{* * *} \\
(0.005)\end{array}$ & $\begin{array}{c}-0.061^{* * *} \\
(0.006)\end{array}$ & $\begin{array}{c}-0.072^{* * *} \\
(0.006)\end{array}$ \\
\hline FAMSIZE & $\begin{array}{c}0.002 \\
(0.004)\end{array}$ & $\begin{array}{c}0.004 \\
(0.003)\end{array}$ & $\begin{array}{c}0.002 \\
(0.004)\end{array}$ & $\begin{array}{c}0.002 \\
(0.003)\end{array}$ & $\begin{array}{c}0.004^{* * *} \\
(0.001)\end{array}$ & $\begin{array}{c}0.004^{* * *} \\
(0.001)\end{array}$ \\
\hline NFNDFAM & $\begin{array}{c}0.001 \\
(0.001)\end{array}$ & $\begin{array}{c}0.001 \\
(0.001)\end{array}$ & $\begin{array}{c}0.002 \\
(0.001)\end{array}$ & $\begin{array}{c}0.001 \\
(0.001)\end{array}$ & $\begin{array}{c}-0.000^{*} \\
(0.000)\end{array}$ & $\begin{array}{c}-0.001^{* * *} \\
(0.000)\end{array}$ \\
\hline TRNOVR & $\begin{array}{l}0.016^{*} \\
(0.009)\end{array}$ & $\begin{array}{c}0.005 \\
(0.004)\end{array}$ & $\begin{array}{c}0.016 \\
(0.010)\end{array}$ & $\begin{array}{l}0.021^{*} \\
(0.010)\end{array}$ & $\begin{array}{c}0.010 \\
(0.009)\end{array}$ & $\begin{array}{c}0.016^{* * *} \\
(0.004)\end{array}$ \\
\hline$V O L$ & $\begin{array}{c}0.386 \\
(0.769)\end{array}$ & $\begin{array}{c}0.052 \\
(0.522)\end{array}$ & $\begin{array}{c}0.835 \\
(1.208)\end{array}$ & $\begin{array}{c}0.897 \\
(1.105)\end{array}$ & $\begin{array}{l}-1.521 \\
(0.927)\end{array}$ & $\begin{array}{c}-1.164^{* * *} \\
(0.175)\end{array}$ \\
\hline OPEX & $\begin{array}{c}-5.856^{* * *} \\
(1.387)\end{array}$ & $\begin{array}{c}-9.187^{* * *} \\
(1.139)\end{array}$ & $\begin{array}{c}-6.573^{* * *} \\
(1.139)\end{array}$ & $\begin{array}{c}-6.796^{* * *} \\
(0.979)\end{array}$ & $\begin{array}{c}-7.990^{* * *} \\
(1.118)\end{array}$ & $\begin{array}{c}-8.093^{* * *} \\
(1.062)\end{array}$ \\
\hline Model & F-M & F-M & F-M & F-M & F-E & $\mathrm{R}-\mathrm{E}$ \\
\hline Std Err & $\mathrm{N}-\mathrm{W}$ & $\mathrm{N}-\mathrm{W}$ & $\mathrm{N}-\mathrm{W}$ & $\mathrm{N}-\mathrm{W}$ & Fund-Time & Fund \\
\hline$R^{2}$ & $13.8 \%$ & $25.1 \%$ & $14.5 \%$ & $16.2 \%$ & $14.2 \%$ & $15.2 \%$ \\
\hline$N$ & 24,224 & 33,225 & 24,224 & 23,664 & 23,664 & 23,664 \\
\hline
\end{tabular}




\section{Robustness Checks}

In Supplement Table VII- IX, we report several robustness tests to different ways of measuring key variables for the main results discussed in Section IV of our paper.

In Supplement Table VII we repeat the analysis of Table IV using the CAPM model and the Fama-French (1993) three-factor model to estimate fund idiosyncratic volatility (IDVOL), performance (NPERF), and systematic risk (BETA). Overall, the findings of Supplement Table VII provide further support for Hypothesis 1 and Hypothesis 2 of our model.

\section{** INSERT SUPPLEMENT TABLE VII HERE **}

In Supplement Table VIII we repeat the analysis of Table IV by controlling for the measure of fund active share proposed by Cremers and Petajisto (2009). The key independent variables IDVOL, NPERF and BETA are estimated using the CAPM model and the Fama-French (1993) three-factor model.

\section{** INSERT SUPPLEMENT TABLE VIII HERE **}

In Supplement Table IX we repeat the analysis of Table VI using the CAPM model and the Fama-French (1993) three-factor model to estimate the key independent variables IDVOL, NPERF, and BETA. The evidence of Table IX for either MGMT or OPEX confirms the validity of Hypothesis ?? of our model.

\section{** INSERT SUPPLEMENT TABLE IX HERE **}

In Supplement Table X we repeat the analysis of Table VIII using the Fama-French (1993) three-factor model to estimate fund idiosyncratic volaitlity IDVOL and gross performance GPERF. The evidence of Table X confirms the validity of Hypothesis 4 of our model.

** INSERT SUPPLEMENT TABLE IX HERE ** 


\section{Supplement Table. VII}

\section{Robustness Tests: The Relationship between Fees and Idiosyncratic Risk}

This table presents the estimated coefficients for the yearly regression of fund fees on selected fund characteristics and idiosyncratic volatility over the period 1994 to 2007. The dependent variable (expressed in percentage terms) is the fund management fees (MGMT) computed as operating expenses minus 12B- 1 fees. Lagged control variables include: logarithm of fund TNA (FNDSIZE); logarithm of family TNA (FAMSIZE); logarithm of the number of months since fund inception (FNDAGE); aggregate sales or purchases of securities (TRNOVR); volatility of the previous 12-month returns ( VOL); and number of funds in the family (NFNDFAM). We use the CAPM one-factor model (CAPM) and the Fama-French (1993) three-factor model (FF3) to estimate fund risk adjusted returns (NPERF), fund idiosyncratic volatility (IDVOL), and fund systematic risk (BETA). In columns (iv) and (viii) we include the interaction variables between fund performance and idiosyncratic risk (either $N P E R F^{*} I D V O L$ obtained from each factor model. To account for possible non-linearities in the feevolatility relationship we include either the square value $\left(I D V O L^{2}\right)$ or the square-root value $(\sqrt{I D V O L})$ of fund idiosyncratic volatility from each factor model. We isolate the effect of small funds on fund fees by including the dummy variable $S M L F N D$ which is equal to 1 if a fund has less than $\$ 5$ million in assets under management. All regressions include untabulated dummy variables for share classes and investment objectives. In all models, we run the two-step estimation procedure of Fama-Macbeth (1973) with Newey-West standard errors (in parentheses). One, two and three asterisks indicate statistical significance at the $10 \%, 5 \%$, and $1 \%$ level, respectively.

\begin{tabular}{|c|c|c|c|c|c|c|c|c|}
\hline & $C A P M$ & $C A P M$ & $C A P M$ & CAPM & FF3 & FF3 & FF3 & FF3 \\
\hline & (i) & (ii) & (iii) & (iv) & (v) & (vi) & (vii) & (viii) \\
\hline IDVOL & $\begin{array}{c}9.353^{* * *} \\
(1.415)\end{array}$ & $\begin{array}{c}17.649^{* * *} \\
(2.558)\end{array}$ & $\begin{array}{c}-7.461^{* *} \\
(2.690)\end{array}$ & $\begin{array}{c}0.999^{* * *} \\
(0.307)\end{array}$ & $\begin{array}{c}9.672^{* * *} \\
(1.015)\end{array}$ & $\begin{array}{c}20.715^{* * *} \\
(2.004)\end{array}$ & $\begin{array}{c}-10.282^{* * *} \\
(2.187)\end{array}$ & $\begin{array}{c}1.813^{* * *} \\
(0.471)\end{array}$ \\
\hline BETA & $\begin{array}{c}0.051 \\
(0.039)\end{array}$ & $\begin{array}{l}-0.013 \\
(0.036)\end{array}$ & $\begin{array}{l}-0.011 \\
(0.035)\end{array}$ & $\begin{array}{c}0.006 \\
(0.013)\end{array}$ & $\begin{array}{c}0.039 \\
(0.043)\end{array}$ & $\begin{array}{l}-0.011 \\
(0.037)\end{array}$ & $\begin{array}{l}-0.023 \\
(0.036)\end{array}$ & $\begin{array}{l}-0.015 \\
(0.019)\end{array}$ \\
\hline NPERF & $\begin{array}{c}-0.385^{* * *} \\
(0.109)\end{array}$ & $\begin{array}{c}-0.366^{* * *} \\
(0.101)\end{array}$ & $\begin{array}{c}-0.364^{* * *} \\
(0.103)\end{array}$ & $\begin{array}{l}-0.016 \\
(0.057)\end{array}$ & $\begin{array}{c}-0.295^{*} \\
(0.155)\end{array}$ & $\begin{array}{c}-0.322^{* *} \\
(0.110)\end{array}$ & $\begin{array}{c}-0.334^{* *} \\
(0.115)\end{array}$ & $\begin{array}{c}-0.096 \\
(0.070)\end{array}$ \\
\hline$I D V O L^{2}$ & & $\begin{array}{c}-1.100^{* * *} \\
(0.261)\end{array}$ & & & & $\begin{array}{c}-1.537^{* * *} \\
(0.259)\end{array}$ & & \\
\hline$\sqrt{I D V O L}$ & & & $\begin{array}{c}5.656^{* * *} \\
(0.920)\end{array}$ & & & & $\begin{array}{c}6.452^{* * *} \\
(0.674)\end{array}$ & \\
\hline NPERF*IDVOL & & & & $\begin{array}{c}-5.605^{* * *} \\
(1.196)\end{array}$ & & & & $\begin{array}{c}-7.088^{* * *} \\
(1.921)\end{array}$ \\
\hline FNDSIZE & $\begin{array}{c}-0.066^{* * *} \\
(0.011)\end{array}$ & $\begin{array}{c}-0.065^{* * *} \\
(0.011)\end{array}$ & $\begin{array}{c}-0.065^{* * *} \\
(0.011)\end{array}$ & $\begin{array}{c}-0.061^{* * *} \\
(0.004)\end{array}$ & $\begin{array}{c}-0.065^{* * *} \\
(0.011)\end{array}$ & $\begin{array}{c}-0.064^{* * *} \\
(0.010)\end{array}$ & $\begin{array}{c}-0.064^{* * *} \\
(0.010)\end{array}$ & $\begin{array}{c}-0.060^{* * *} \\
(0.004)\end{array}$ \\
\hline FNDAGE & $\begin{array}{c}0.000 \\
(0.005)\end{array}$ & $\begin{array}{c}0.000 \\
(0.005)\end{array}$ & $\begin{array}{l}-0.000 \\
(0.005)\end{array}$ & $\begin{array}{l}-0.008 \\
(0.015)\end{array}$ & $\begin{array}{l}-0.002 \\
(0.005)\end{array}$ & $\begin{array}{l}-0.003 \\
(0.005)\end{array}$ & $\begin{array}{l}-0.004 \\
(0.005)\end{array}$ & $\begin{array}{c}-0.010 \\
(0.015)\end{array}$ \\
\hline FAMSIZE & $\begin{array}{c}-0.015^{* * *} \\
(0.004)\end{array}$ & $\begin{array}{c}-0.015^{* * *} \\
(0.004)\end{array}$ & $\begin{array}{c}-0.015^{* * *} \\
(0.004)\end{array}$ & $\begin{array}{c}-0.001 \\
(0.001)\end{array}$ & $\begin{array}{c}-0.015^{* * *} \\
(0.004)\end{array}$ & $\begin{array}{c}-0.014^{* * *} \\
(0.004)\end{array}$ & $\begin{array}{c}-0.014^{* * *} \\
(0.004)\end{array}$ & $\begin{array}{c}-0.001 \\
(0.001)\end{array}$ \\
\hline NFNDFAM & $\begin{array}{c}0.001 \\
(0.001)\end{array}$ & $\begin{array}{c}0.001 \\
(0.000)\end{array}$ & $\begin{array}{c}0.001 \\
(0.000)\end{array}$ & $\begin{array}{c}-0.001^{* * *} \\
(0.000)\end{array}$ & $\begin{array}{c}0.001 \\
(0.001)\end{array}$ & $\begin{array}{c}0.001 \\
(0.000)\end{array}$ & $\begin{array}{c}0.001 \\
(0.000)\end{array}$ & $\begin{array}{c}-0.001^{* * *} \\
(0.000)\end{array}$ \\
\hline TRNOVR & $\begin{array}{c}0.044^{* * *} \\
(0.006)\end{array}$ & $\begin{array}{c}0.042^{* * *} \\
(0.006)\end{array}$ & $\begin{array}{c}0.043^{* * *} \\
(0.006)\end{array}$ & $\begin{array}{c}0.013^{* * *} \\
(0.003)\end{array}$ & $\begin{array}{c}0.044^{* * *} \\
(0.006)\end{array}$ & $\begin{array}{c}0.038^{* * *} \\
(0.005)\end{array}$ & $\begin{array}{c}0.039^{* * *} \\
(0.005)\end{array}$ & $\begin{array}{c}0.011^{* * *} \\
(0.003)\end{array}$ \\
\hline$V O L$ & $\begin{array}{l}-1.850 \\
(1.391)\end{array}$ & $\begin{array}{c}-1.071 \\
(1.273)\end{array}$ & $\begin{array}{l}-0.800 \\
(1.195)\end{array}$ & $\begin{array}{c}-0.608 \\
(1.132)\end{array}$ & $\begin{array}{l}-0.146 \\
(0.922)\end{array}$ & $\begin{array}{l}-0.121 \\
(0.964)\end{array}$ & $\begin{array}{c}0.221 \\
(0.833)\end{array}$ & $\begin{array}{l}-0.495 \\
(1.121)\end{array}$ \\
\hline SMLFND & $\begin{array}{l}0.069^{* *} \\
(0.027)\end{array}$ & $\begin{array}{l}0.065^{* *} \\
(0.026)\end{array}$ & $\begin{array}{l}0.068^{* *} \\
(0.027)\end{array}$ & $\begin{array}{c}0.059^{* * *} \\
(0.021)\end{array}$ & $\begin{array}{l}0.068^{* *} \\
(0.026)\end{array}$ & $\begin{array}{l}0.063^{* *} \\
(0.025)\end{array}$ & $\begin{array}{l}0.067^{* *} \\
(0.026)\end{array}$ & $\begin{array}{c}0.059^{* * *} \\
(0.021)\end{array}$ \\
\hline$R^{2}$ & $36.1 \%$ & $37.3 \%$ & $37.1 \%$ & $37.2 \%$ & $36.4 \%$ & $37.9 \%$ & $37.7 \%$ & $38.4 \%$ \\
\hline$N$ & 24,135 & 24,135 & 24,135 & 24,135 & 24,135 & 24,135 & 24,135 & 24,135 \\
\hline
\end{tabular}




\section{Supplement Table. VIII}

Robustness Tests: Mutual Fund Fees, Active Share and Idiosyncratic Volatility This table presents the estimated coefficients for the yearly regression of fund fees on selected fund characteristics and idiosyncratic volatility over the period 1994 to 2007 . The dependent variable (expressed in percentage terms) is the fund management fees (MGMT) computed as operating expenses minus $12 \mathrm{~B}-1$ fees). As an alternative dependent variable we also consider the fund total operating expenses (OPEX). Lagged control variables include: logarithm of fund TNA (FNDSIZE); logarithm of family TNA (FAMSIZE); logarithm of the number of months since fund inception (FNDAGE); aggregate sales or purchases of securities (TRNOVR); volatility of the previous 12-month returns ( VOL); and number of funds in the family (NFNDFAM). We use the following three models to estimate mutual fund risk adjusted returns NPERF, fund idiosyncratic volatility IDVOL, and portfolio exposure to systematic risk $\left(B E T A_{R M R F}\right)$ : the CAPM model $(C A P M)$ in columns (i)-(ii), the Fama and French (1993) three-factor model (3-Factor) in columns (iii)-(iv), and the Carhart (1997) four-factor model (4-Factor) in columns (v)-(vi). We also control for the average active share of fund portfolio, ACTIVESHR which is computed as half of the difference between the holdings of a mutual fund and the holdings of its benchmark (see Cremers and Petajisto (2009) for more details on the construction of this measure). We isolate the effect of small funds on fund fees by including the dummy variable $S M L F N D$ which is equal to 1 if a fund has less than $\$ 5$ million in assets under management. All regressions include untabulated dummy variables for share classes and investment objectives. In all models, we run the two-step estimation procedure of Fama-Macbeth (1973) with Newey-West heteroskedasticity and autocorrelation robust standard errors (in parentheses). One, two and three asterisks indicate statistical significance at the $10 \%, 5 \%$, and $1 \%$ level, respectively.

\begin{tabular}{|c|c|c|c|c|c|c|}
\hline & $C A P M$ & CAPM & 3-Factor & 3-Factor & 4-Factor & 4-Factor \\
\hline & $M G M T$ & OPEX & MGMT & OPEX & MGMT & OPEX \\
\hline & (i) & (ii) & (iii) & (iv) & (v) & (vi) \\
\hline IDVOL & $\begin{array}{c}6.737^{* * *} \\
(1.665)\end{array}$ & $\begin{array}{c}7.209^{* * *} \\
(1.865)\end{array}$ & $\begin{array}{c}7.693^{* * *} \\
(1.338)\end{array}$ & $\begin{array}{c}8.189^{* * *} \\
(1.454)\end{array}$ & $\begin{array}{c}8.228^{* * *} \\
(1.431)\end{array}$ & $\begin{array}{c}8.972^{* * *} \\
(1.648)\end{array}$ \\
\hline$B_{E T A_{R M R F}}$ & $\begin{array}{l}-0.003 \\
(0.020)\end{array}$ & $\begin{array}{c}0.010 \\
(0.028)\end{array}$ & $\begin{array}{c}0.001 \\
(0.009)\end{array}$ & $\begin{array}{l}-0.016 \\
(0.014)\end{array}$ & $\begin{array}{c}0.108 \\
(0.089)\end{array}$ & $\begin{array}{c}0.108 \\
(0.089)\end{array}$ \\
\hline NPERF & $\begin{array}{l}-0.299 \\
(0.168)\end{array}$ & $\begin{array}{c}-0.369^{*} \\
(0.185)\end{array}$ & $\begin{array}{c}-0.449^{*} \\
(0.239)\end{array}$ & $\begin{array}{c}-0.522^{* *} \\
(0.208)\end{array}$ & $\begin{array}{c}-0.524^{* *} \\
(0.199)\end{array}$ & $\begin{array}{c}-0.598^{* * *} \\
(0.161)\end{array}$ \\
\hline ACTIVESHR & $\begin{array}{c}0.275^{* * *} \\
(0.039)\end{array}$ & $\begin{array}{c}0.265^{* * *} \\
(0.053)\end{array}$ & $\begin{array}{c}0.250^{* * *} \\
(0.028)\end{array}$ & $\begin{array}{c}0.238^{* * *} \\
(0.030)\end{array}$ & $\begin{array}{c}0.245^{* * *} \\
(0.029)\end{array}$ & $\begin{array}{c}0.233^{* * *} \\
(0.028)\end{array}$ \\
\hline FNDSIZE & $\begin{array}{c}-0.053^{* * *} \\
(0.005)\end{array}$ & $\begin{array}{c}-0.068^{* * *} \\
(0.005)\end{array}$ & $\begin{array}{c}-0.052^{* * *} \\
(0.004)\end{array}$ & $\begin{array}{c}-0.066^{* * *} \\
(0.003)\end{array}$ & $\begin{array}{c}-0.051^{* * *} \\
(0.004)\end{array}$ & $\begin{array}{c}-0.066^{* * *} \\
(0.004)\end{array}$ \\
\hline FNDAGE & $\begin{array}{c}-0.036^{* * *} \\
(0.004)\end{array}$ & $\begin{array}{c}-0.054^{* * *} \\
(0.005)\end{array}$ & $\begin{array}{c}-0.036^{* * *} \\
(0.005)\end{array}$ & $\begin{array}{c}-0.055^{* * *} \\
(0.006)\end{array}$ & $\begin{array}{c}-0.037^{* * *} \\
(0.006)\end{array}$ & $\begin{array}{c}-0.056^{* * *} \\
(0.006)\end{array}$ \\
\hline FAMSIZE & $\begin{array}{c}-0.010^{* * *} \\
(0.003)\end{array}$ & $\begin{array}{l}-0.003 \\
(0.002)\end{array}$ & $\begin{array}{c}-0.010^{* * *} \\
(0.003)\end{array}$ & $\begin{array}{l}-0.002 \\
(0.002)\end{array}$ & $\begin{array}{c}-0.010^{* * *} \\
(0.003)\end{array}$ & $\begin{array}{l}-0.002 \\
(0.002)\end{array}$ \\
\hline NFNDFAM & $\begin{array}{c}-0.000 \\
(0.000)\end{array}$ & $\begin{array}{l}-0.001^{*} \\
(0.000)\end{array}$ & $\begin{array}{l}-0.000 \\
(0.000)\end{array}$ & $\begin{array}{l}-0.001^{*} \\
(0.000)\end{array}$ & $\begin{array}{l}-0.000 \\
(0.000)\end{array}$ & $\begin{array}{l}-0.001^{*} \\
(0.000)\end{array}$ \\
\hline TRNOVR & $\begin{array}{c}0.040^{* * *} \\
(0.006)\end{array}$ & $\begin{array}{c}0.034^{* * *} \\
(0.007)\end{array}$ & $\begin{array}{c}0.035^{* * *} \\
(0.005)\end{array}$ & $\begin{array}{c}0.029^{* * *} \\
(0.007)\end{array}$ & $\begin{array}{c}0.035^{* * *} \\
(0.005)\end{array}$ & $\begin{array}{c}0.029^{* * *} \\
(0.007)\end{array}$ \\
\hline$V O L$ & $\begin{array}{l}-1.133 \\
(0.653)\end{array}$ & $\begin{array}{l}-0.900 \\
(0.840)\end{array}$ & $\begin{array}{l}0.667^{*} \\
(0.344)\end{array}$ & $\begin{array}{c}1.024 \\
(0.621)\end{array}$ & $\begin{array}{c}0.550 \\
(0.359)\end{array}$ & $\begin{array}{c}0.789 \\
(0.559)\end{array}$ \\
\hline SMLFND & $\begin{array}{l}-0.007 \\
(0.045)\end{array}$ & $\begin{array}{l}-0.069 \\
(0.048)\end{array}$ & $\begin{array}{l}-0.001 \\
(0.036)\end{array}$ & $\begin{array}{c}-0.061^{*} \\
(0.033)\end{array}$ & $\begin{array}{c}-0.002 \\
(0.034)\end{array}$ & $\begin{array}{c}-0.062^{*} \\
(0.031)\end{array}$ \\
\hline$R^{2}$ & $38.4 \%$ & $66.0 \%$ & $38.7 \%$ & $66.0 \%$ & $38.8 \%$ & $66.1 \%$ \\
\hline$N$ & 13,123 & 13,123 & 13,123 & 13,123 & 13,123 & 13,123 \\
\hline
\end{tabular}




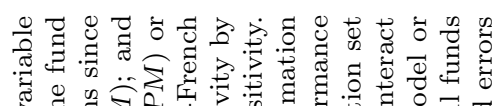
In⿴囗十) Hin Min

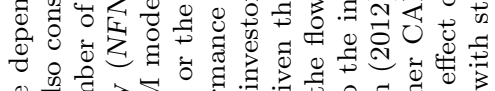

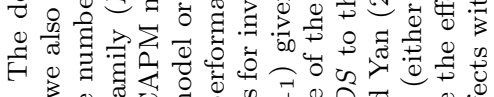

ఫ

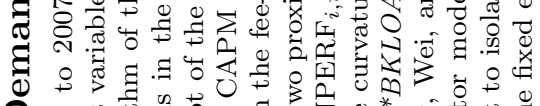

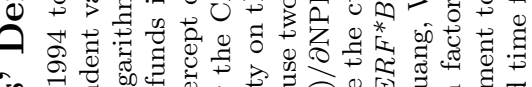
in

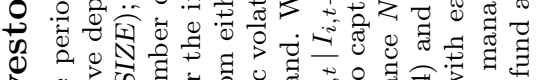
至 。

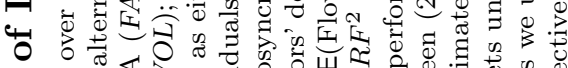

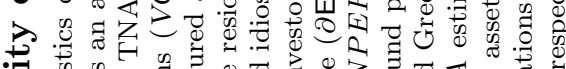

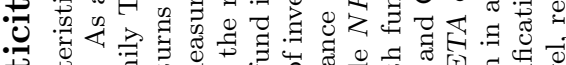

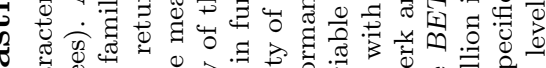

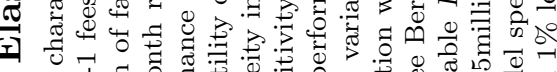

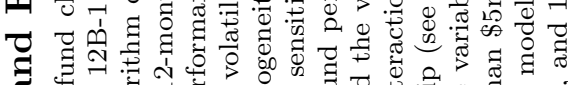
ส $\begin{gathered}\text { D. } \\ 0\end{gathered}$

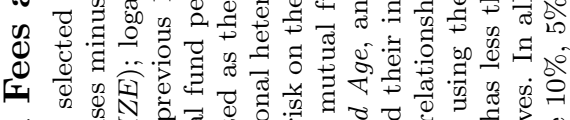

萡

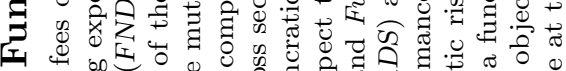
б

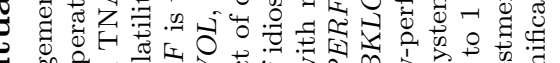

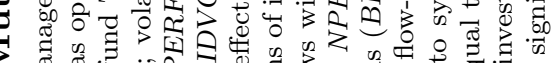

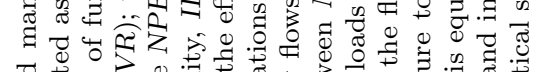

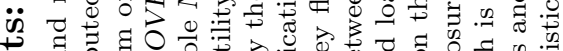

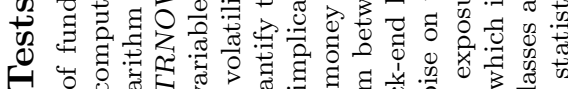

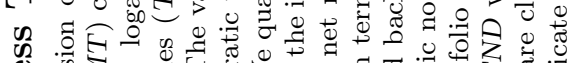
क

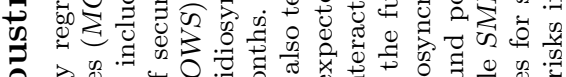

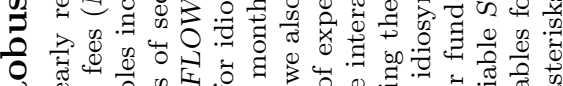

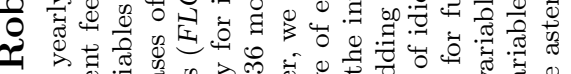

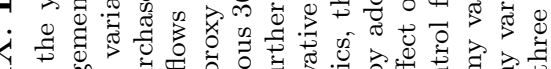

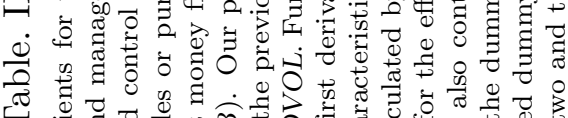

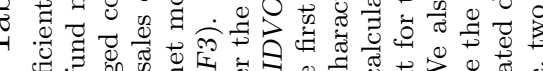

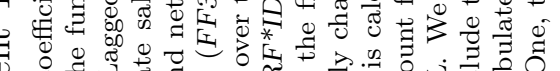

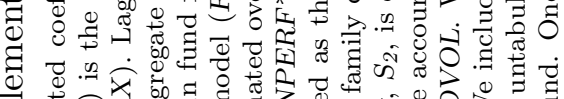

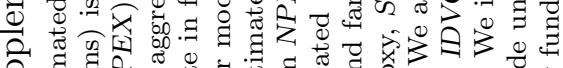

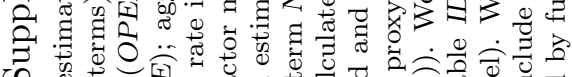
\&

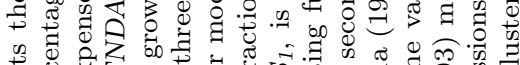

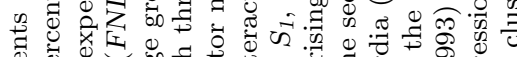
要

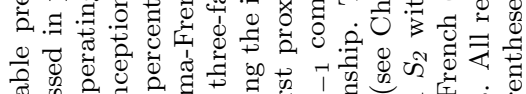

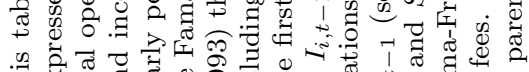

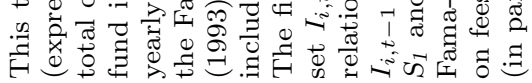

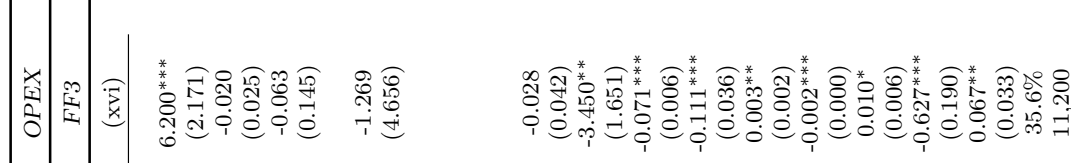

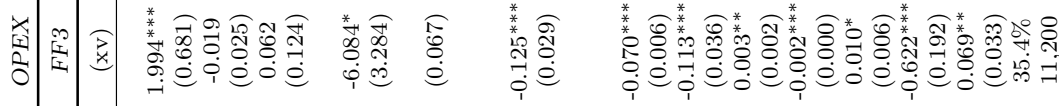

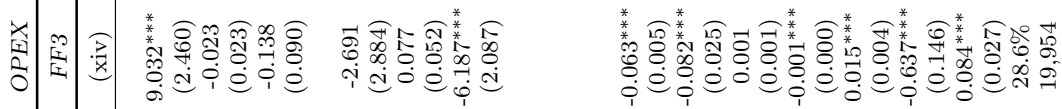

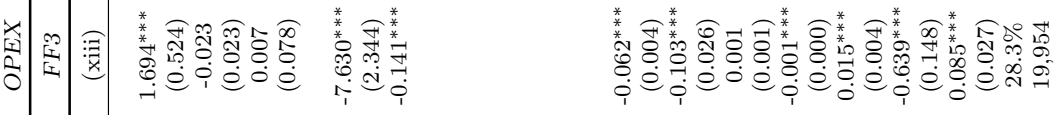

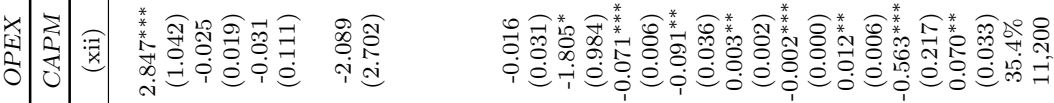

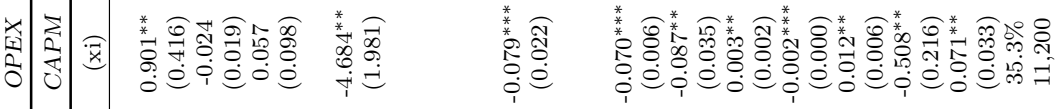

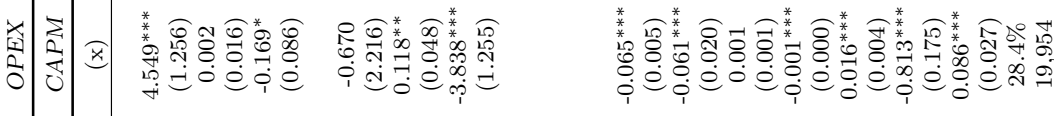

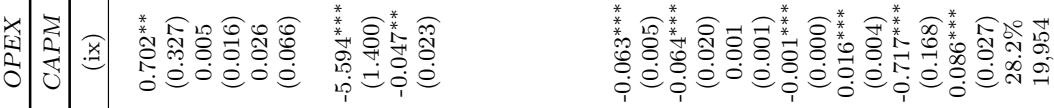

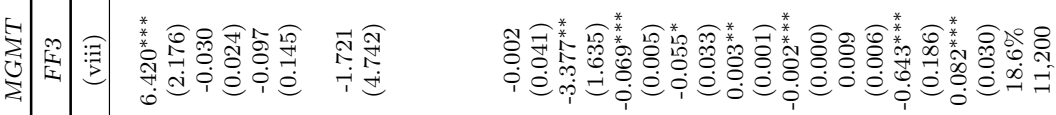

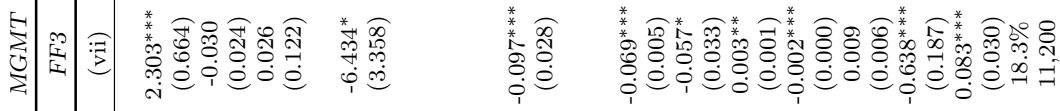

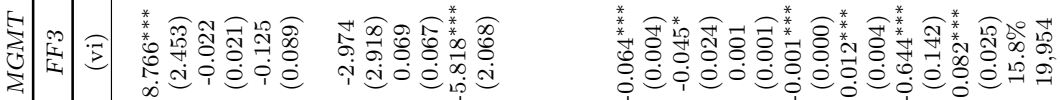

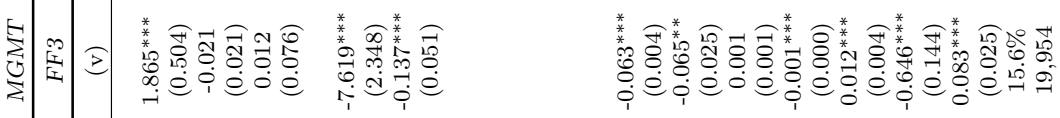

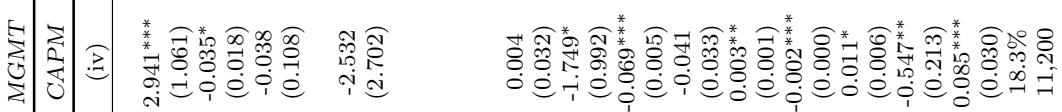

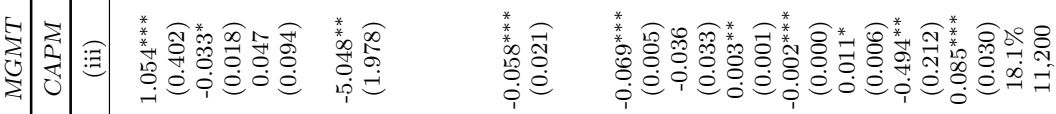

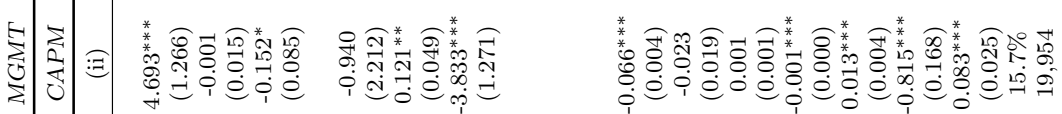

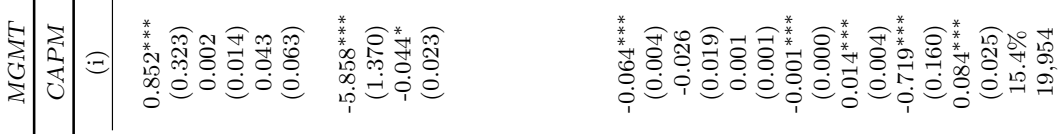

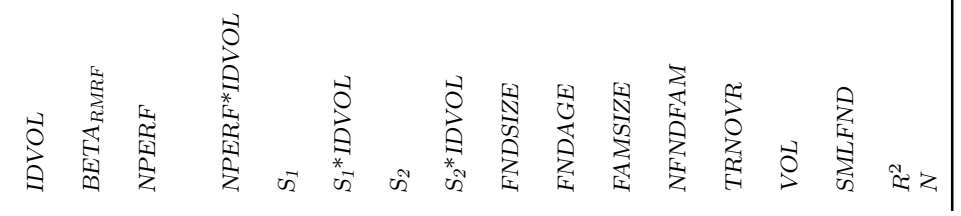




\section{Supplement Table. X}

\section{Mutual Fund Fees and Before-Fee Performance}

This table examines the sensitivity of different mutual fund fees to gross risk-adjusted returns while controlling for cross-sectional variations in fund idiosyncratic volatility from January 1994 to December 2007. We estimate the fee-performance sensitivity using as dependent variable five different fee specifications: (a) management fees (MGMT) computed as total operating expenses minus 12b-1 fees; (b) actual management fee reported by the fund in its statement of operations and available over the period from 1999 through 2007 (MGMT2); (c) total operating expenses (OPEX); (d) 12b-1 fees (12b-1); and (e) marketing fees (MKTING) which are computed as $12 \mathrm{~b}-1$ fees plus $1 / 7$-th of fund front-end loads. Our main independent variable is the fund before-fee abnormal returns, GPERF, computed as the difference between the fund's before-fee excess return and the lagged vector of betas multiplied by the vectors of factor realizations in month $t$. Fund gross abnormal returns are estimated using the Fama-French (1993) before-fee risk-adjusted returns over the previous five years (requiring a minimum of 48 months of available observations). To test our model prediction on the relationship between fees and fund idiosyncratic volatility we include the variable $I D V O L$. To account for possible non-linearities in the fee-volatility relationship we introduce the variable $\sqrt{I D V O L}$. We isolate the effect on the fee-performance sensitivity of $I D V O L$ using the interaction term GPERF $\times I D V O L$. All regression models are estimated using the Fama and MacBeth (1973) approach with Newey and West (1987) heteroskedasticity and autocorrelation consistent standard errors (in parentheses). One, two and three asterisks indicate statistical significance at the $10 \%, 5 \%$, and $1 \%$ level, respectively.

\begin{tabular}{|c|c|c|c|c|c|c|c|}
\hline & Fee & GPERF & IDVOL & $G P E R F \times I D V O L$ & $\sqrt{I D V O L}$ & $R^{2}$ & Obs. \\
\hline (i) & $M G M T$ & $\begin{array}{l}-0.138 \\
(0.123)\end{array}$ & & & & $0.6 \%$ & 10,934 \\
\hline (ii) & $M G M T$ & $\begin{array}{l}-0.106 \\
(0.142)\end{array}$ & $\begin{array}{c}13.140^{* * *} \\
(1.255)\end{array}$ & & & $11.2 \%$ & 10,934 \\
\hline (iii) & $M G M T$ & $\begin{array}{l}-0.069 \\
(0.121)\end{array}$ & $\begin{array}{c}14.899^{* * *} \\
(1.543)\end{array}$ & $\begin{array}{l}-22.980 \\
(16.890)\end{array}$ & & $13.4 \%$ & 10,934 \\
\hline (iv) & $M G M T$ & $\begin{array}{l}-0.060 \\
(0.133)\end{array}$ & $\begin{array}{l}-7.427 \\
(6.882)\end{array}$ & $\begin{array}{c}-32.997^{*} \\
(16.672)\end{array}$ & $\begin{array}{c}7.292^{* * *} \\
(1.786)\end{array}$ & $15.4 \%$ & 10,934 \\
\hline (v) & MGMT2 & $\begin{array}{l}-0.108 \\
(0.129)\end{array}$ & & & & $0.3 \%$ & 9,359 \\
\hline (vi) & MGMT2 & $\begin{array}{l}-0.120 \\
(0.135)\end{array}$ & $\begin{array}{c}5.165^{* * *} \\
(1.327)\end{array}$ & & & $2.3 \%$ & 9,359 \\
\hline (vii) & MGMT2 & $\begin{array}{l}-0.090 \\
(0.122)\end{array}$ & $\begin{array}{c}5.531^{* * *} \\
(1.555)\end{array}$ & $\begin{array}{l}-12.080 \\
(8.201)\end{array}$ & & $2.4 \%$ & 9,359 \\
\hline (viii) & MGMT2 & $\begin{array}{l}-0.055 \\
(0.124)\end{array}$ & $\begin{array}{l}-1.793 \\
(2.755)\end{array}$ & $\begin{array}{l}-3.755 \\
(2.459)\end{array}$ & $\begin{array}{c}6.006^{* * *} \\
(1.025)\end{array}$ & $3.4 \%$ & 9,359 \\
\hline (ix) & OPEX & $\begin{array}{c}-0.370^{* *} \\
(0.177)\end{array}$ & & & & $0.8 \%$ & 10,934 \\
\hline$(\mathrm{x})$ & OPEX & $\begin{array}{c}-0.339^{*} \\
(0.190)\end{array}$ & $\begin{array}{c}11.850^{* * *} \\
(1.194)\end{array}$ & & & $6.9 \%$ & 10,934 \\
\hline (xi) & OPEX & $\begin{array}{c}-0.253^{*} \\
(0.144)\end{array}$ & $\begin{array}{c}13.627^{* * *} \\
(1.503)\end{array}$ & $\begin{array}{c}-53.326^{* *} \\
(21.564)\end{array}$ & & $9.1 \%$ & 10,934 \\
\hline (xii) & OPEX & $\begin{array}{c}-0.248^{*} \\
(0.135)\end{array}$ & $\begin{array}{l}-9.897 \\
(7.079)\end{array}$ & $\begin{array}{c}-53.262^{* *} \\
(20.738)\end{array}$ & $\begin{array}{c}7.700^{* * *} \\
(1.806)\end{array}$ & $10.2 \%$ & 10,934 \\
\hline (xiii) & $12 B-1$ & $\begin{array}{c}-0.232^{* *} \\
(0.096)\end{array}$ & & & & $0.8 \%$ & 10,934 \\
\hline (xiv) & $12 B-1$ & $\begin{array}{c}-0.233^{* *} \\
(0.096)\end{array}$ & $\begin{array}{c}-1.290^{*} \\
(0.659)\end{array}$ & & & $1.0 \%$ & 10,934 \\
\hline$(\mathrm{xv})$ & $12 B-1$ & $\begin{array}{c}-0.184^{*} \\
(0.092)\end{array}$ & $\begin{array}{c}-1.272^{* *} \\
(0.571)\end{array}$ & $\begin{array}{c}-17.346^{* * *} \\
(5.343)\end{array}$ & & $1.5 \%$ & 10,934 \\
\hline (xvi) & $12 B-1$ & $\begin{array}{c}-0.188^{*} \\
(0.095)\end{array}$ & $\begin{array}{l}-2.470 \\
(2.200)\end{array}$ & $\begin{array}{c}-20.265^{* * *} \\
(5.916)\end{array}$ & $\begin{array}{c}0.409 \\
(0.617)\end{array}$ & $1.6 \%$ & 10,934 \\
\hline (xvii) & MKTING & $\begin{array}{c}-0.393^{* *} \\
(0.154)\end{array}$ & & & & $0.7 \%$ & 10,934 \\
\hline (xviii) & MKTING & $\begin{array}{l}-0.293 \\
(0.181)\end{array}$ & $\begin{array}{c}2.863 \\
(3.601)\end{array}$ & & & $3.0 \%$ & 10,934 \\
\hline$(x i x)$ & MKTING & $\begin{array}{c}0.071 \\
(0.348)\end{array}$ & $\begin{array}{c}6.897 \\
(7.573)\end{array}$ & $\begin{array}{l}-84.127 \\
(56.237)\end{array}$ & & $5.7 \%$ & 10,934 \\
\hline$(\mathrm{xx})$ & MKTING & $\begin{array}{c}0.117 \\
(0.336)\end{array}$ & $\begin{array}{l}-13.260 \\
(12.221)\end{array}$ & $\begin{array}{l}-86.398 \\
(53.941)\end{array}$ & $\begin{array}{l}5.917^{*} \\
(3.159)\end{array}$ & $5.0 \%$ & 10,934 \\
\hline
\end{tabular}

